\title{
دور أحداث العنف والحروب في الفكر والناتج المعماري \\ The Role of Violent Events and Wars in Thought and Architectural Output
}

\author{
د/ ألفت عبد الغنى سليمان حلوه -مدرس بقسم الهنسة المعمارية -كلية الهندة بالمطرية -جامعة حلوان
}

Olfat_hlwa@yahoo.com

\section{ملخص البحث}

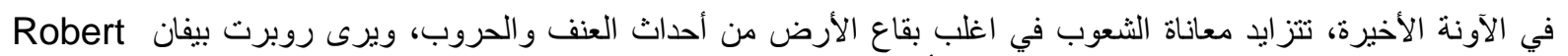

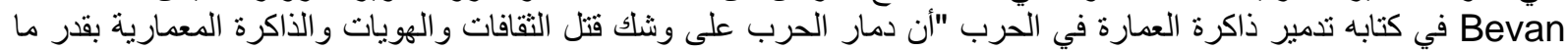

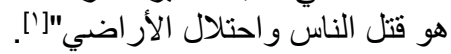

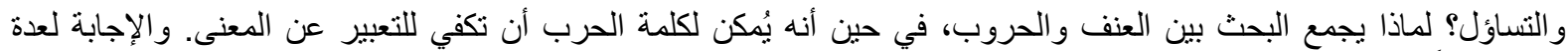

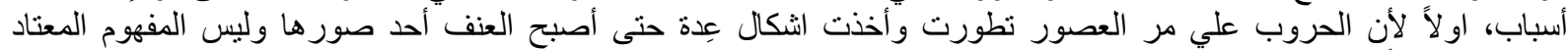

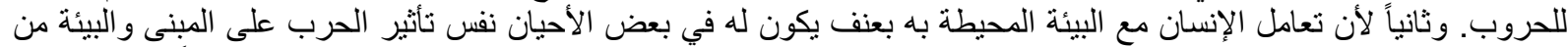

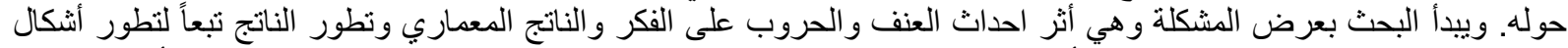

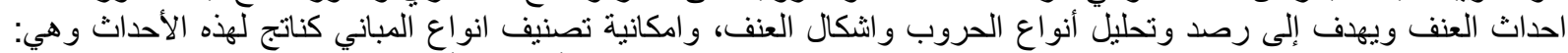

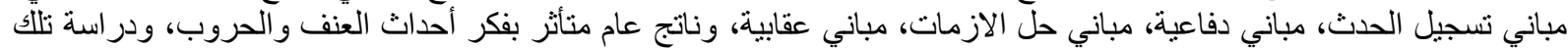

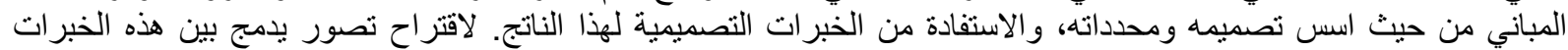

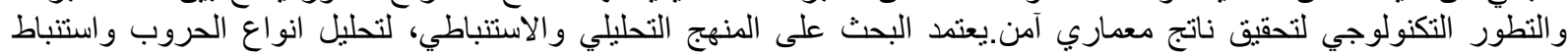

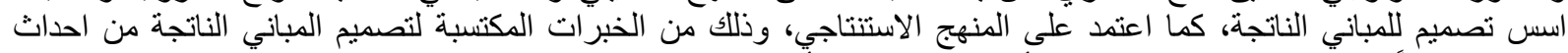

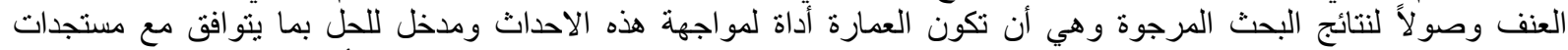

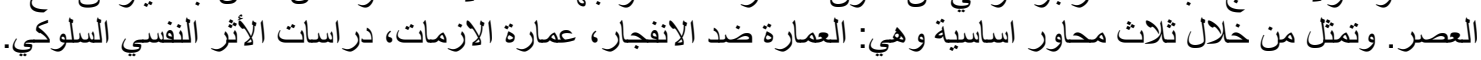

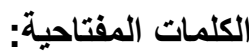

أحداث العنف، الحروب، الناتج المعماري، تسجيل الحدث، معايير تصميم الأمن بالمباني.

|

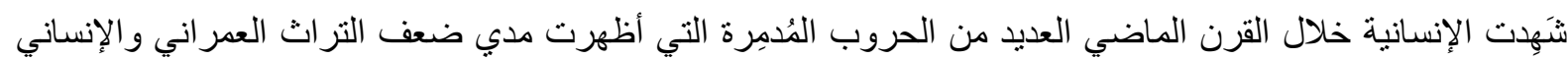

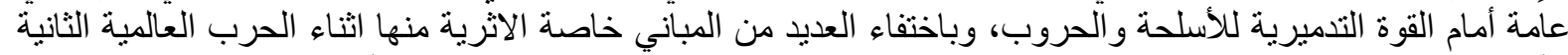

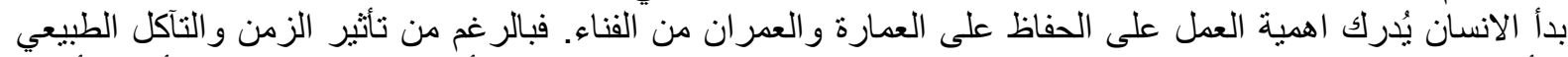

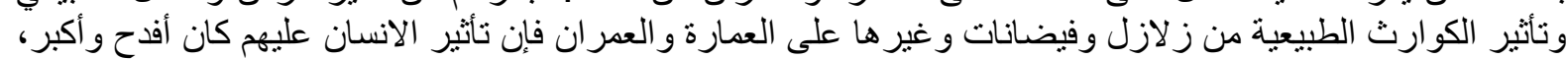

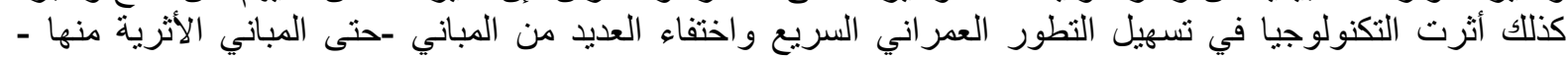

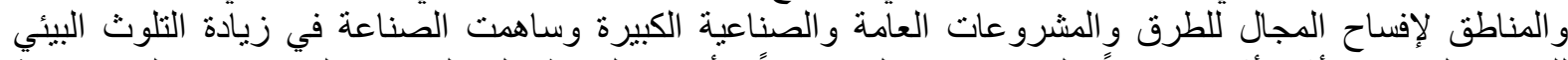

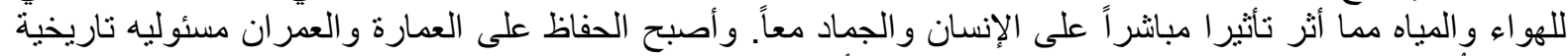

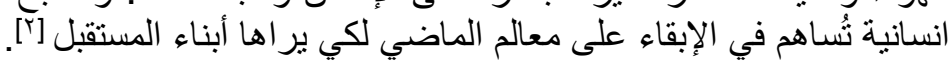

${ }^{[1]}$ Robert Bevan, “The Destruction of Memory - Architecture at War”, ISBN: 1861893191, Publisher: Reaktion Books, UK, 2007.

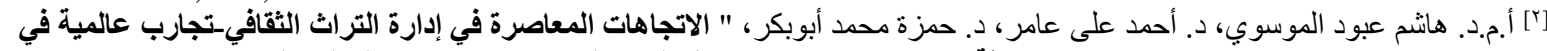

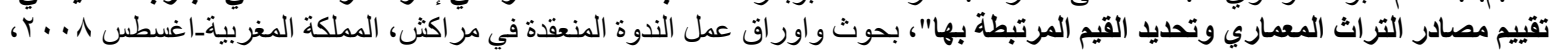

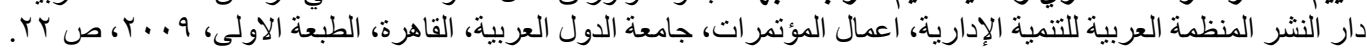




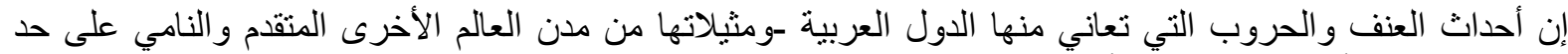

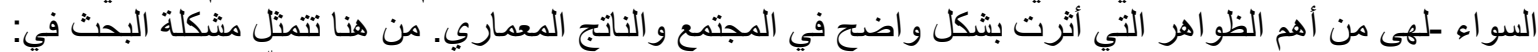

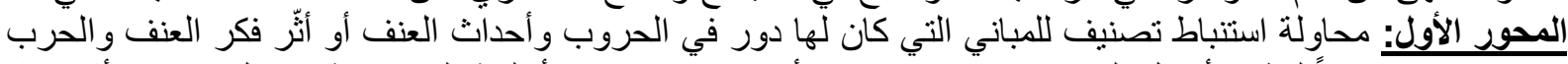

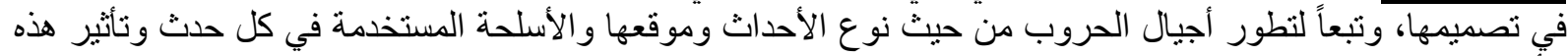

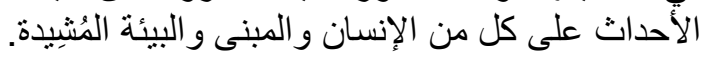

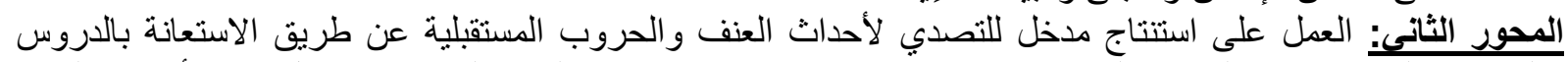

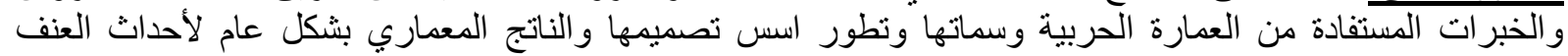

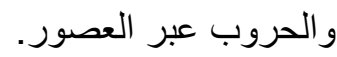

\section{1/ 1/ أهداف البحث}

$$
\text { تهدف الدراسة في هذا البحث إلى تحقيق الاتي: }
$$

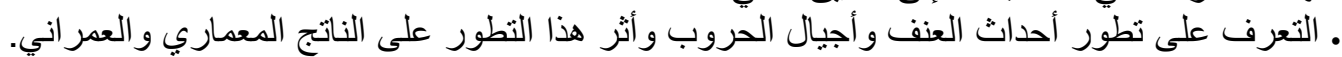

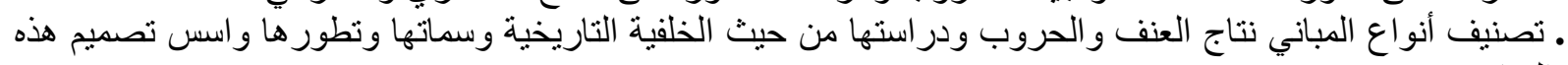

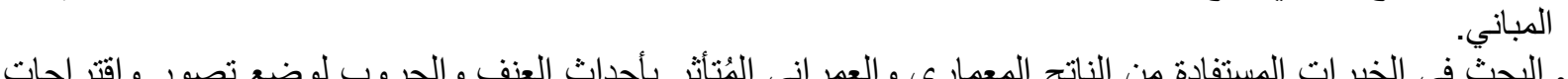

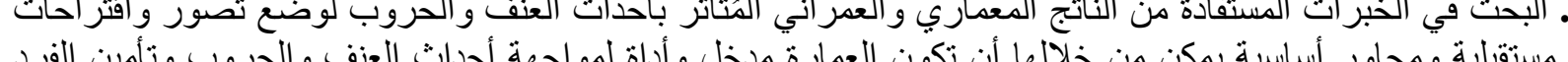

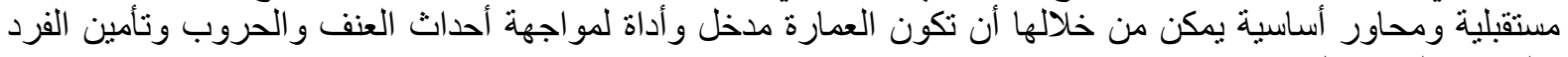

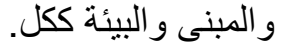

$$
\text { بر ا فرضية البحث }
$$

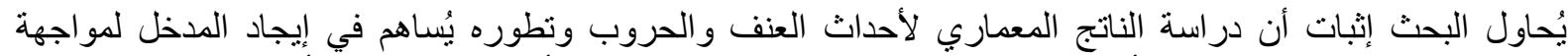

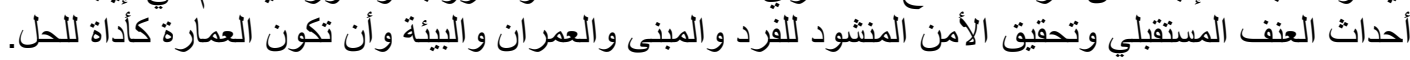

1/ء

لتحقيق الفرضية يُتبع المنهج النظري و التحليلي كأسلوب بحثي، وتم بواسطة تحديد ثناث خطوات كأساس منهي لهذه

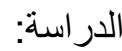

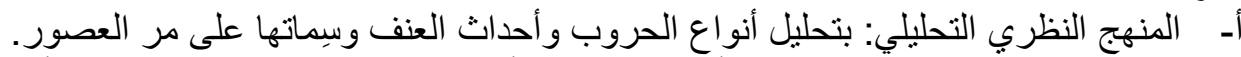

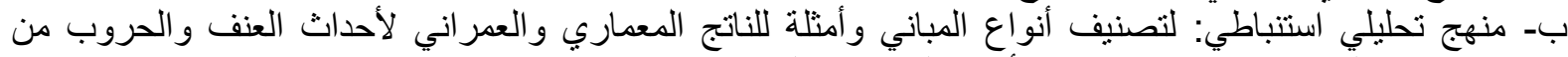

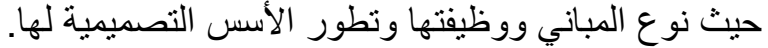

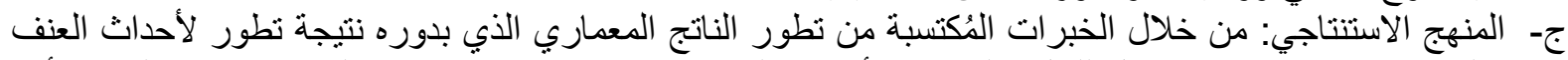

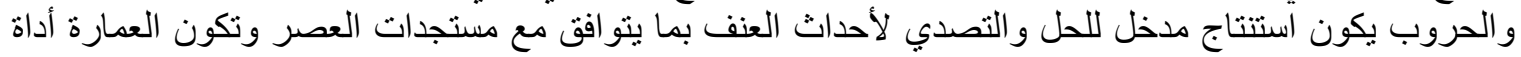
لمواجهة هذه الاحداث.

r

من المبادئ العسكرية المتفق عليها والحاكمة للخطط و التدريبات التي تقوم بها الجيوش هو الاستعدادات الدائمة وتأهيل

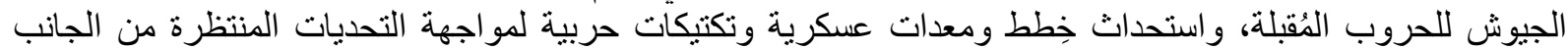

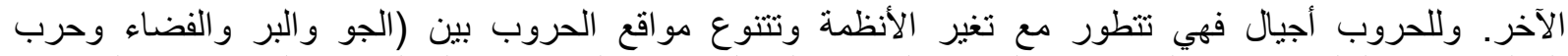

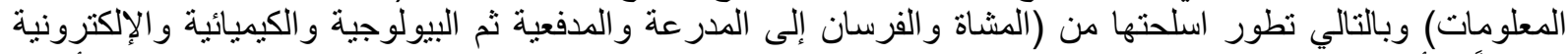

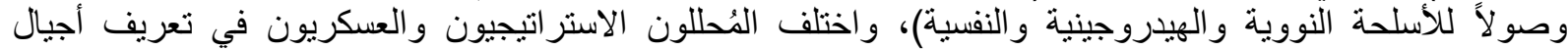
الحروب وبعضهم يرى أن أنو اعها كالاتي: 


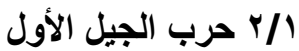

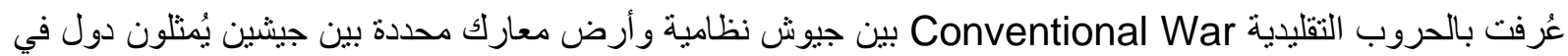

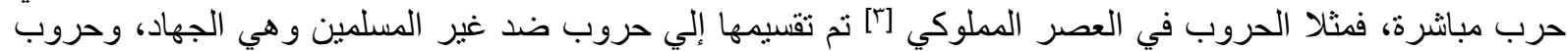

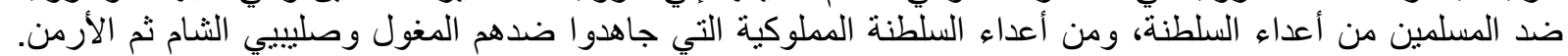
ومن أعداء السلطنة من المسلمين من خارج السلطنة مثل الأيوبيين، ومن أعداء أعداء السلطنة الداخليين مثل العربان و والخارجين.

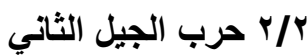

تُعرف بحرب العصابات Guerilla War والتي كانت تدور في دول أمريكا اللاتينية، بدأ في أعقاب تغير النظام الدولي

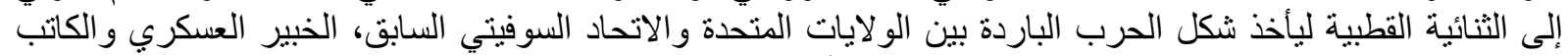

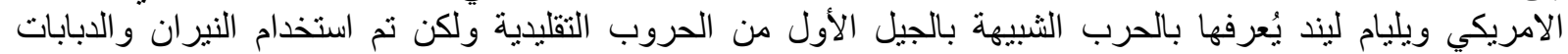

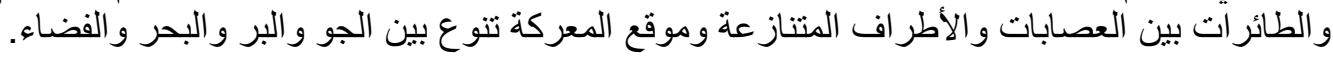

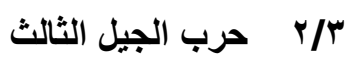

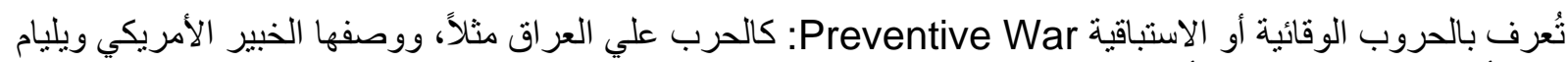

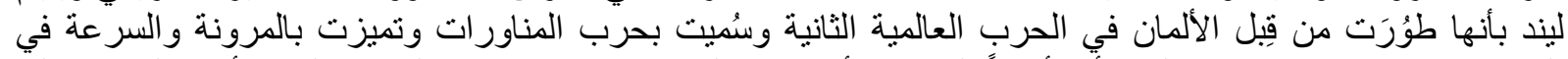

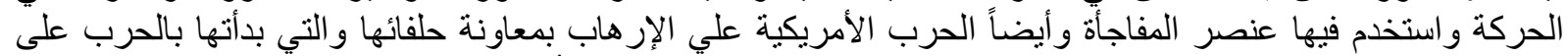

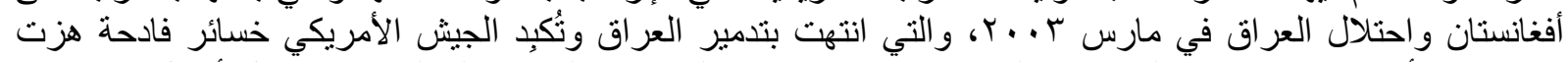

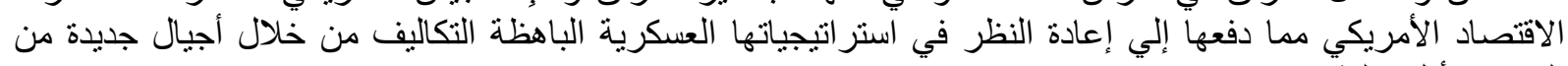

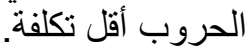

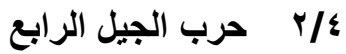

الجيل الرابع من الحروب Fourth-Generation Warfare أو اختصارا Asymmetric Warfare

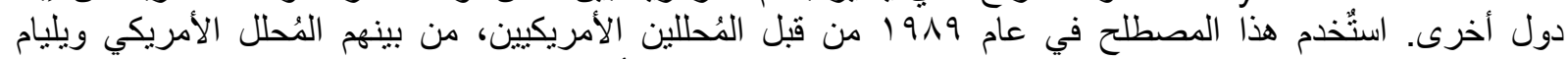

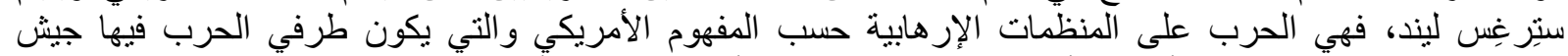

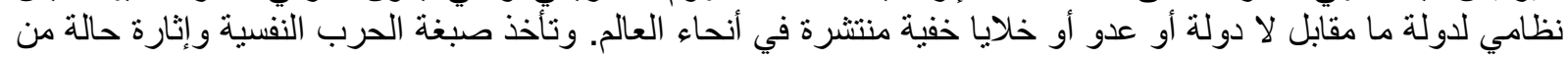

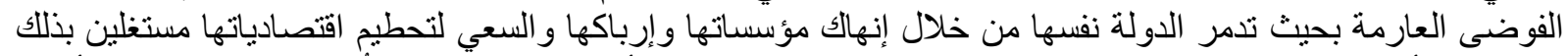

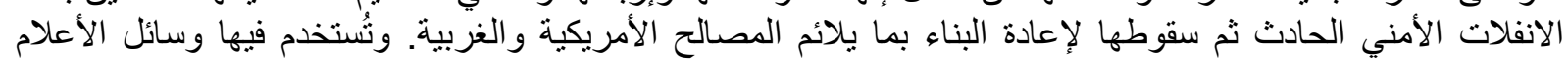

الجديد و التقليدي منها.

حرب الجيل الخامس وما يليها

حروب الجيل الخامس 5GW و الاعتماد على قوة الكيانات الصغيرة المدربة و التشكيلات العصابية و الجماعات الإرهابية

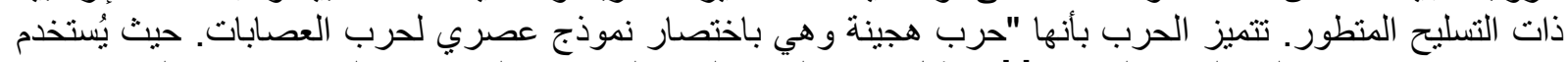

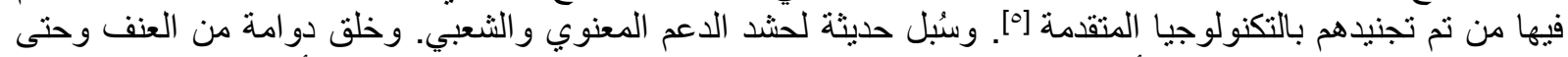

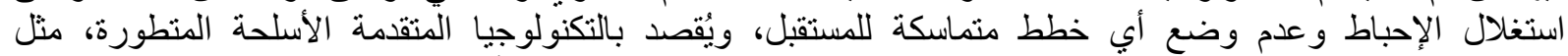

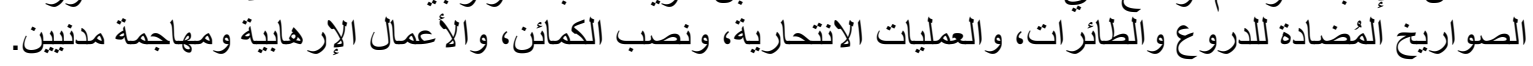

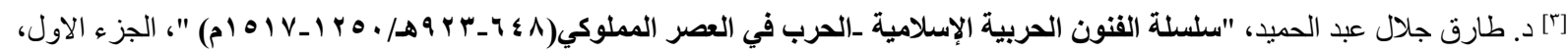

${ }^{[4]}$ http://alialamri.wordpress.com/2013/04/06/ (Accessed 20-2-2014)

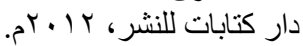
[] هالة عصام الدين،" أجيال الحروب"، الأهر ام اليومي،1521247
} 
حروب الجيل الخامس تمتاز أيضا على الرابع في استخدام التحالفات. أي تطويع الحلفاء من الدول التي تثنترك في مصالح

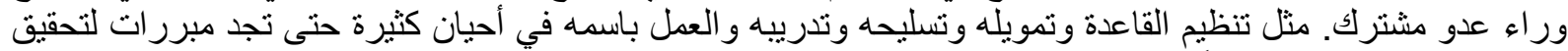

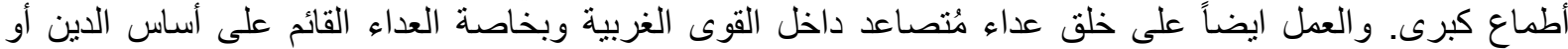

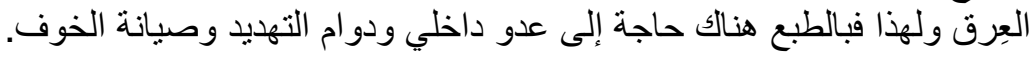

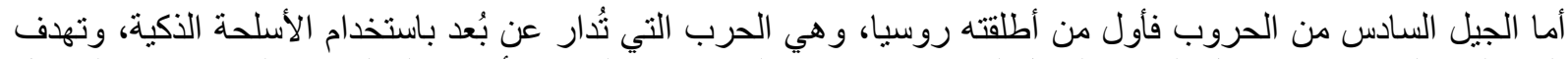

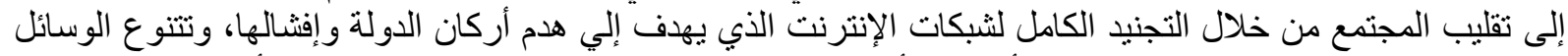

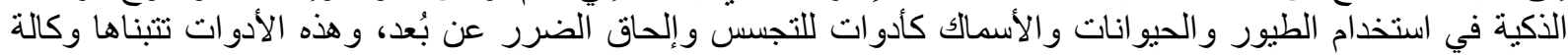

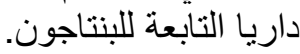

فالحرب في جو هرها تبادُل منظم للعنف، والدعاية في جوهر ها عملية إقناع منظمة، الأولى حسية تُهاجم الجسد والثانية

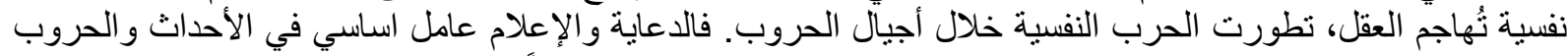

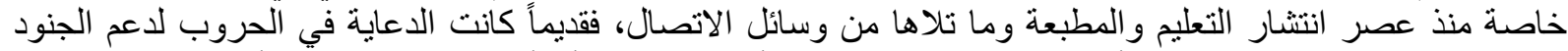

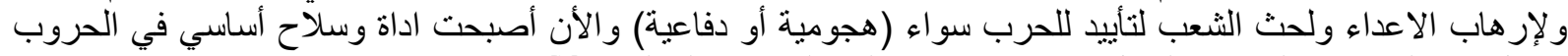

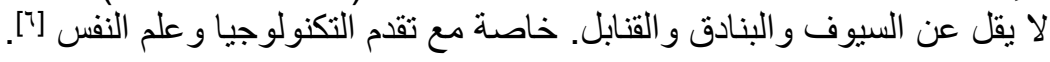

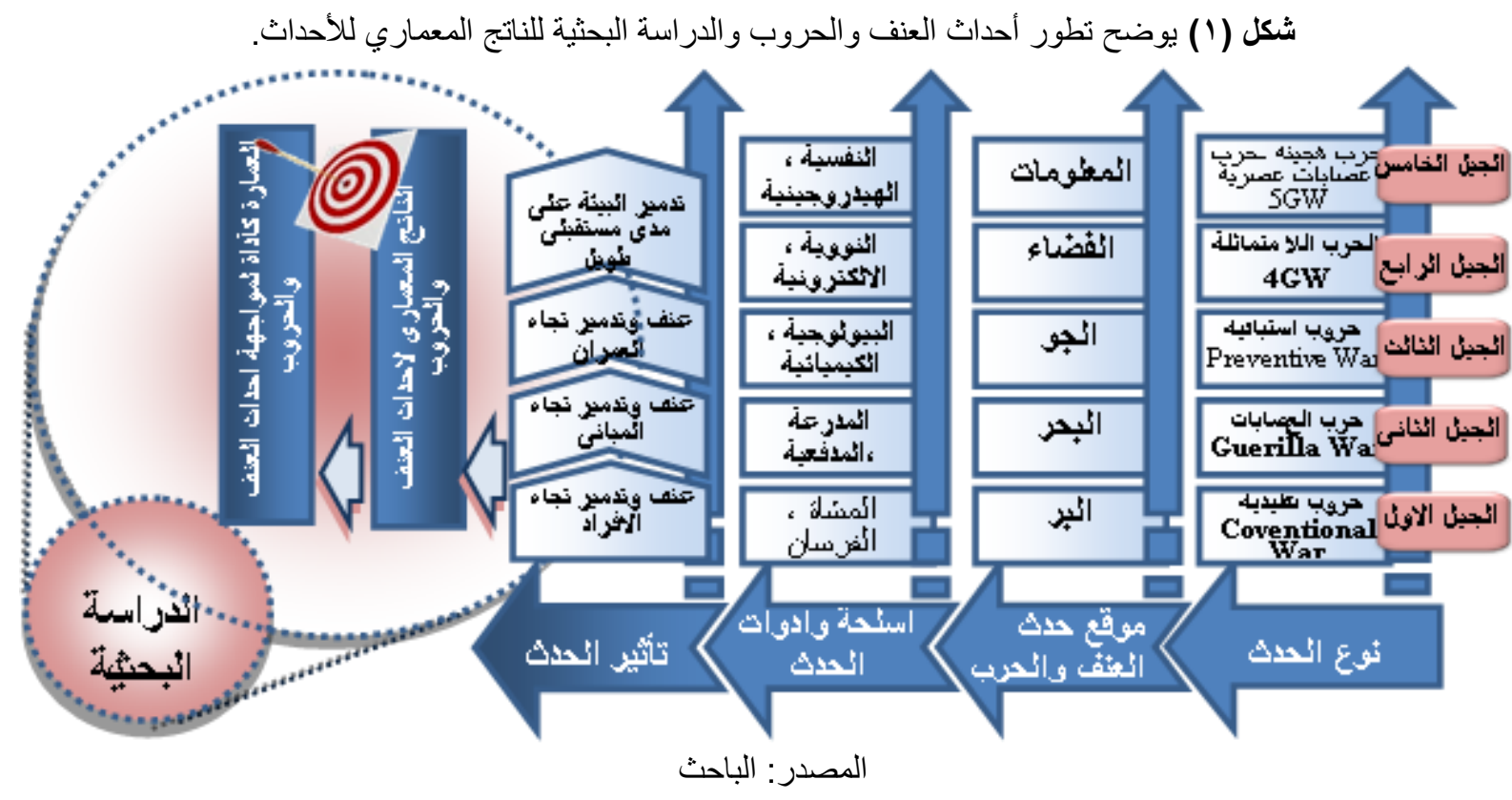

r أثر احداث العنف والحروب على الناتج المعماري

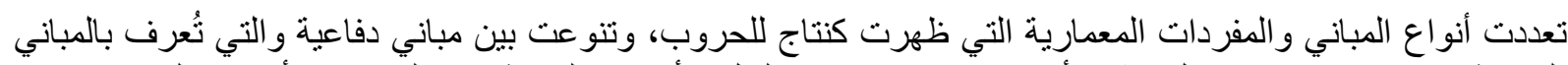

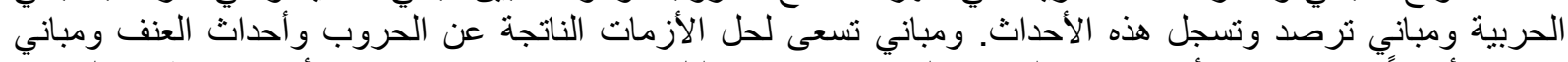

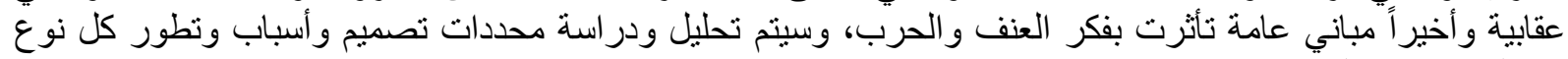
من المباني فيما يلي:

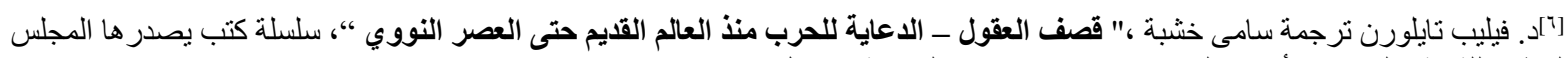

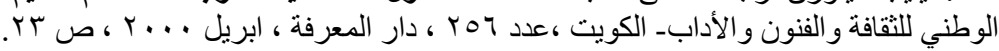




\section{ا مفردات معمارية ومباني لتسجيل الحدث 1/// ا مفردات معمارية معمارية}

و هي تسجيل الحدث على الجدران أو الأقواس أو الأعمدة التذكارية والمسلات، بالإضافة لتخليد أسماء الحُكام والقادة

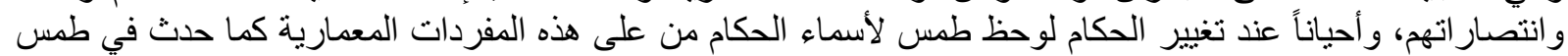

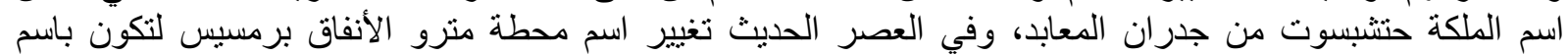

الثهداء.

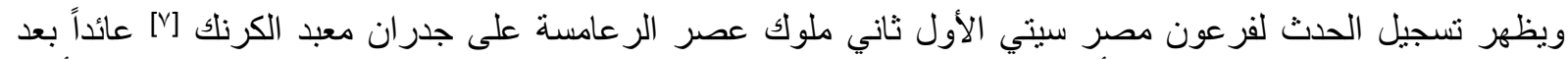

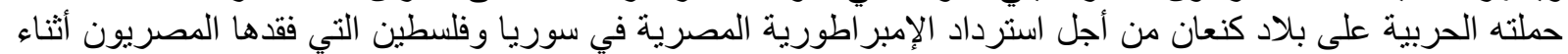

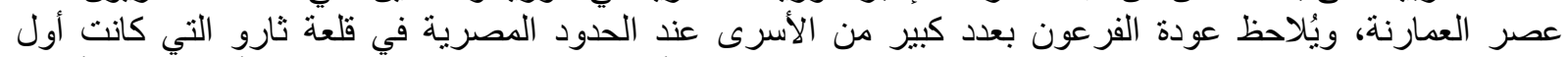

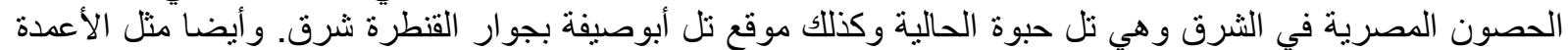

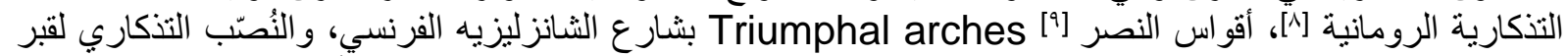

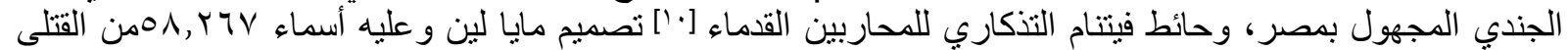

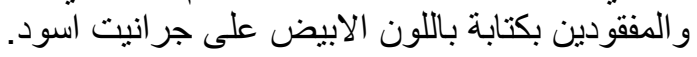

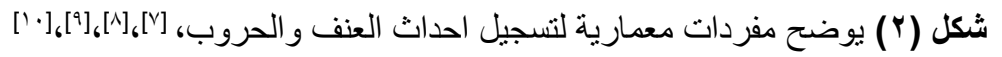

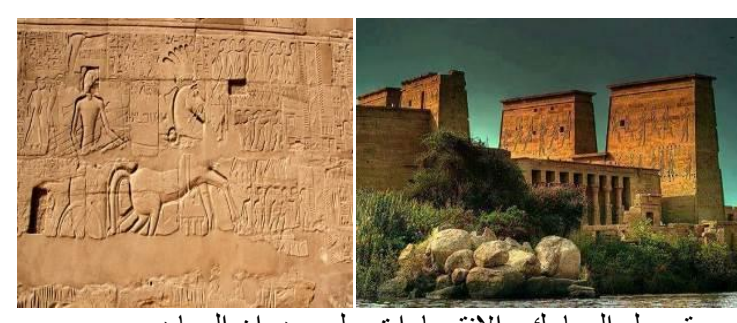

تسجيل المعارك و الانتصار ات على جدران المعابد ـمصر

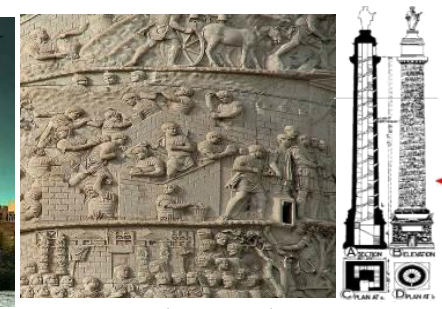

الاعمدة التذكارية الرومانية

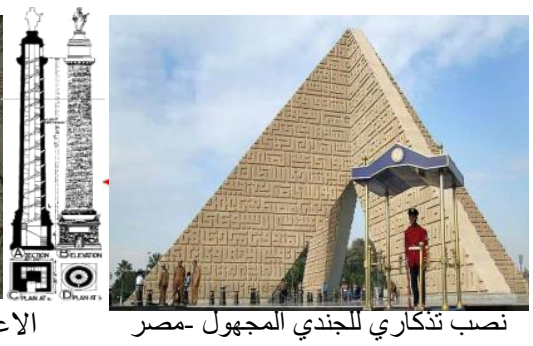

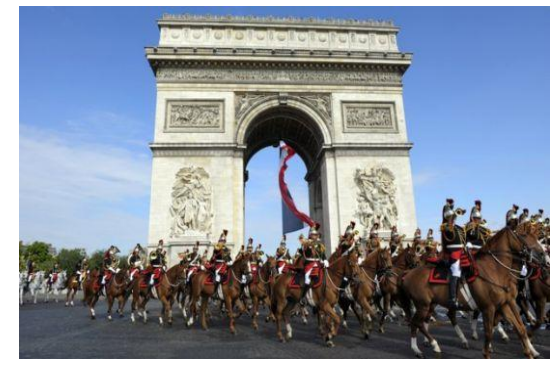

مصر، امتداد المتحف اليهودي ببرلين -

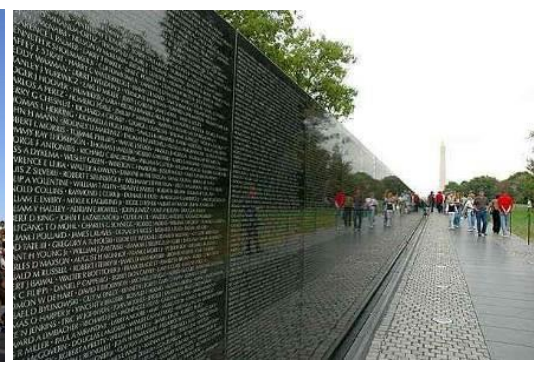

جدار ستريت - حائط تذكاري قدامى المحاربين في فيتنامواشنطن -امريكا

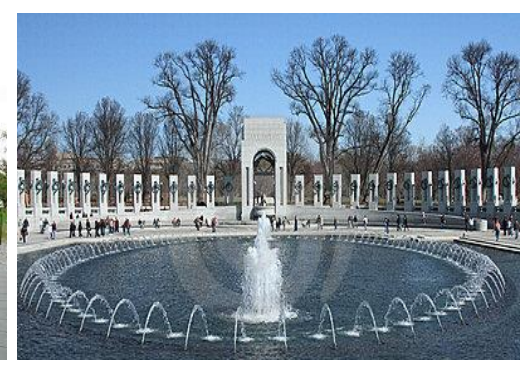

النصب التذكاري للحرب العالمية الثانية-و اشنطن امريكا

\section{T/T/ مباني ترصد وتُؤرخ الحدث في موقعه}

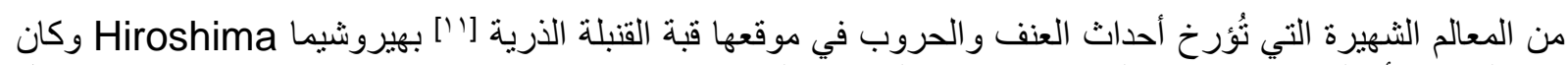

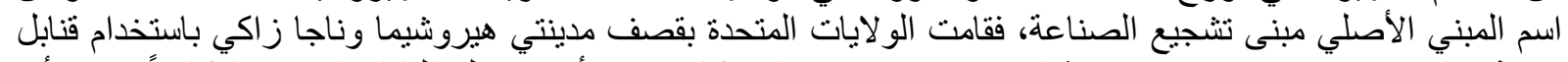

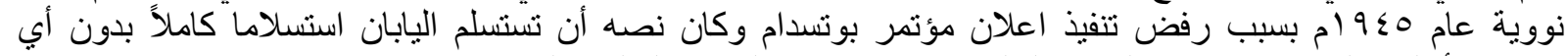

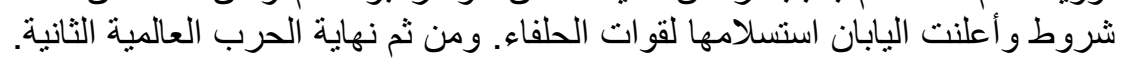

\footnotetext{
${ }^{[7]}$ http://godofmuseums.blogspot.com/2012/09/blog-post_4394.htm, (Accessed 20-4-2014)

${ }^{[8]}$ Banister Fletcher, F.R.I.B.A.," A History Of Architecture On The Comparative Method", Bradbury, Agnew, \& CO. L1X, Printers, London And Tonbridge,2000.

${ }^{[9]}$ http://english.sina.com/world/p/2011/0714/380993.html, (Accessed 20-4-2014).

${ }^{[10]} \mathrm{http}: / /$ www.trumanblog.com/tag/vietnam-memorial ,(Accessed 25-4-2014).

${ }^{[11]} \mathrm{http}: / /$ www.richard-seaman.com/Travel/Japan/Hiroshima/AtomicDome/ ,(Accessed 20-4-2014)
} 
وجعلت التفجيرات اليابان تعتمد المبادئ الثناثة غير النووية بعد الحرب، والتي تمنع الأمة من التسلح النووي. وكان مبنى

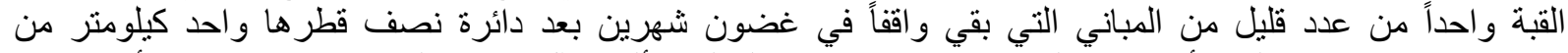

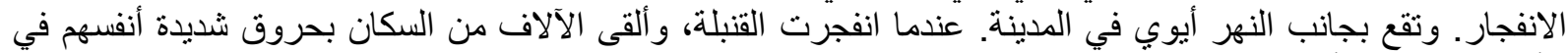

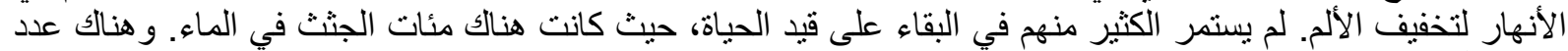

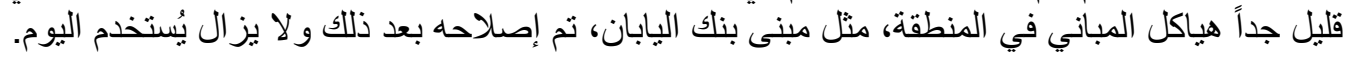

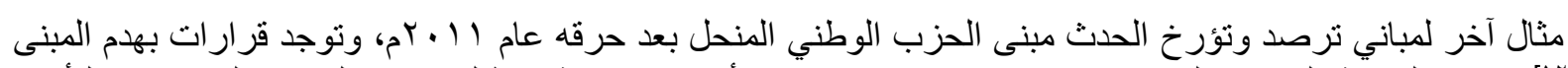

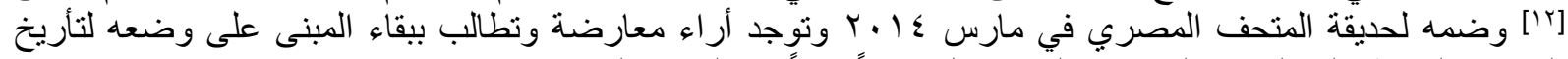

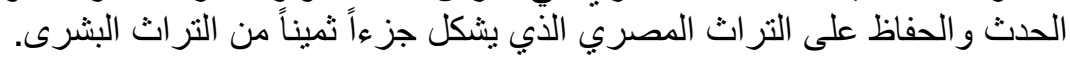

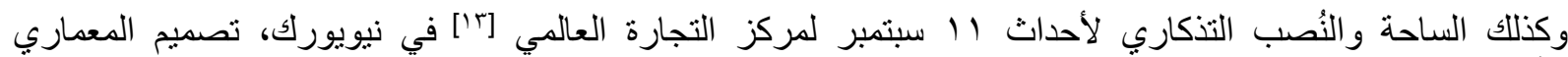

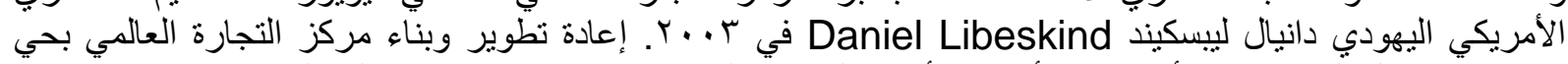

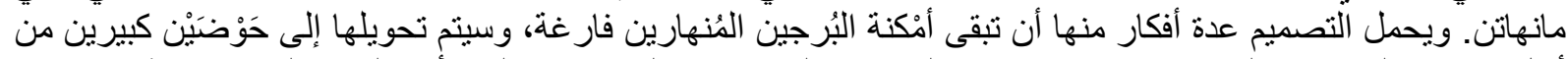

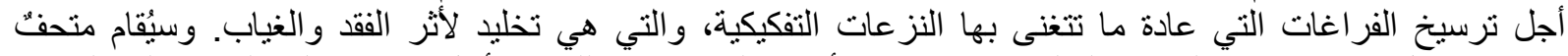

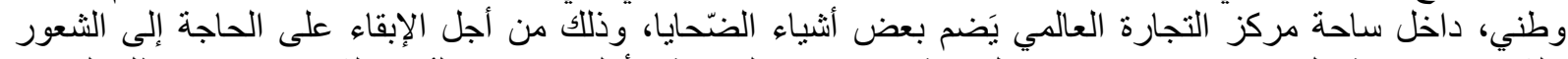

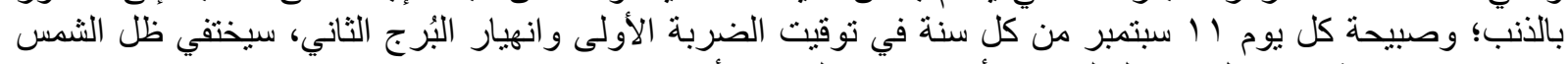

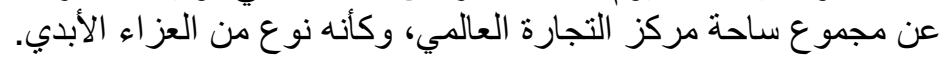

\section{r/ T/ T/ مباني المتاحف والبانورامات للحدث}

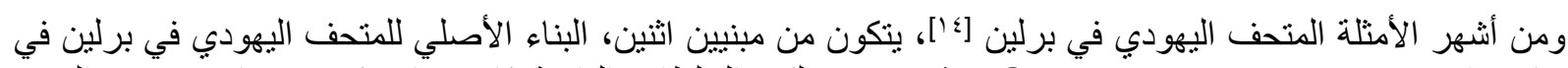

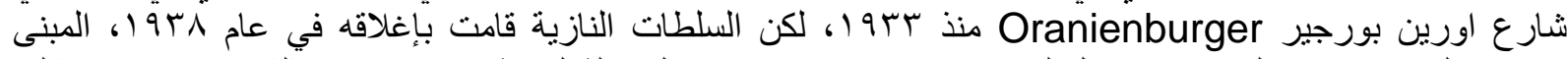

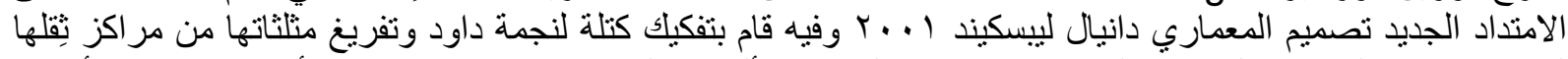

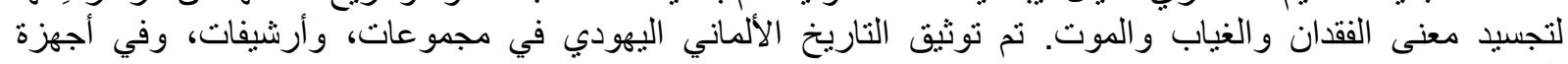
الحاسوب.

شكل (ّ) يوضح مباني تؤرخ احداث العنف (موقع برجي التجارة العالمي ــ امريكا، قبة القنبلة الذرية بهيروشيما ـاليابان، مقر
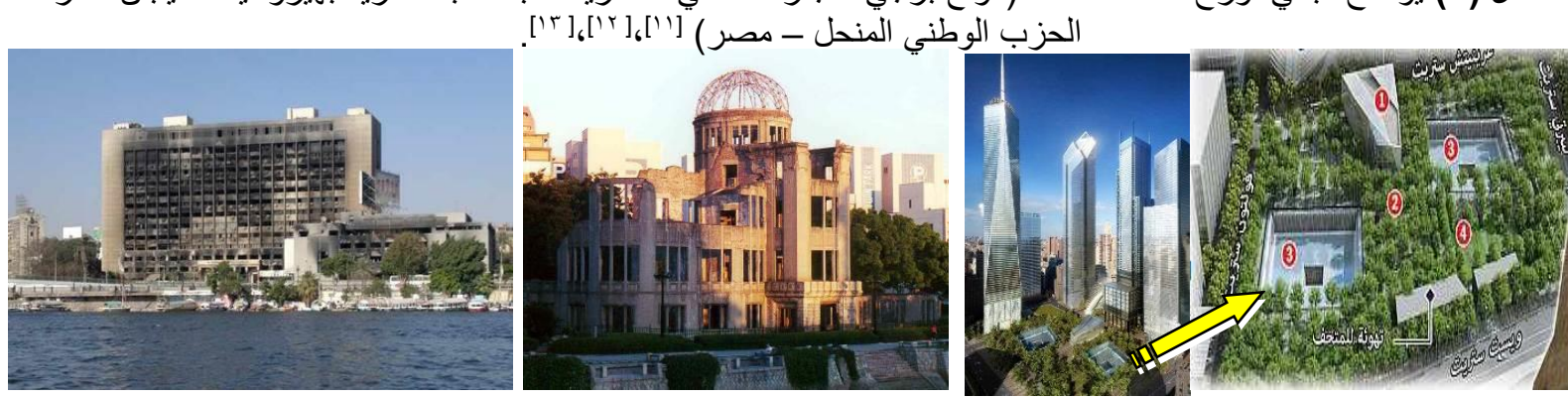

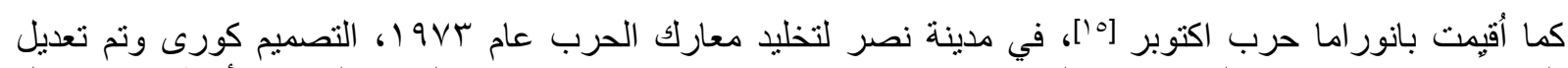

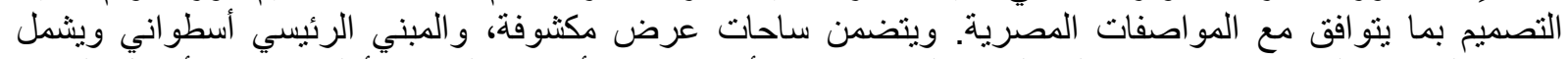

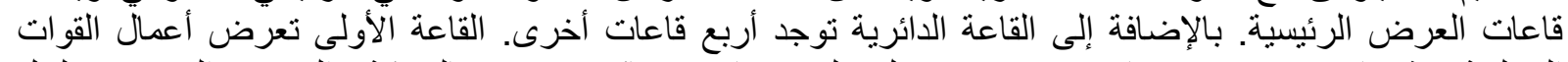

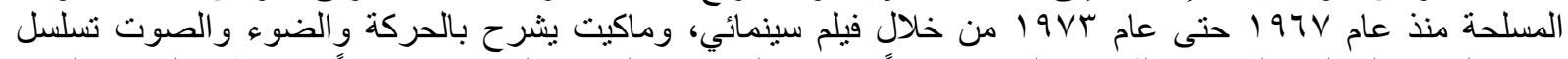

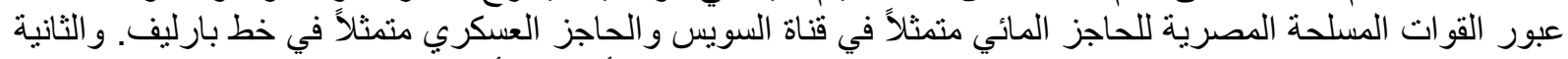

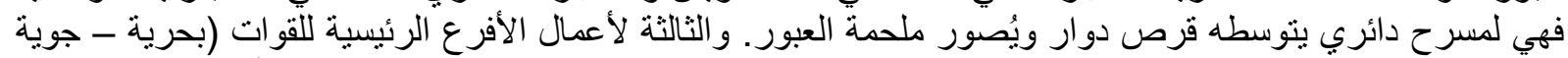

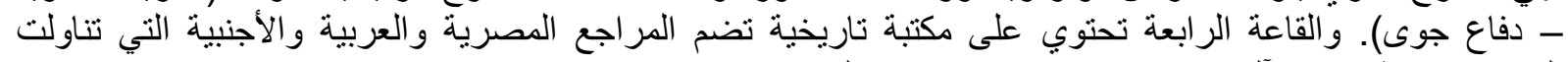

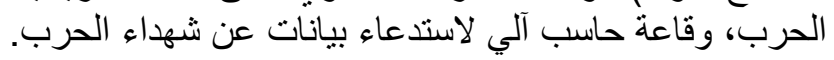

\footnotetext{
${ }^{[12]}$ http://www.youm7.com/News.asp?NewsID=1580656\#.UzQ0H_mSwbd ,(Accessed 11-5-2014)

${ }^{[13]} \mathrm{http}: / /$ daniel-libeskind.com/projects , (Accessed 20-4-2014)

${ }^{[14]}$ Daniel Libeskind, "Jewish Museum Berlin", G + B Arts International, Publisher: Verlag der Kunst. 1999-06, ISBN10: 9057012529

${ }^{[15]}$ Nae' ma Samir, Waheed Samy, “October War Panorama”, Free days Egypt Magazine,Touist monthly free magazine, Issue 115 - October 2013, http://www.freedaysegypt.com/magazine/freedaysegypt_115_lr.pdf ,P6175
} 


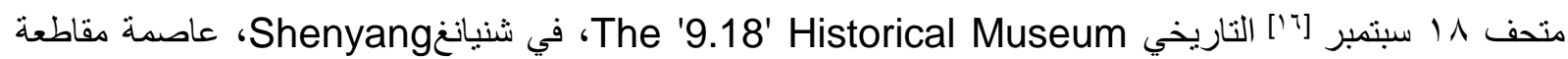

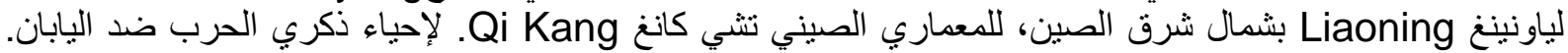

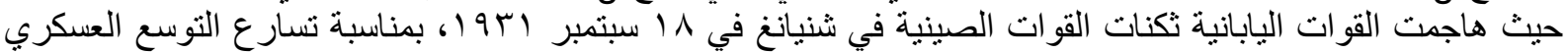

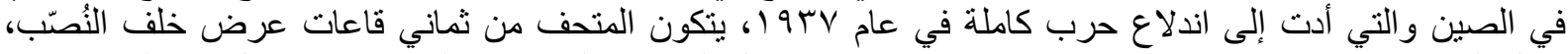

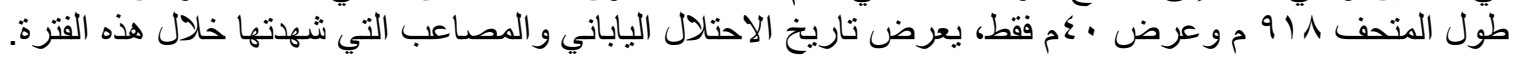

\section{r/r}

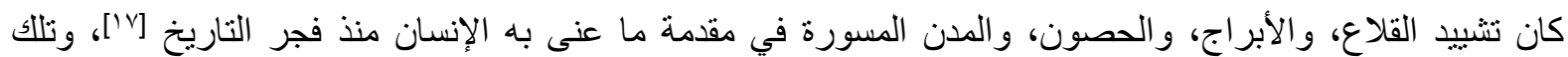

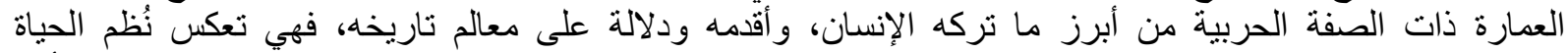

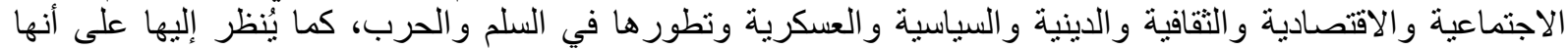

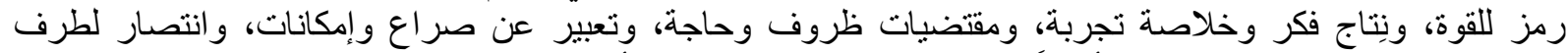

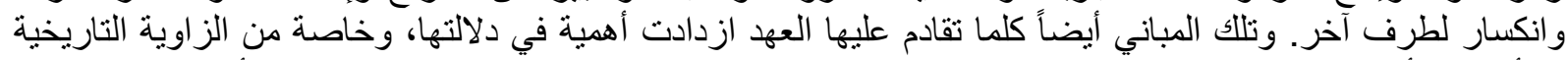

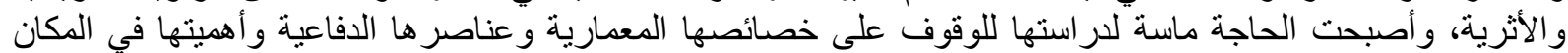

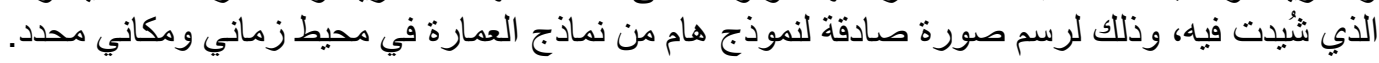

شكل (؛ ) يوضح مباني متاحف وبانور امات الحدث (متحف 1 1 سبتمبر التاريخي - الصين، بانور اما حرب السادس من اكتوبر -
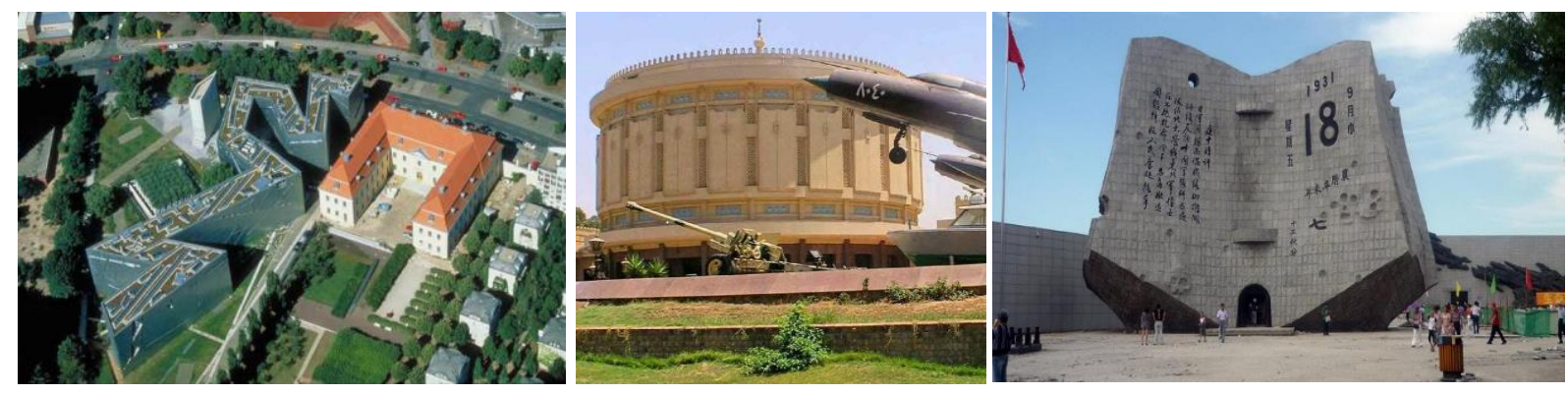

(آ/ 1/ مفردات معمارية (الاسوار والبوابات)

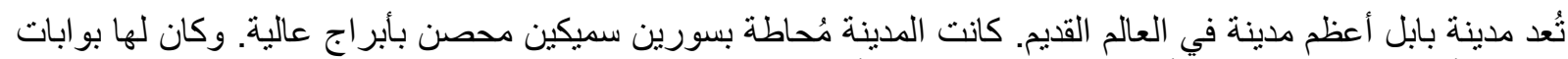

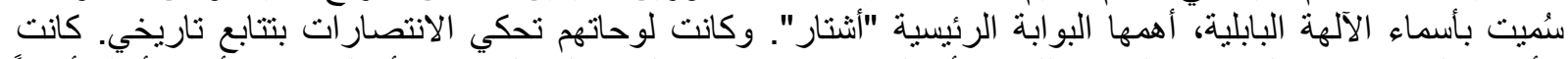

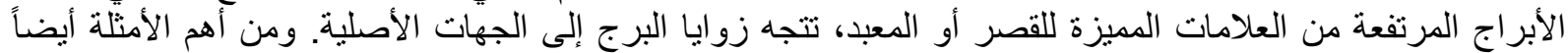

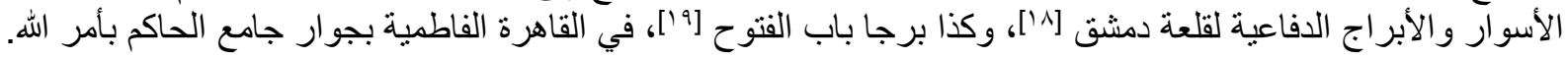

\footnotetext{
[16]http://www.gwu.edu/ memory/issues/museums/9.18HistoricalMuseum.html ,(Accessed 20-2-2014)

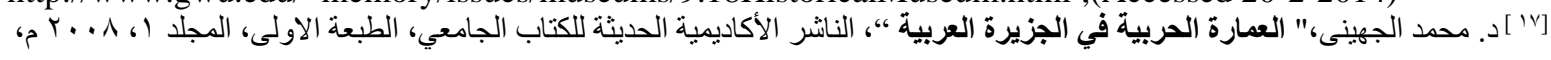
[1/1 ] د. محمد الجهيني،" إطلالة على العمارة الحربية في شرق العالم الإسلامي عبر العصور-سماتها وأحلث ما كتب عنها بالعالم"، الناثر

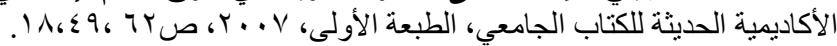

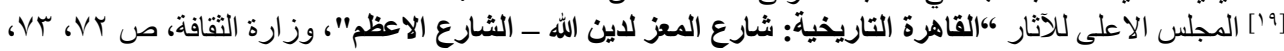
http://permedjat.blogspot.com/2013/09/El-moaezStreetTheGreatestStreet.html
} 


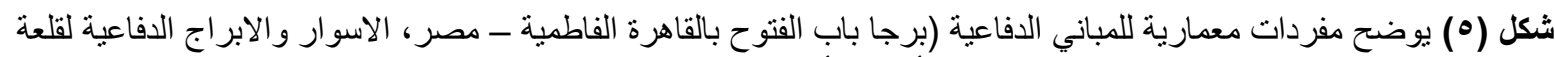

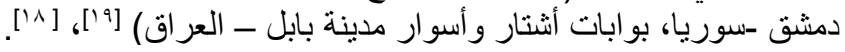
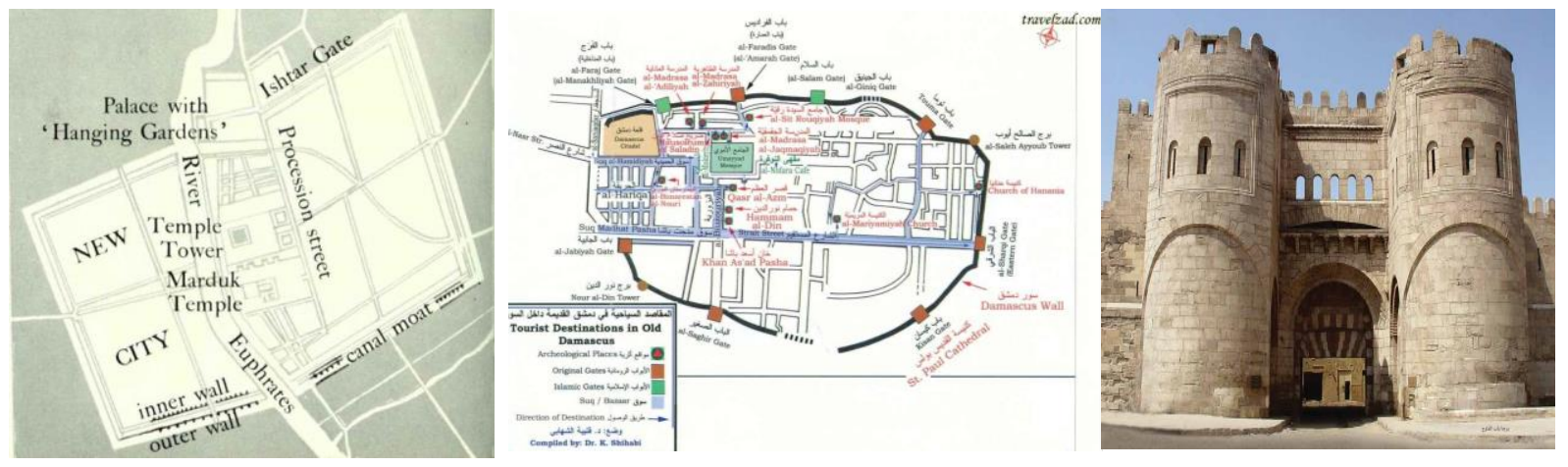

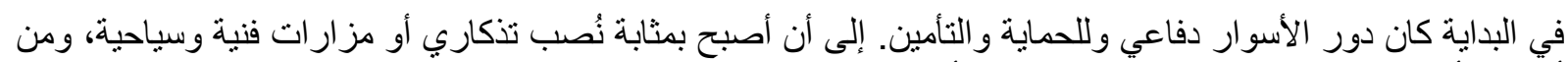

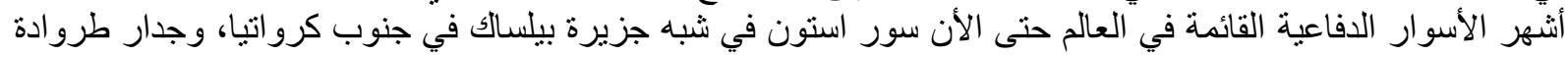

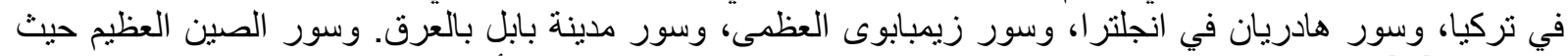

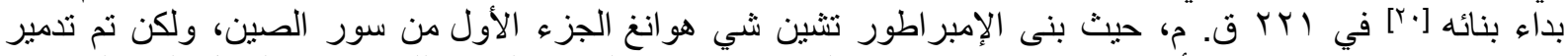

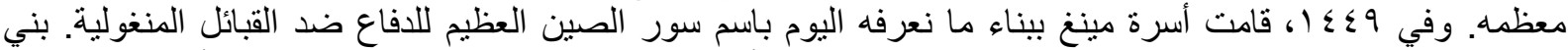

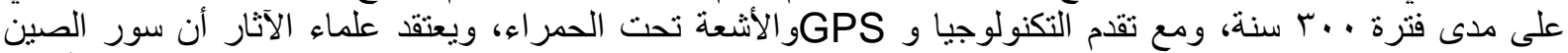

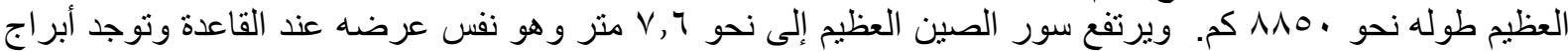

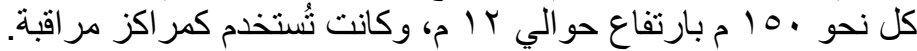

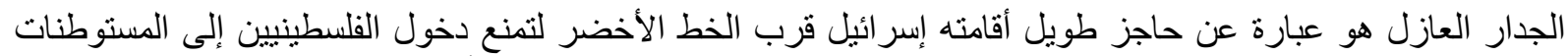

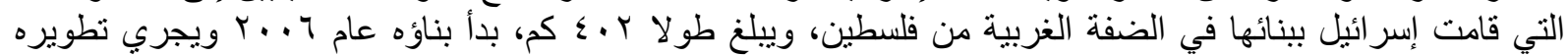

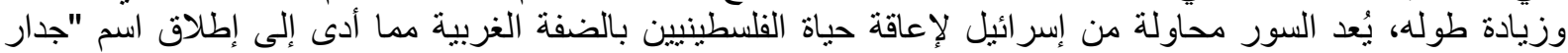

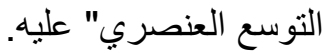
سور برلين يفصل بين علئ ألمانيا الثرقية [بr'] (المُحتلة من الاتحاد السوفيتي وقتها) و المانيا الغربية (المُحتلة من امريكا

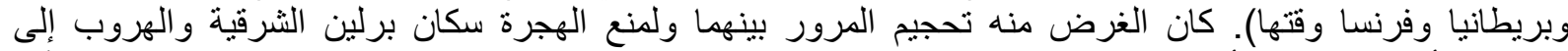

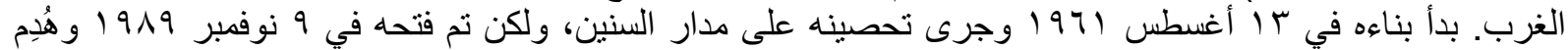

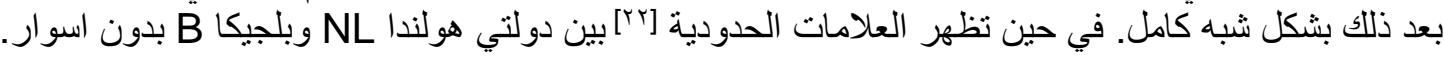

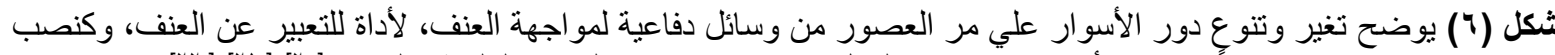

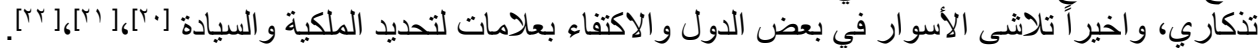

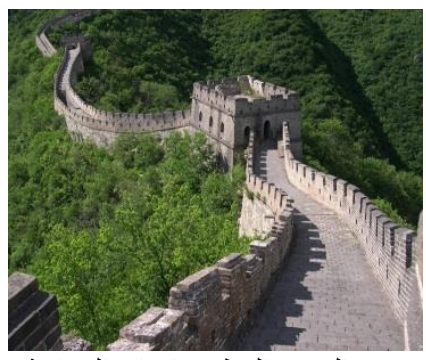

سور الصين العظيم و ابر اج المراقبة

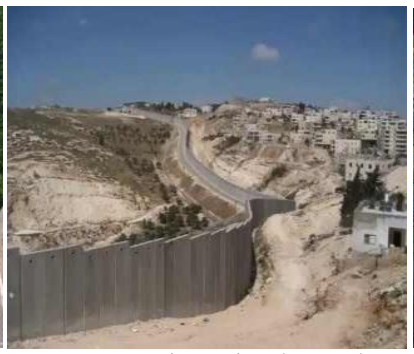

الجدار العازل شمال قطاع غزة

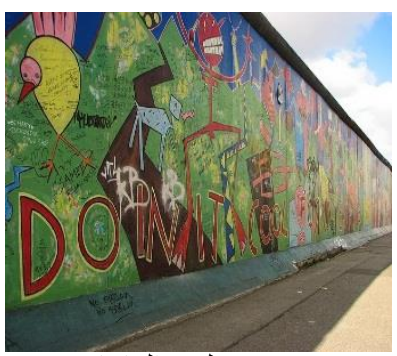

سور برلين، المانيا

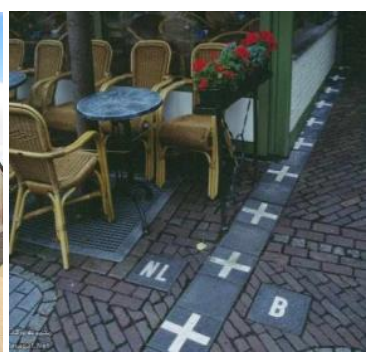

حدود هولندا وبلجيكا

\footnotetext{
${ }^{[20]} \mathrm{http}: / /$ www.thaqafnafsak.com/2012/10/blog-post_5628.html ,(Accessed 11-5-2014)

${ }^{[21]}$ http://first-ten.blogspot.com/2013/12/10_1324.html,(Accessed 20-4-2014)

${ }^{[22]} \mathrm{http}: / / \mathrm{www} . w a r a q a t . n e t / 13925 /,($ Accessed 11-5-2014)
} 


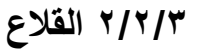

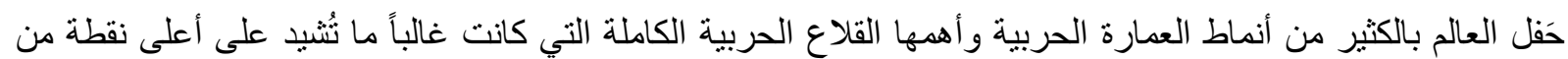

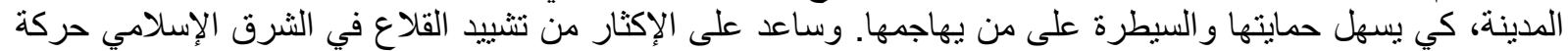

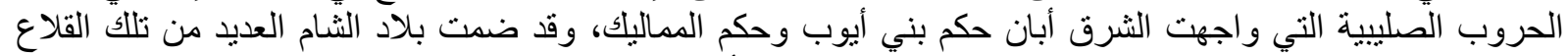

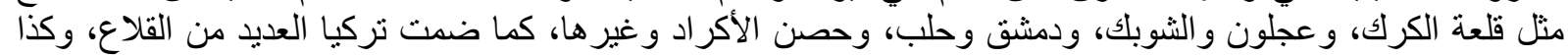
إيران، ومنطقة آسيا الوسطى وعلى والهند.

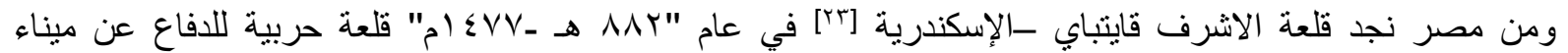

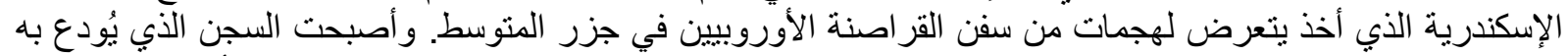

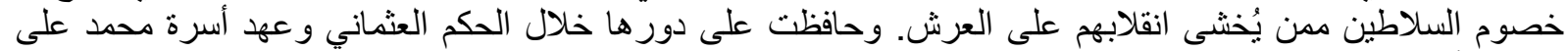

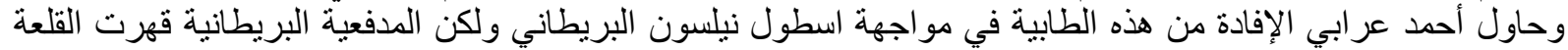

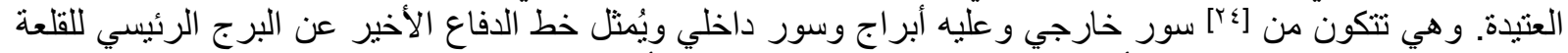

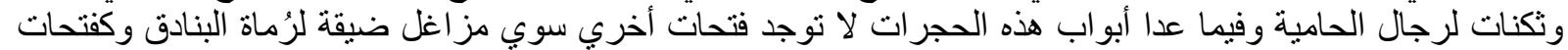

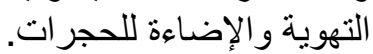

وقد زُود البرج الرئيسي بعدد من السقاطات من البحر أو البر حيث توجد فوق المدخل، وكانت تُشتخدم في إلقاء المواد

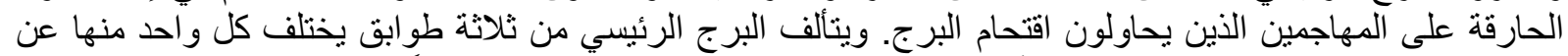

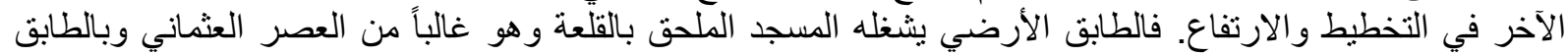

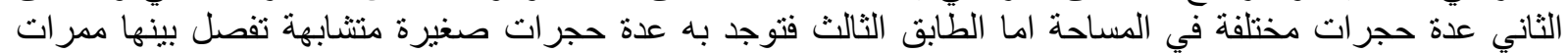

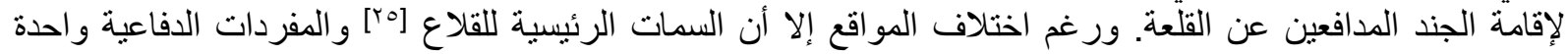
على مر العصور.

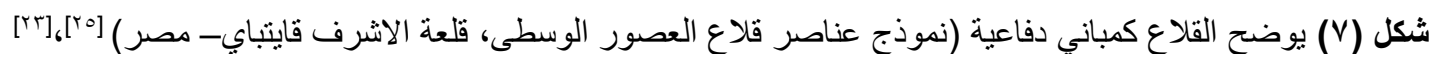

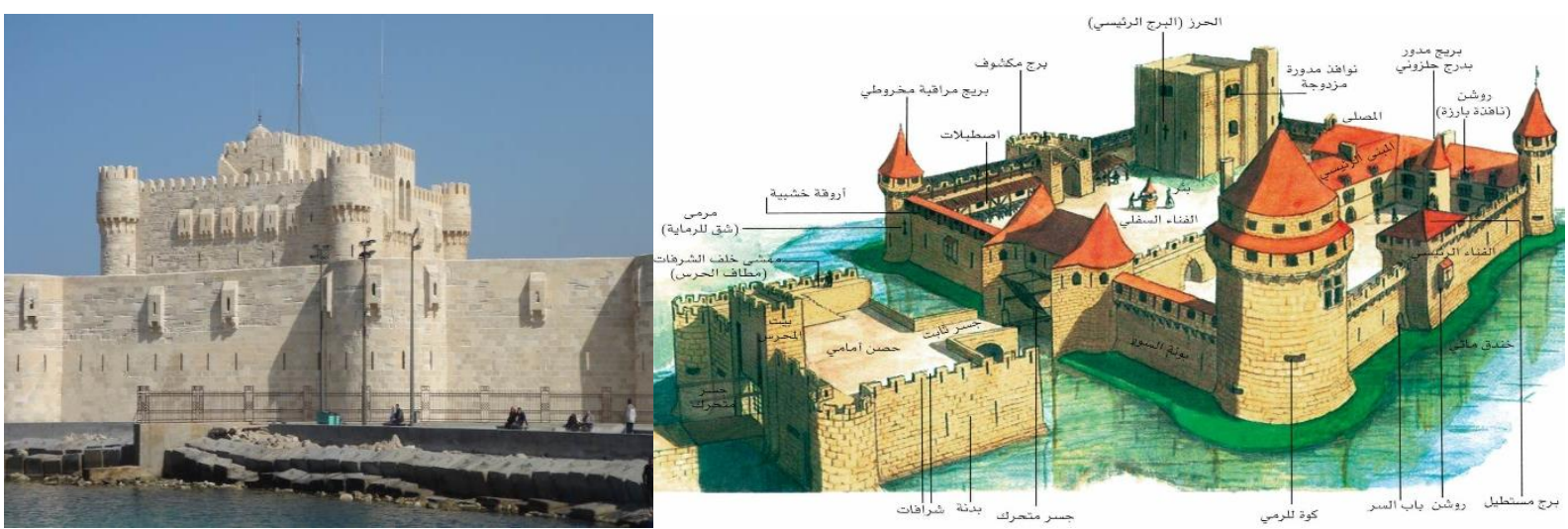

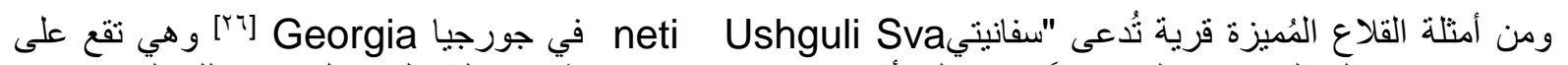

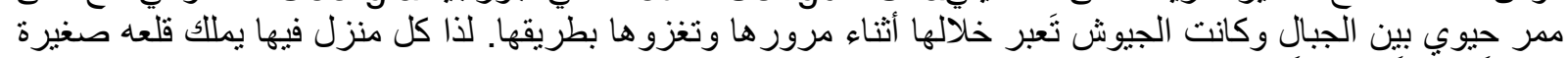

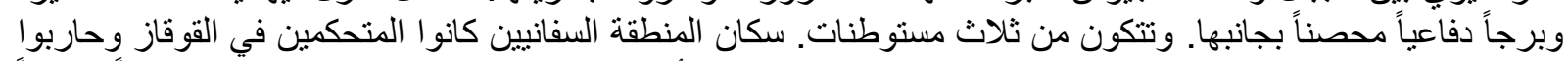

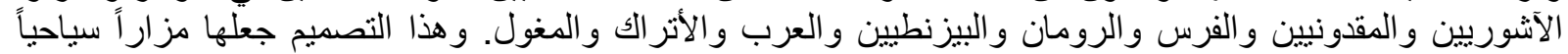
و مُسجل كموقع للنزراث العالمي لليونسكو. والرون

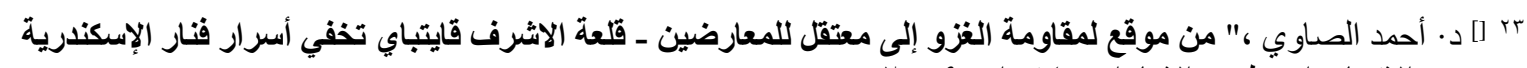

${ }^{[24]} \mathrm{http}: / / \mathrm{www}$. alittihad.ae/details.php?id=4534\&y=2009\&article=full

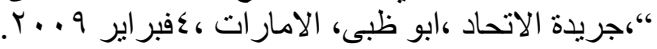

${ }^{[25]} \mathrm{http}: / / \mathrm{www}$. arab-ency.com/index.php ,(Accessed 20-4-2014)

${ }^{[26]} \mathrm{http}: / / \mathrm{www} . d u b b e d-a d v e n t o u r e r . c o m / t r i p s / t r e k k i n g-s v a n e t i,($ Accessed 11-5-2014) 
شكل (^) يوضح قلعة لكل منزل للتحصين و الدفاع بسبب الموقع - قرية سفانيتيiUshguli Svaneti ، جورجيا [יזبـشكل ( )

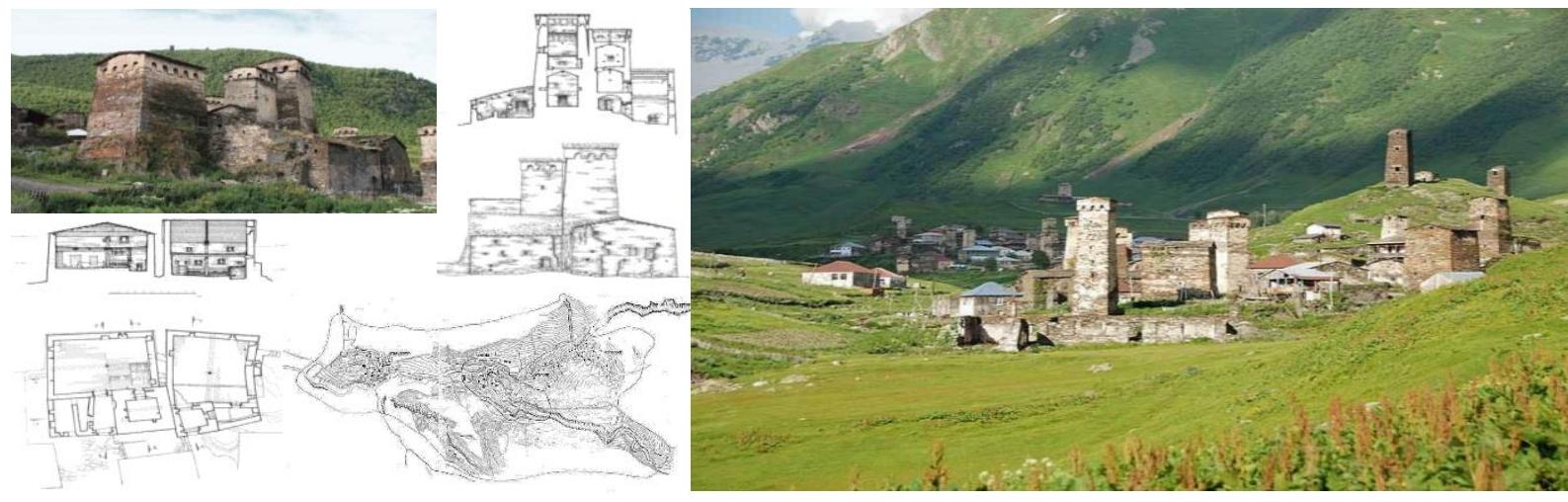

أما نهاية عصر القلاع فكان نتيجة النطور السريع الذي طر أ على الأسلحة النارية ومنذ أن اكتسحت الجيوش الفرنسية

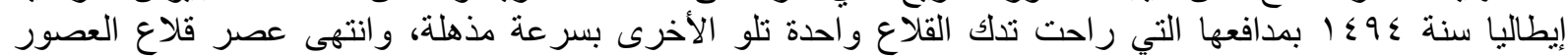

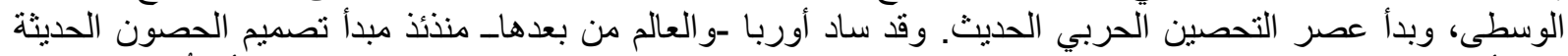

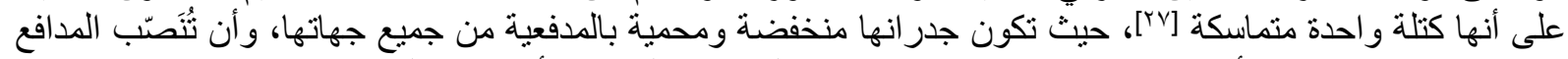

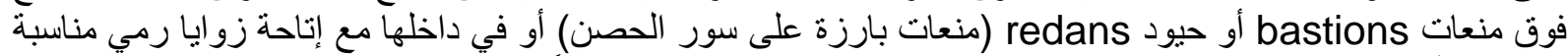

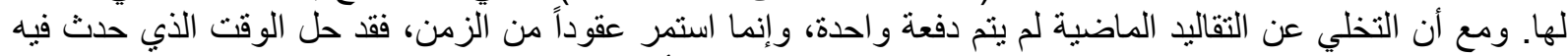

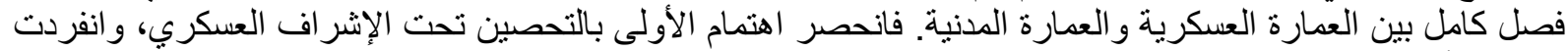

بمبادئ و أعر اف خاصة بهاه، وتفنتت الثانية بيناء القصور و الفيلات فانية الفخمة.

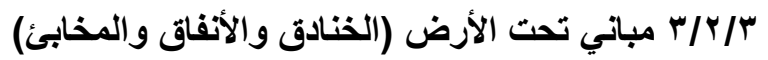

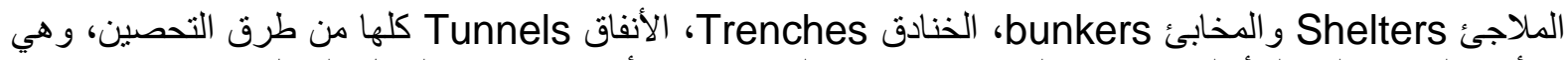

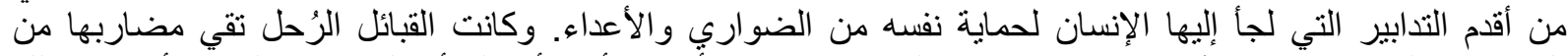

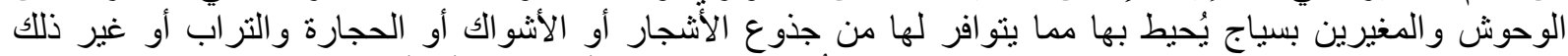

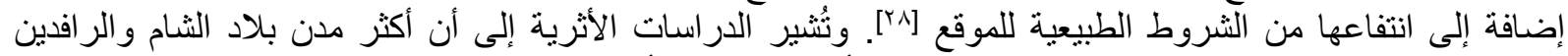

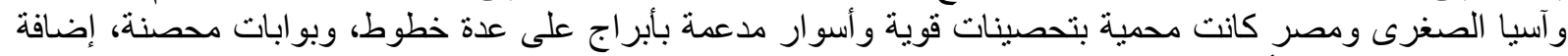

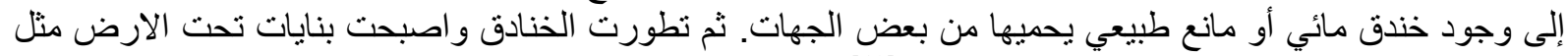

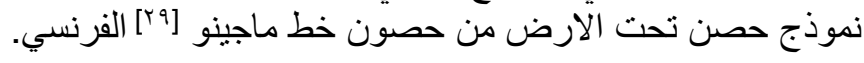

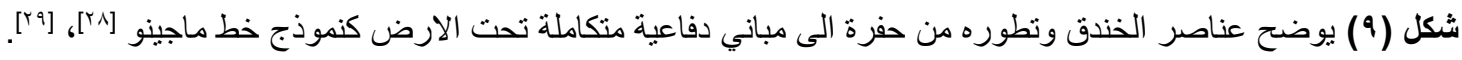
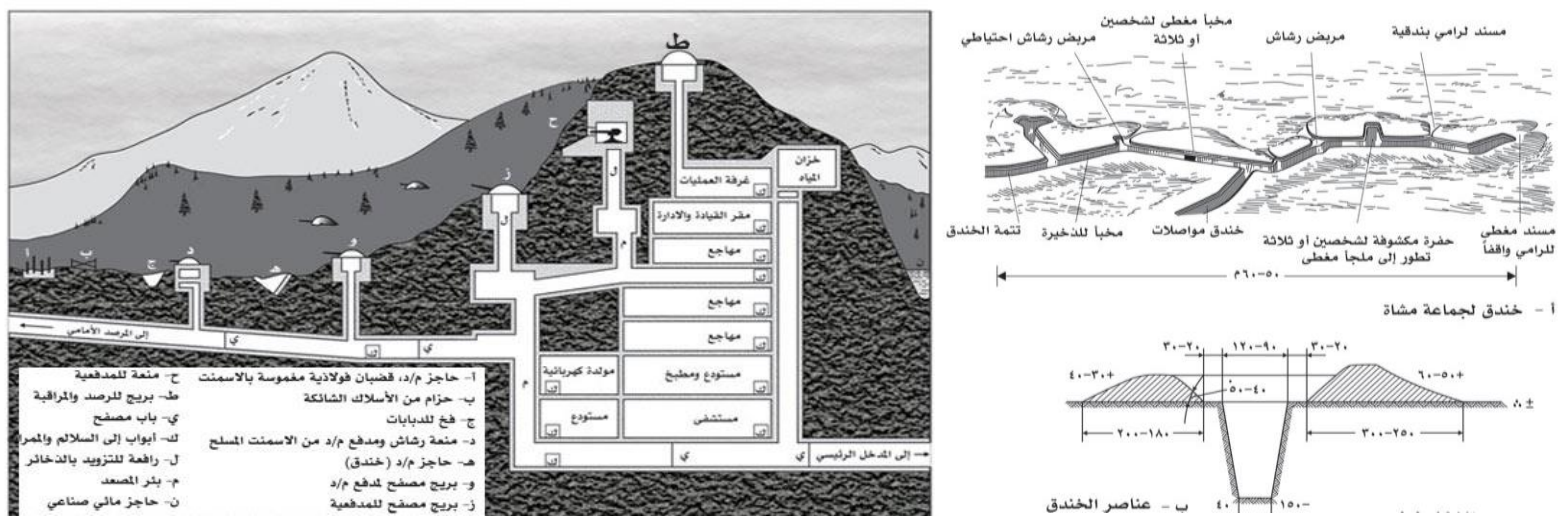

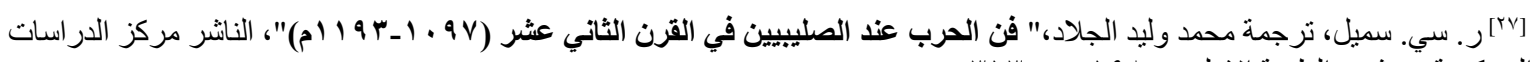

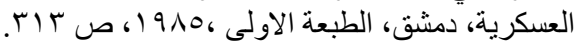

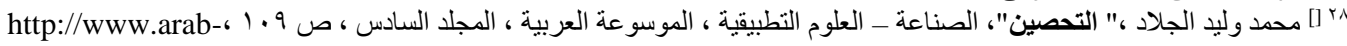
ency.com/index.php?module=pnEncyclopedia\&func=display_term\&id=3247\&m=1 ${ }^{[29]}$ Ian V. Hogg, "The History of Fortification”, Orbis Publishing; 1st edition, London, ISBN-10: 0856130281, November 1981. 


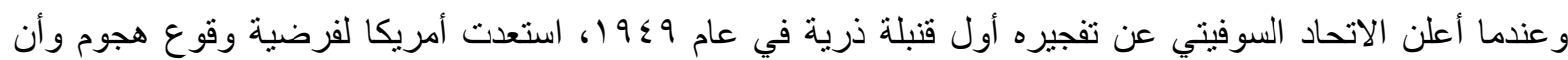

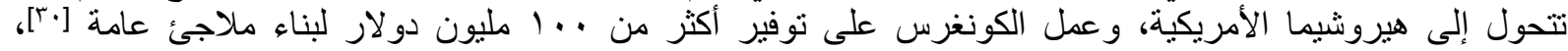

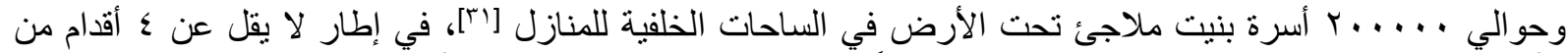

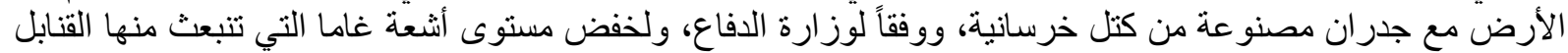

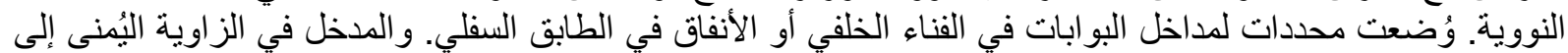

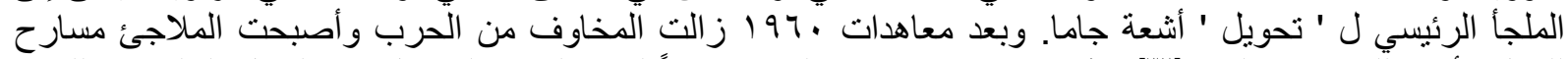

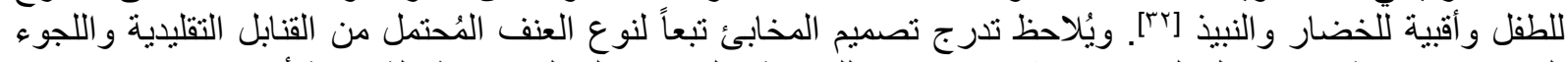

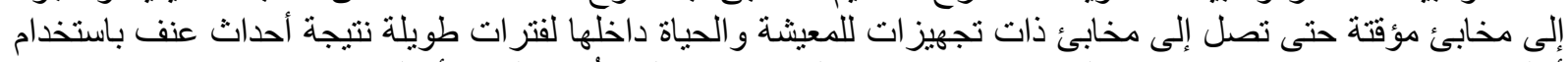
أسلحة كيمائية ونووية وهيدروجينية التي لا تكتفى بتدمير المباني فقط ولكن تُدمر البيئة بأكملها.

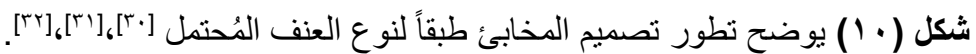
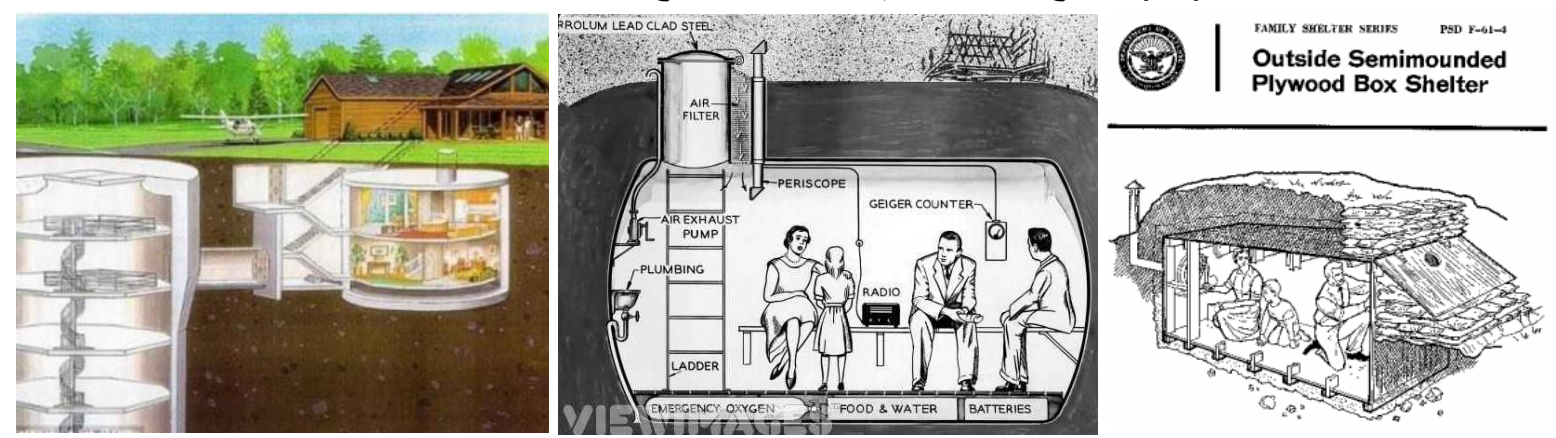

شكل (1') يوضح مساقط أفقية وقطاعات وعناصر مأوي فاخر غير قابل للتدمير وضد الأسلحة النووية في ولاية كانساس، أمريكا[؟؟.
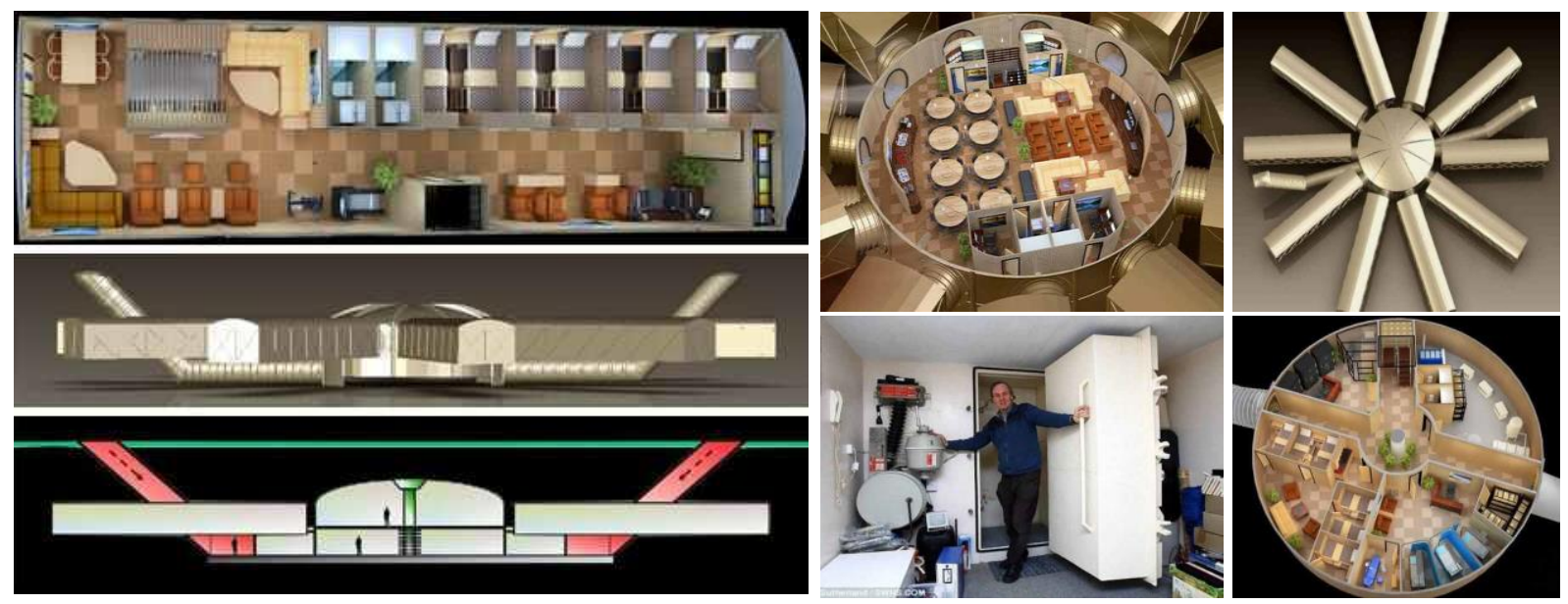

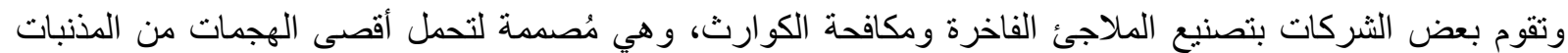

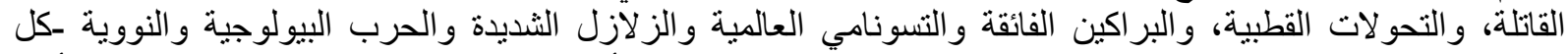

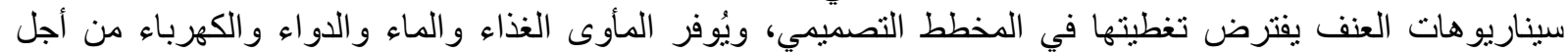

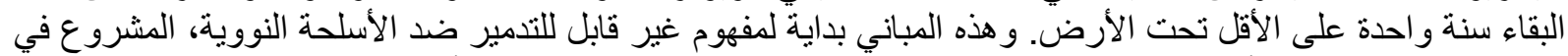

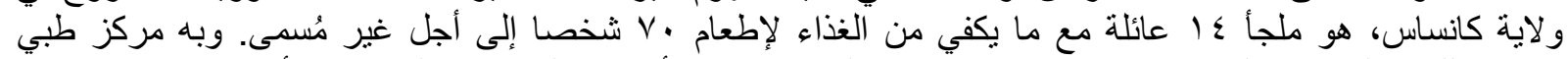

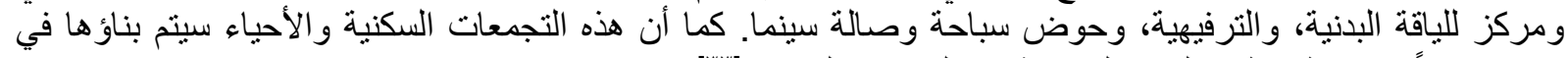

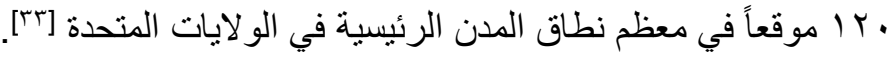

[30] Paul Vitello, "Steuart Pittman Dies at 93; Led Fallout Shelter Program", The New York edition, NY Times, February 21, 2013, Page B17, http://www.nytimes.com/2013/02/19/us/steuart-pittman-head-of-fallout-shelter-program-dies-at-

93.html?ref=obituaries\&_r=0

${ }^{[31]}$ Richard Fleetwood, “SHELTER: How Fallout Shelters Work”,http://www.survivalring.org/survival/shelter-howfallout-shelters-work/

${ }^{[32]} \mathrm{http}: / / \mathrm{www}$. loti.com/fifties_history/surviving_nuclear_attack.htm,(Accessed 11-5-2014)

${ }^{[33]}$ Iqbal Imran, "Underground nuclear bomb proof home worth \$18 million ”, Saranac Lake, NY: USA | Jun 01, 2012, http://www.allvoices.com/contributed-news/12292064-underground-nuclear-bomb-proof-home-worth18-million-for-sale-at-only-172-million, (Accessed 29-5 -2014) 


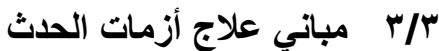

بالرغم من أن مباني علاج الأزمات وسبق التصنيع تُمثل حل لأحداث العنف والحروب و التعويض عن فاقد المباني

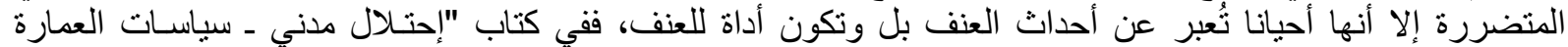

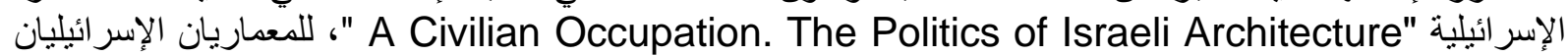

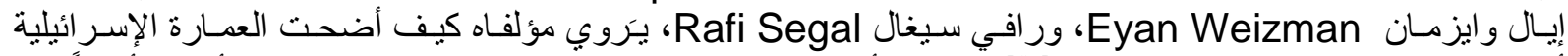

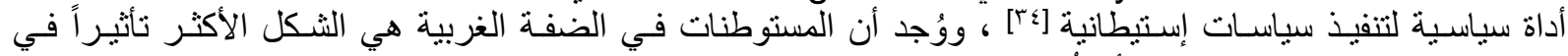

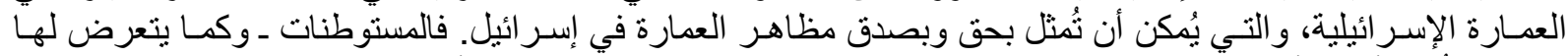

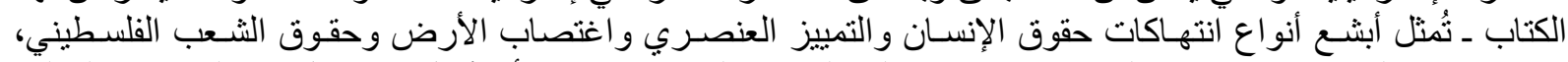

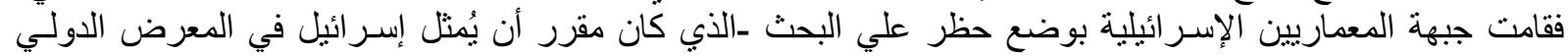

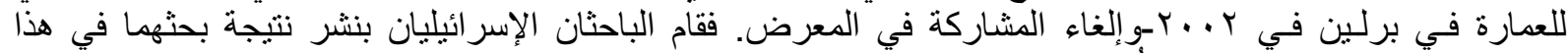

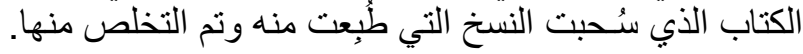

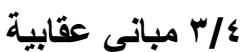

تمثلت في السجون والمعتقلات التي تطور دور ها من كونها مؤسسات عقابية حتى أصبحت مؤسسات إصلاح و إعادة

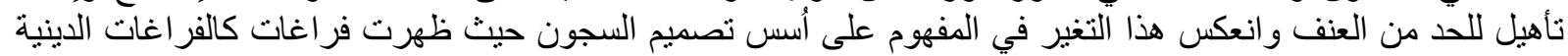

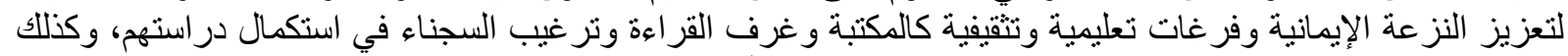

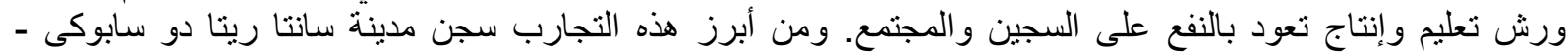
Santa Rita do Sapucai Prison التبديل على درجات ثابتة لتوليد الكهرباء.

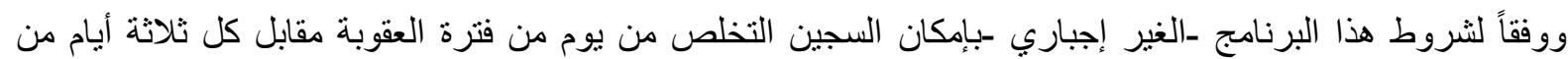

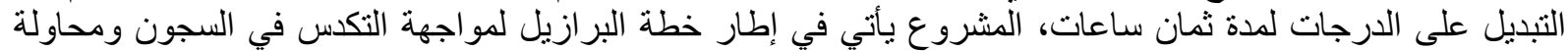

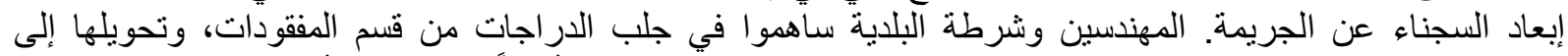

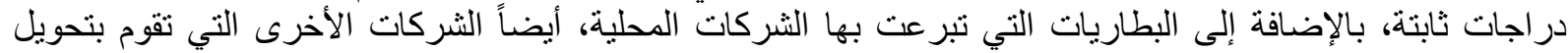

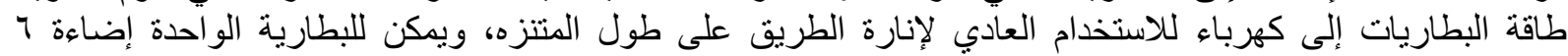

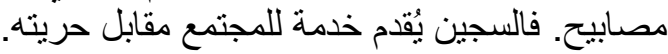

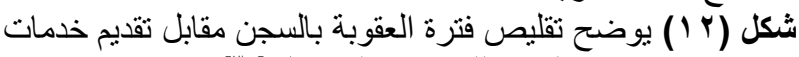

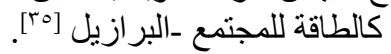

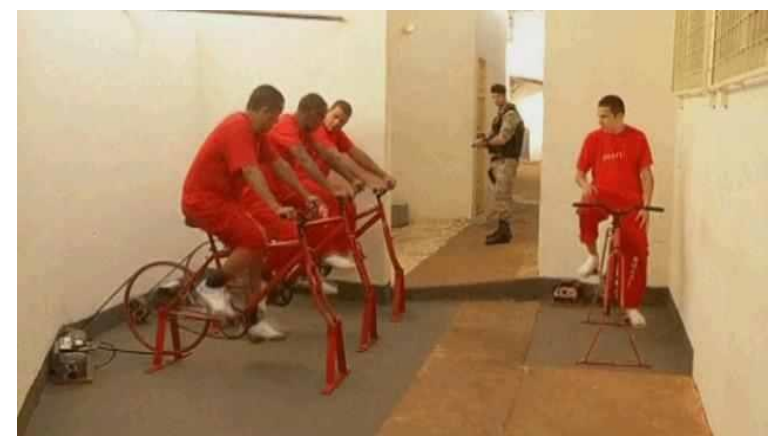

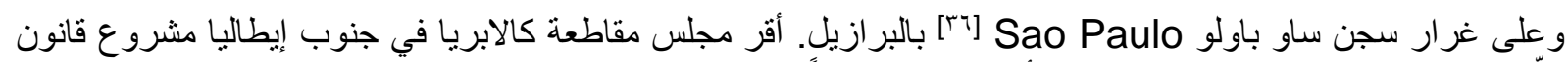

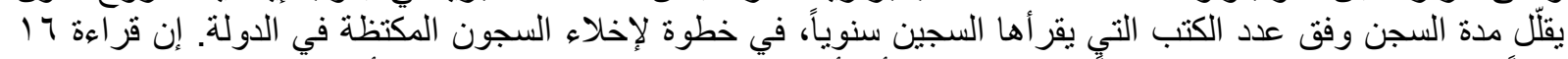

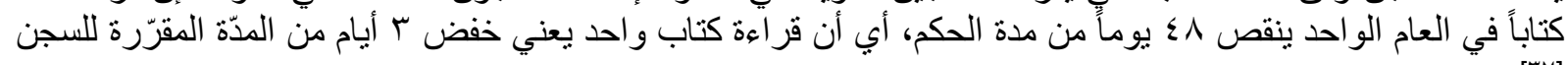

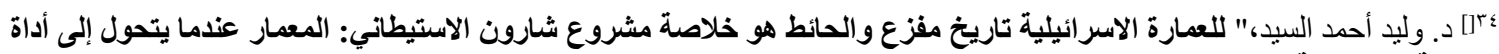

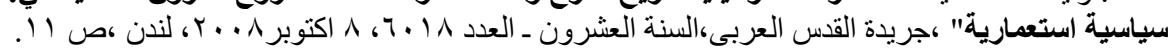
${ }^{[35]}$ http://www.telegraph.co.uk/news/worldnews/southamerica/brazil/9356129/Brazil-prisoners-reading-booksto-shorten-their-sentences.html, (Accessed 19-1-2014)

${ }^{[36]} \mathrm{http} / / /$ knowledge-ks.blogspot.com/2012/07/blog-post_6859.html\#ixzz31RCQeSwb ,(Accessed 20-1-2014)

${ }^{[37]}$ http:///hayat.com/Articles/, (Accessed 29-5 -2014) 


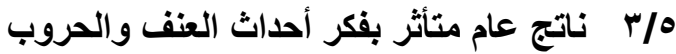

أ- العثوائيات

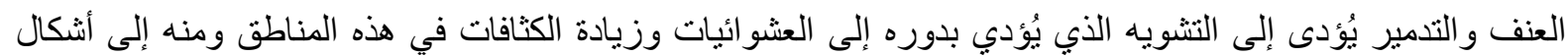

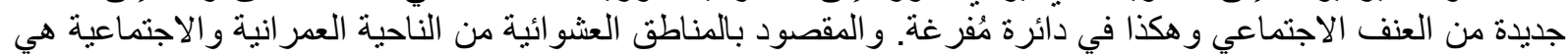

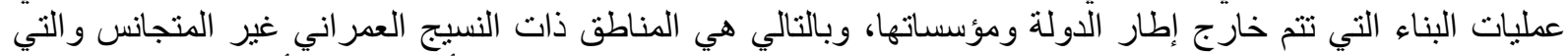

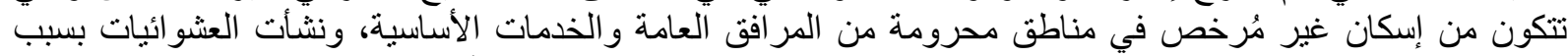

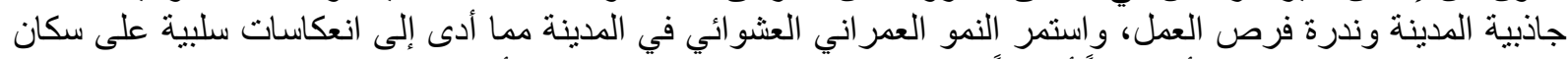

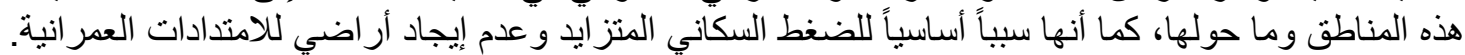

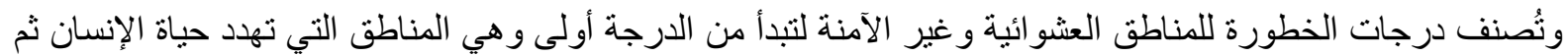

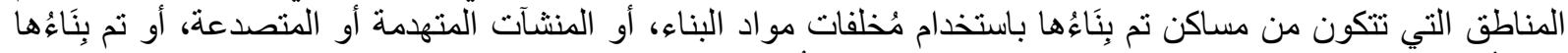

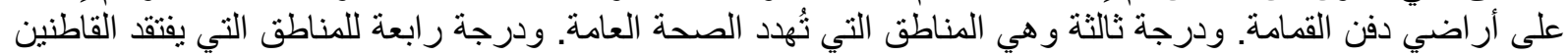

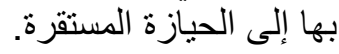

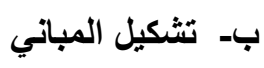

أخذ التأثر بفكر العنف و الحروب يرمى بظلاله على تشكيل المباني في عدة اتجاهات ورؤى منها:

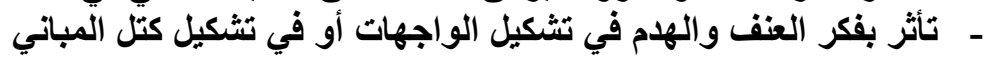

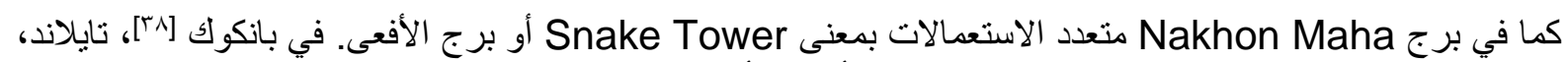

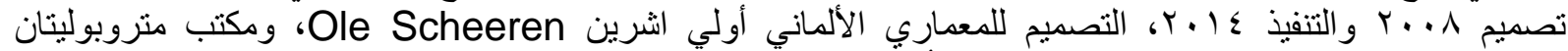

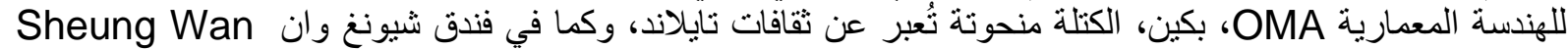

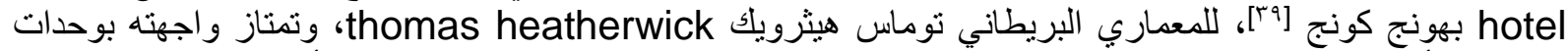
موديولية (أربعة احجام مختلفة من المكعبات) تتجمع الآلاف منها بشكل عشو ائي فنظهر الو اجهة كأنها مُحطمة.

شكل (؛ ا ) فندق شيونغ وان Sheung Wan هونج كونج،

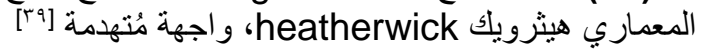
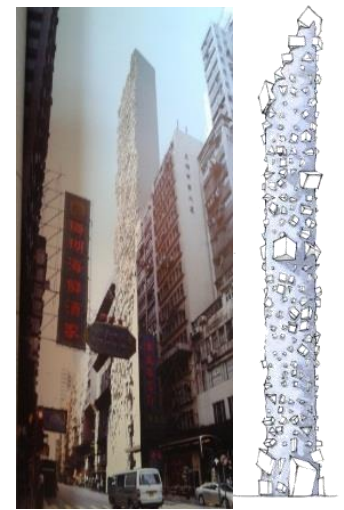

شكل (ب I ا) برج الأفعى MahaNakhon، تايلاند، للمعماري

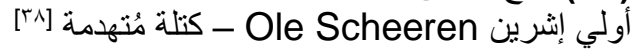

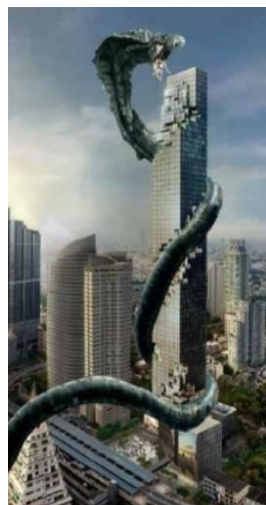

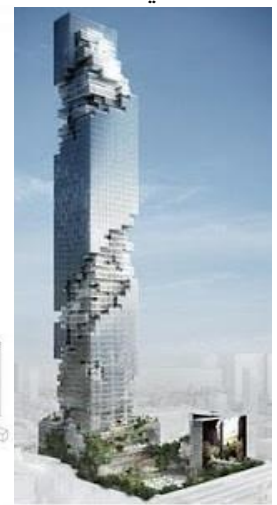

- تائثر بفكر العنف والحرب والانفجارات في كتل مباني مختلفة الانثطة والاستعمارات

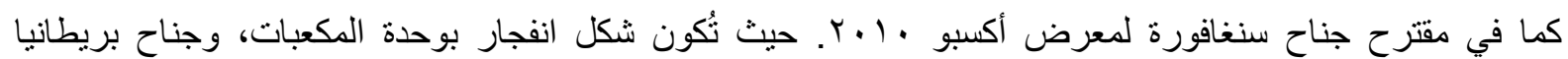

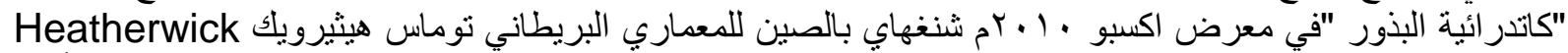

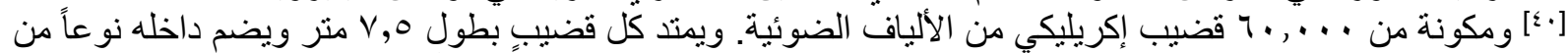

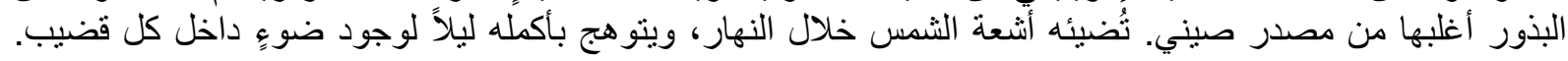

${ }^{[38]} \mathrm{http}: / /$ www.buro-os.com/mahanakhon/,(Accessed 20-4-2014)

${ }^{[39]}$ Yuhong Zhu, "Surmount Style + Copy II ", Volume 1, Material facade shape window ,Sheung Wan hotel ,Hong Kong, China, thomas heatherwick Studio ,Edited by: Hong Kong Architecture Science Press, HKASP Amsterdam, ISBN: 978-988-15680-0-7 , 2013, P 136,139

${ }^{[40]}$ Thomas Heatherwick, “ Making”, The Monacelli Press, New York, edition 8, 2012, ISBN: 9781580933346 


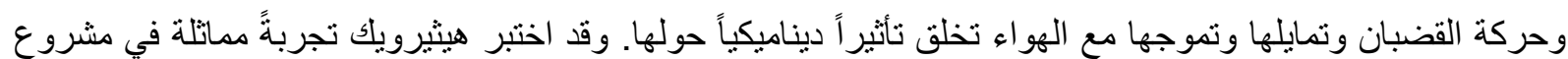

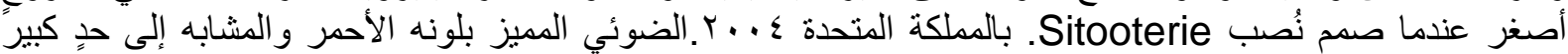

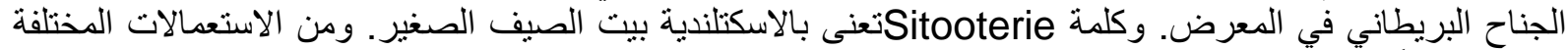

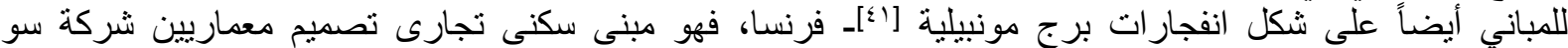

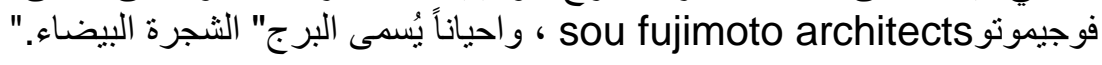

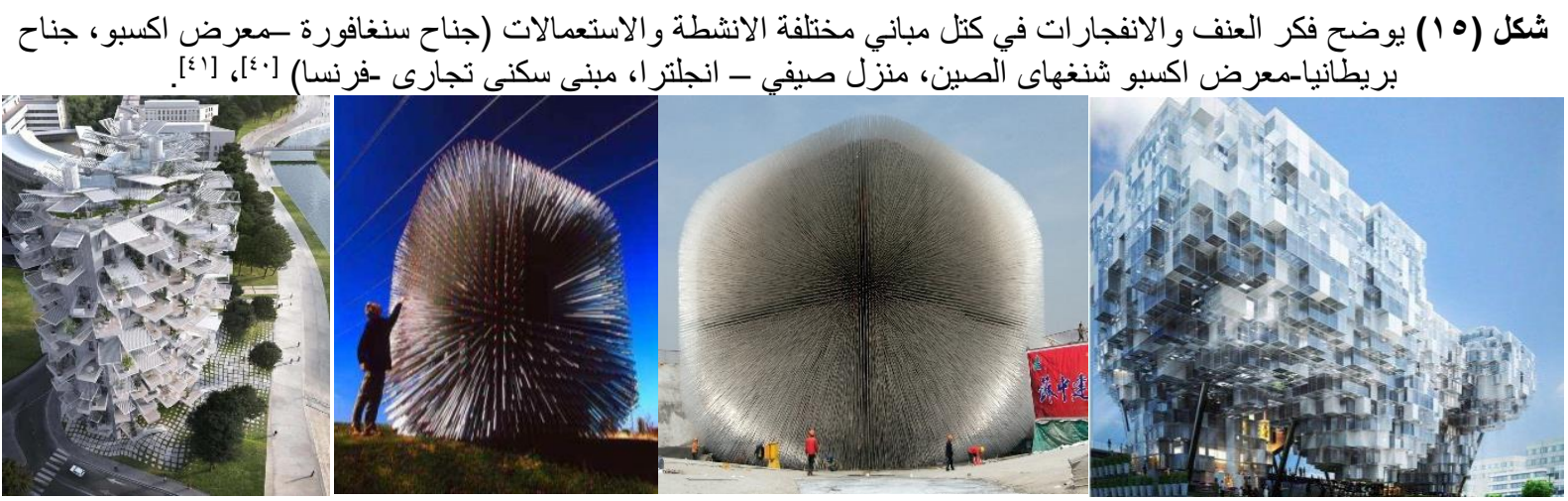

- تأثر بفكر العنف والحرب والانفجارات في كتل مباني بشكل صريح للحدث أو موقع الحدث

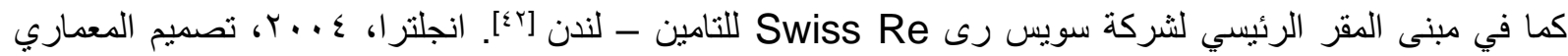

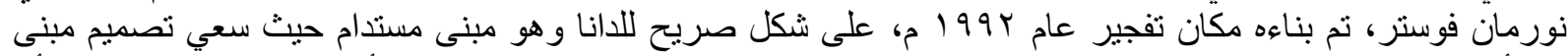

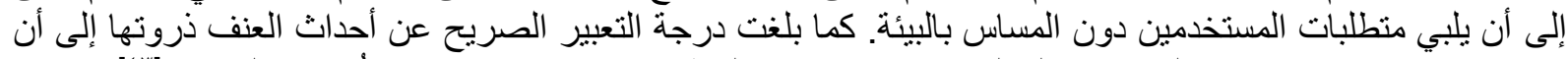

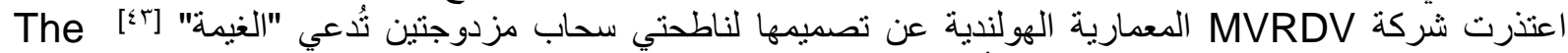
Cloud

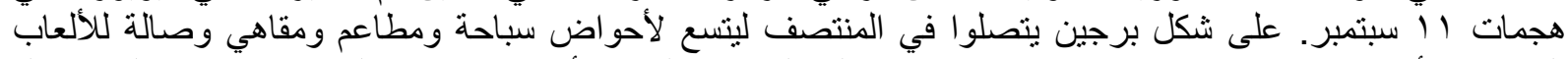

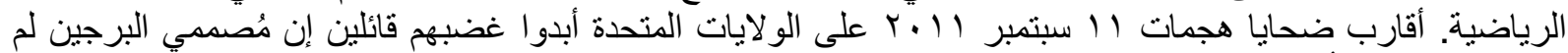

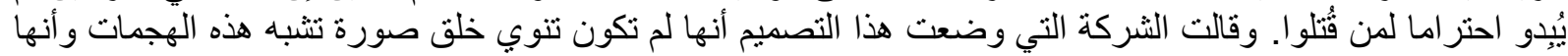
لم تر هذا التشابه اثثاء عملية التصميم. ولم يُنفف هذا التصميم.
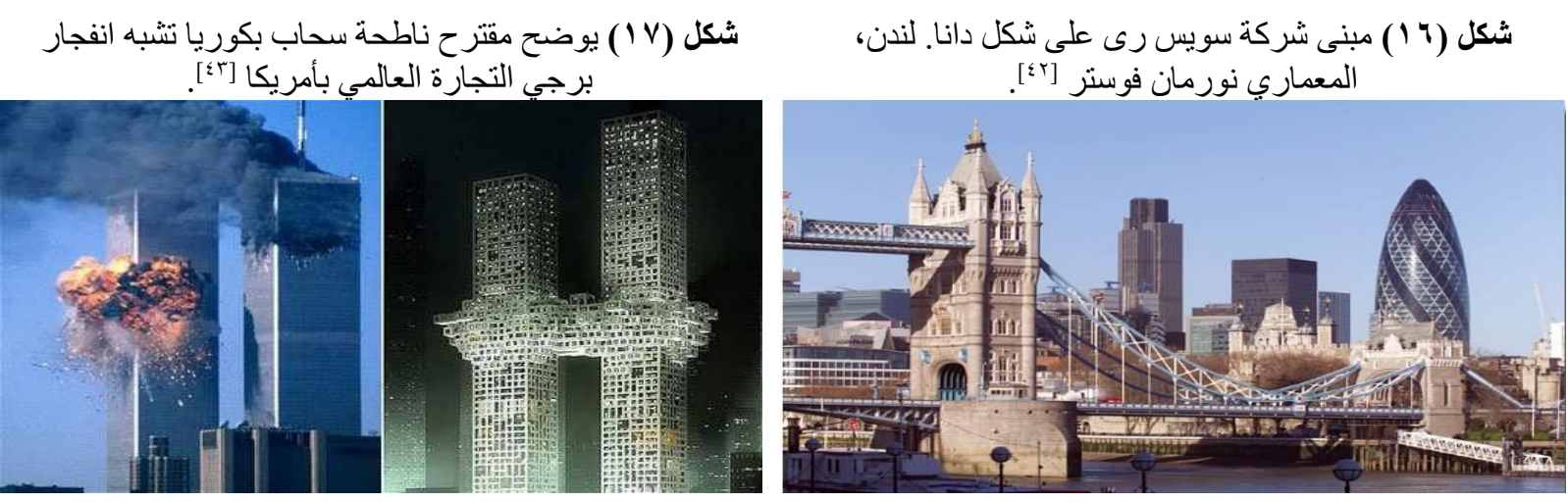

- - تأثر بفكر العنف والحرب والانفجارات في تصور المعماريين للناتج المعماري والعمراني للمستقبل.

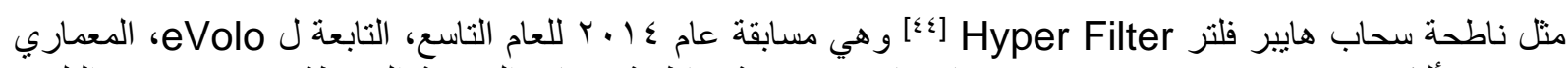

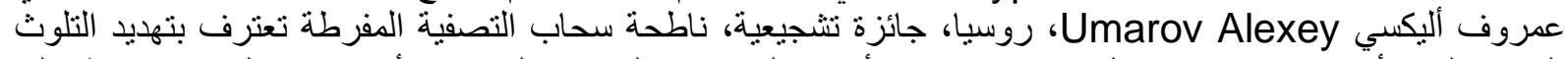

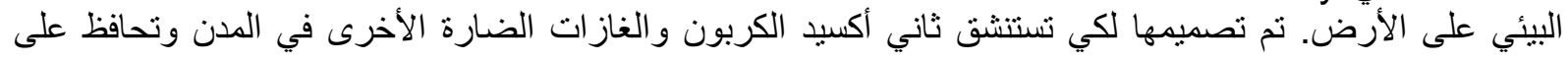

\footnotetext{
${ }^{[41]} \mathrm{http}: / /$ www.designboom.com/architecture/sou-fujimoto-white-tree-architectural-folly-of-the-21st-centurymontpellier-03-07-2014/

${ }^{[42]} \mathrm{http}: / /$ www.webpages.uidaho.edu/arch504ukgreenarch/2009Archs-CaseStudies/Swiss\%20Re-Final.pdf ,P.6

${ }^{[43]} \mathrm{http}: / /$ dechive.blogspot.com/2011/12/seoul-south-koreas-cloud-buildings-are.html

${ }^{[44]} \mathrm{http} / / / \mathrm{www}$. evolo.us/competition/hyper-filter-skyscraper/
} 
الأكسجين مُركز. ينكون غلاف المبنى من أنبوب طويل من المُرشحات لضمات الفئ عملية التنظيف. وتحرير الهواء النقي في

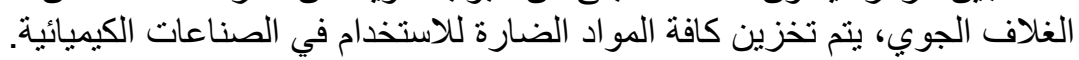

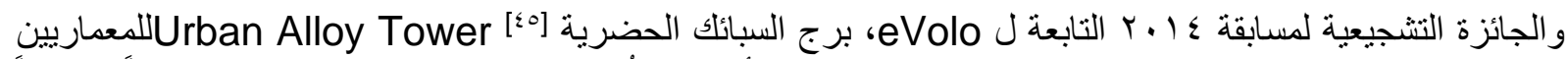

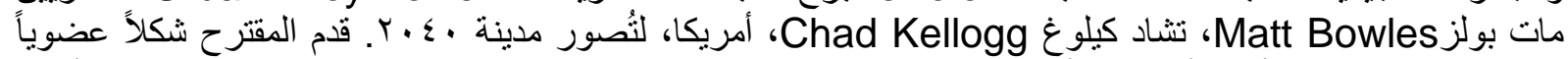

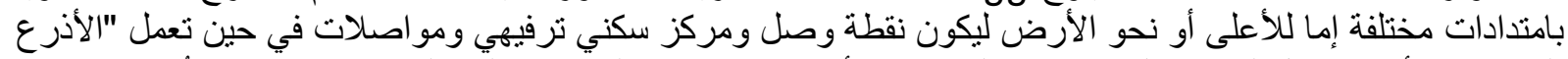

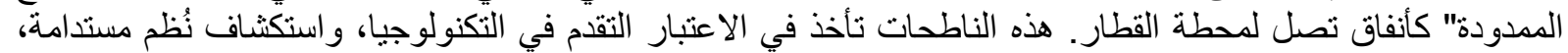

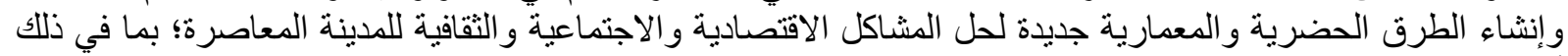

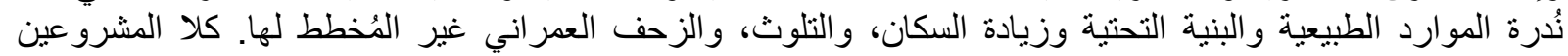

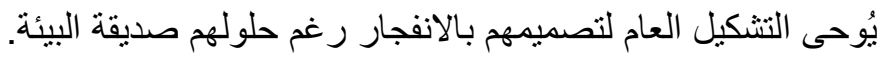

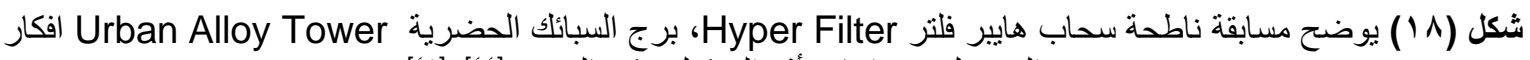

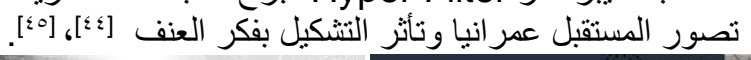
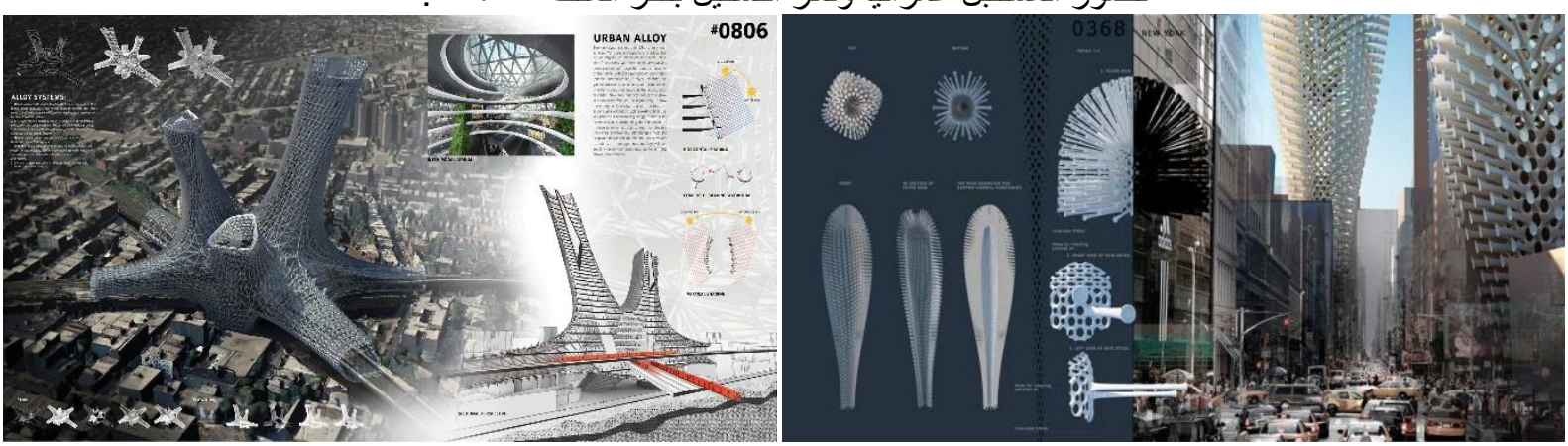

- تأثر بفكر العنف والانفجارات في تحديد هوية مبنى معماري ما

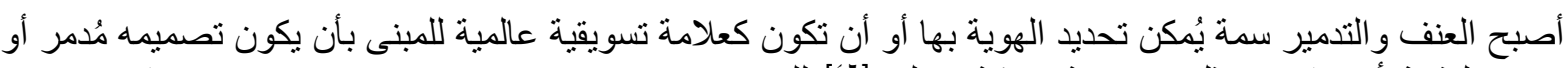

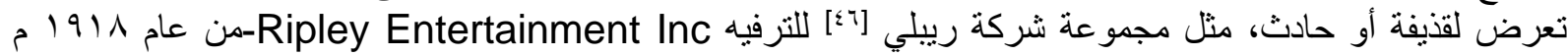

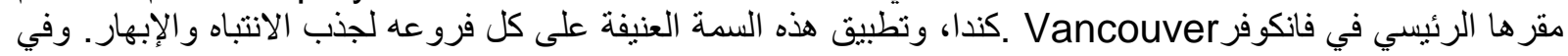

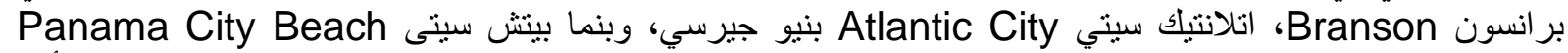

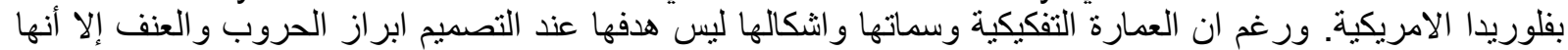
أحياناً أضافت هذا الانطباع ورأ الصورة الذهنية للمتلقي.

شكل (9 (1) العلامة التسويقية لمباني فروع شركة ريبلي للترفيه Ripley Entertainment Inc بتصميم كتل مُدمرة أو تعرضت
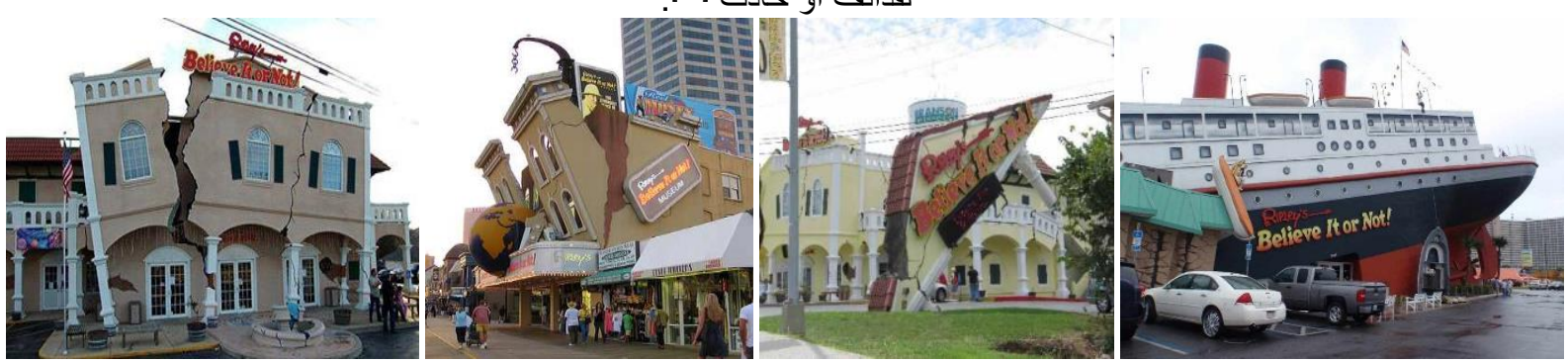

الفراغات الخارجية

تأثر تصميم الفر اغات الخارجية بفكر العنف والحروب كما في مدخل محطة منرو أنفاق في فر انكفورت علي شكل قطار

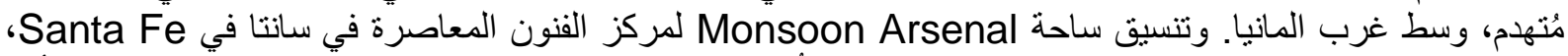

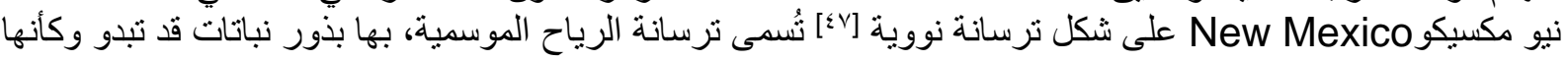

${ }^{[45]}$ Carlo Aiello, “eVolo Skyscrapers 2- 150 new projects redefine building high ",eVolo Publications ,ISBN: 978-1938740053,2014, http://www.evolo.us/

${ }^{[46]} \mathrm{http}: / / \mathrm{www}$. ripleys.com/attractions/

${ }^{[47]}$ http://inhabitat.com/ 
سلسلة من المخاريط البرتقالية الخطرة التي تنفجر ببطء وبمرور الوقت هذا التثكيل مخيف المظهر يختفي على المسطح

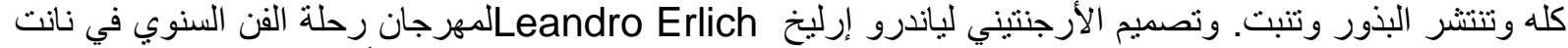

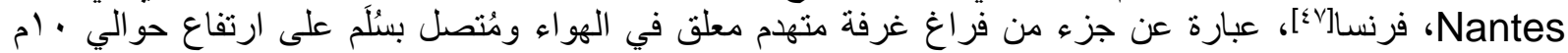

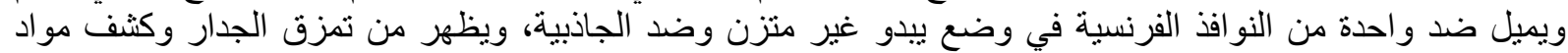

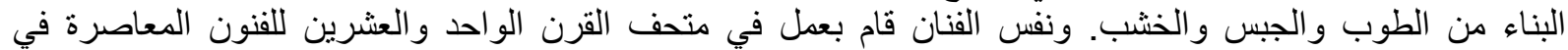

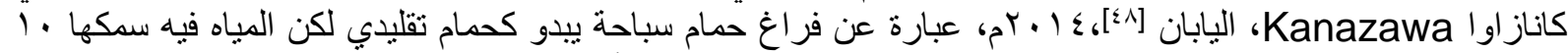

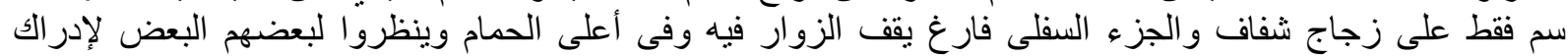
مفاهيم الحياة و الغرق ووجهات النظر وتصور الجزه الذات الذات للأخرين.

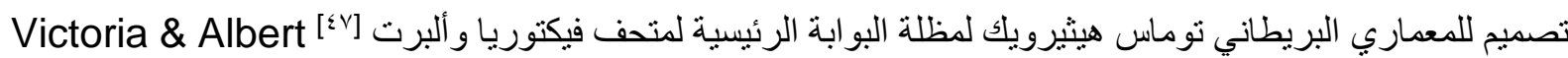

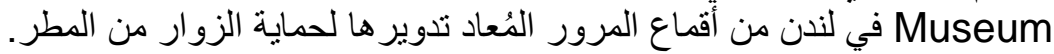

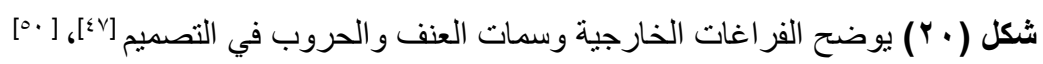

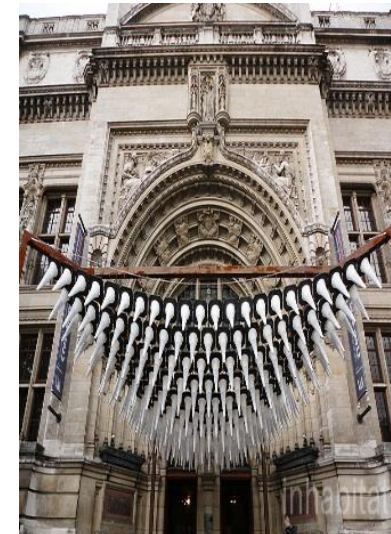

مظلة بو ابة لمتحف فيكتوريا وألبرت ـاقماع مقلوبة _لندن

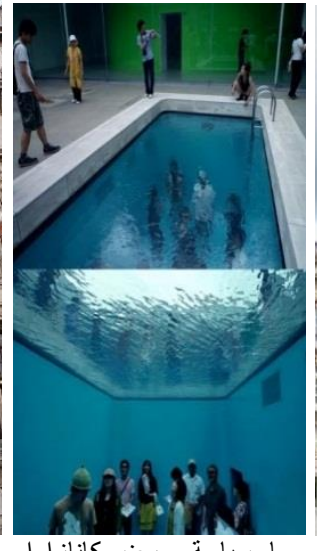

حمام سباحة معرض كاناز او إبان Kanazawa

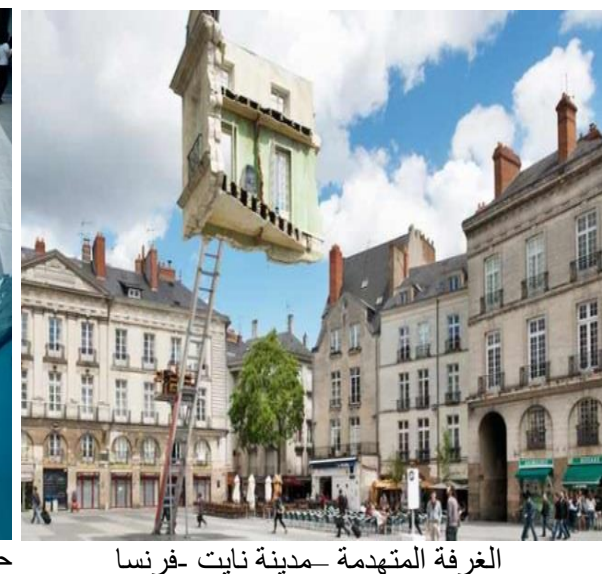

الغرفة المتهدمة ــمدينة نايت ـفرنسا

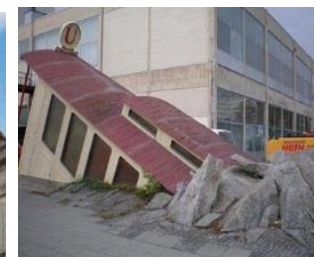

محطة فرانكفورت -المانيا

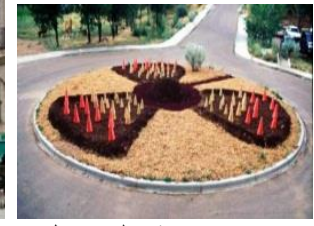

تنسيق ساحة على شكل ترسانة نووية

د- الفراغات الداخلية

لم تتجو الفر اغات الداخلية من التأثر بأحداث العنف والحروب، و على سبيل المثال تصميم نجفة أو ثريا للمعماري دانيال

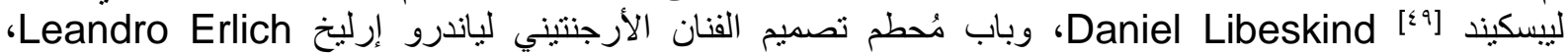

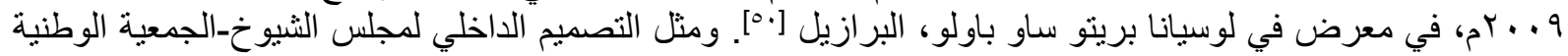

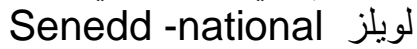

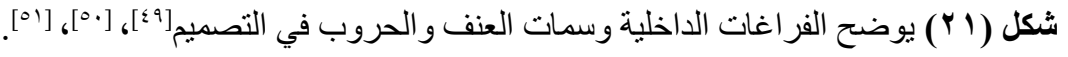
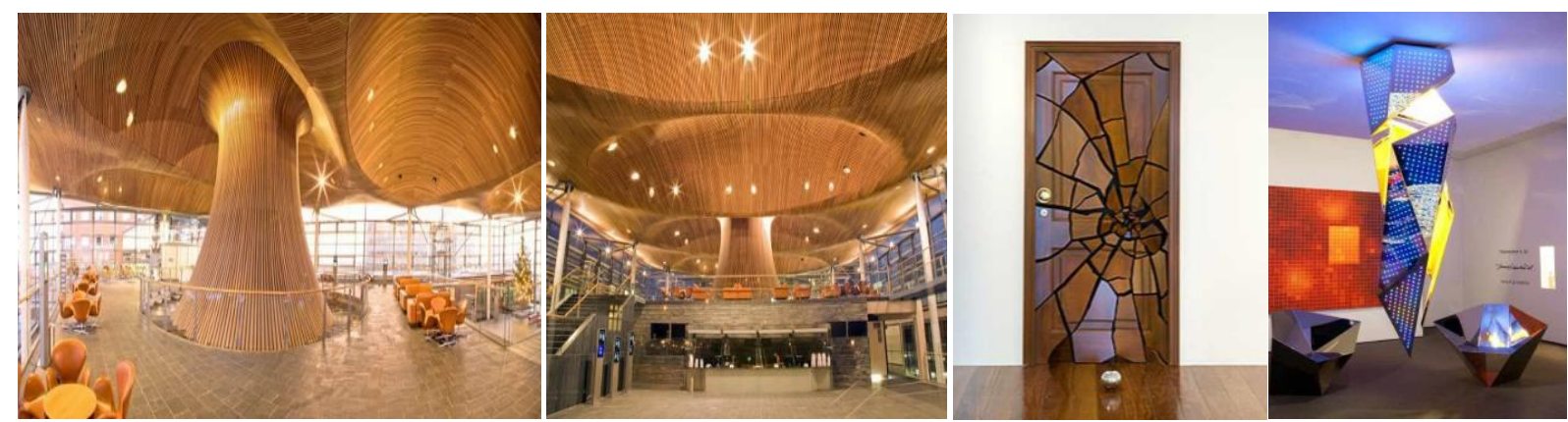

\footnotetext{
${ }^{[48]}$ http://wakarimasen.fr/kanazawa/, (Accessed 29-5 -2014)

${ }^{[49]} \mathrm{http}: / /$ daniel-libeskind.com/design , (Accessed 22-4 -2014)

${ }^{[50]} \mathrm{http}: / / \mathrm{www}$. leandroerlich.com.ar/works.php?id=27\#
} 
وظهرت أثار العنف و الحروب في تصميم الاثاث للفر اغات الداخلية بأن تكون مُحترقة أو مُنصدعة أو على هيئة انفجار

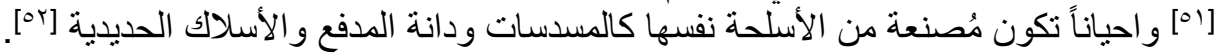

\section{؛ العمارة كأداة لمواجهة احداث الحروب والعنف}

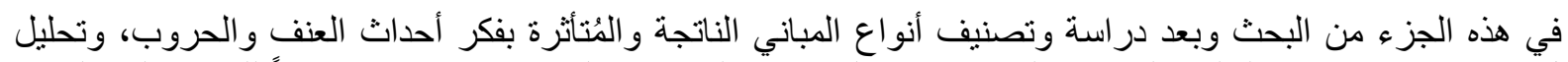

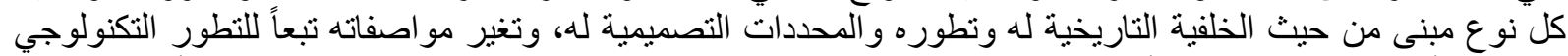

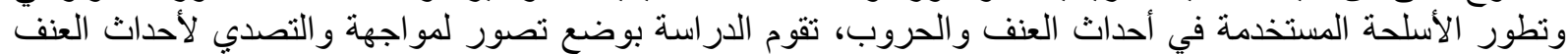

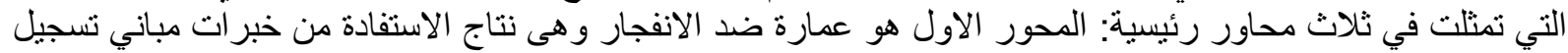

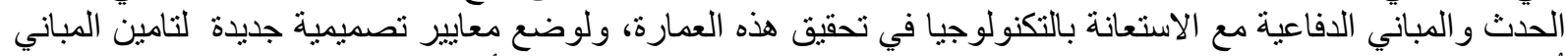

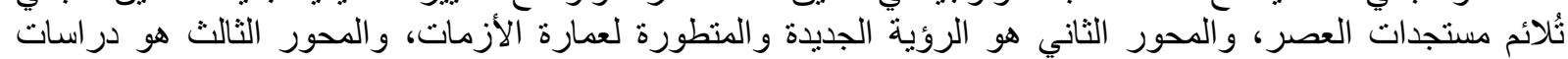

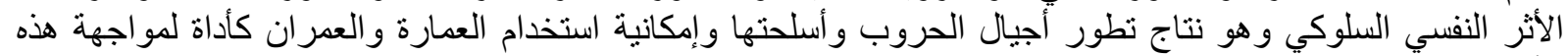

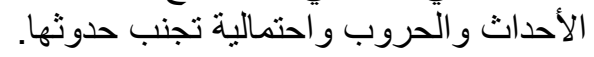

شكل (Yr) يوضح إعادة تصميم مبنى السفارة الامريكية_لندن، أسس تصميم ومفردات معمارية دفاعية برؤية حديثة ومستدامة[ع].
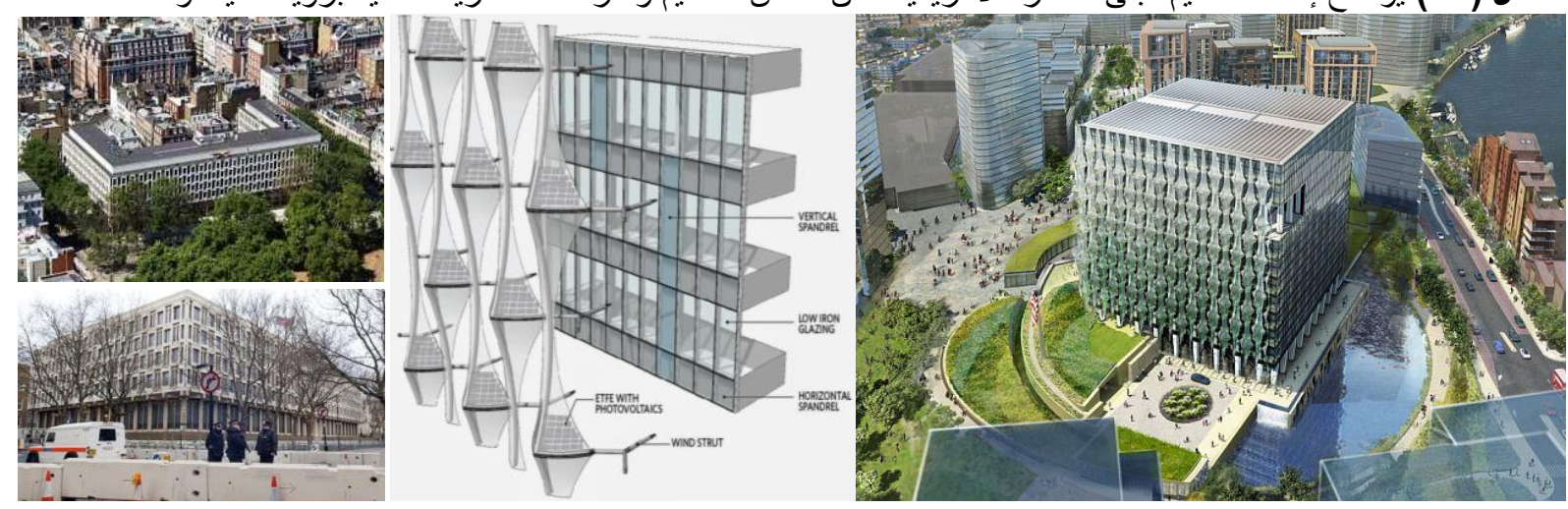

التوجيه الجديد الذي صدر من قبل المعهد الملكي للمهندسين المعماريين البريطانيين (RIBA) مع وزارة الداخلية ومكتب إنباء

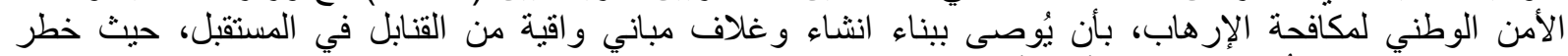

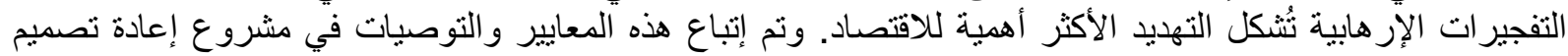

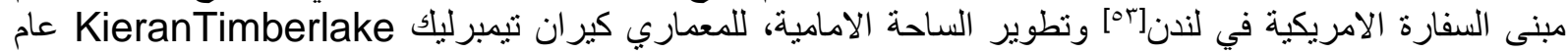

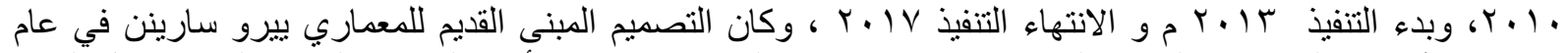

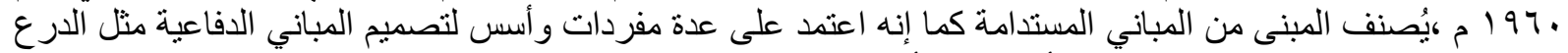

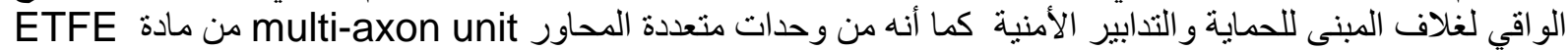

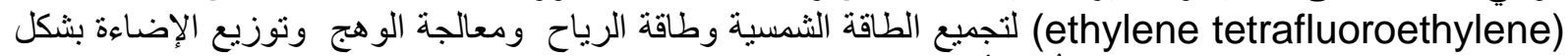

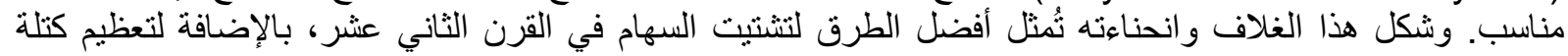

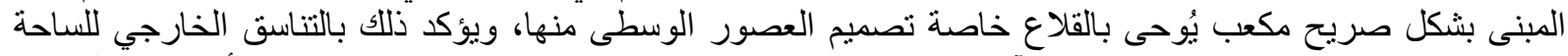

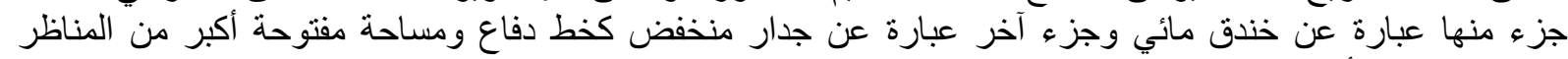
الطبيعية لتكثَف أب خطر عن عنُوند.

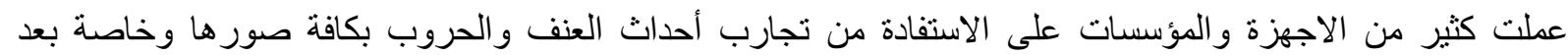

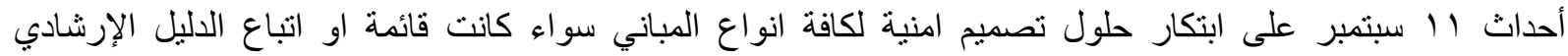

\footnotetext{
${ }^{[51]}$ http://www.greenerimpact.com/wp-content/uploads/2012/10/ren.jpg

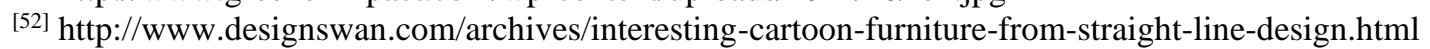

${ }^{[53]} \mathrm{http}: / / \mathrm{www} . k i e r a n t i m b e r l a k e . c o m / p a g e s / v i e w / 88 /$ embassy-of-the-united-states-of-america/parent:3
} 


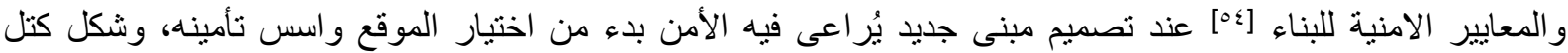

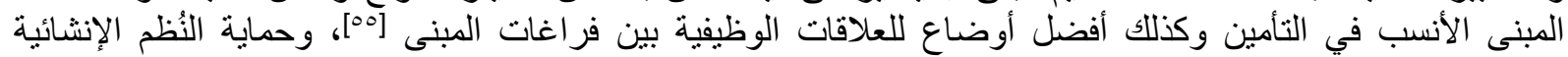

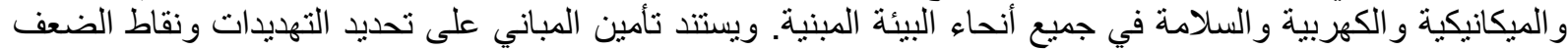

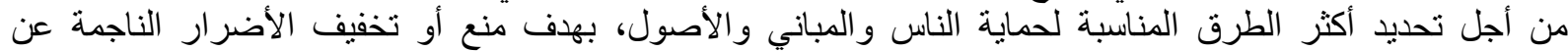

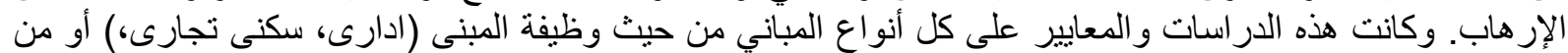

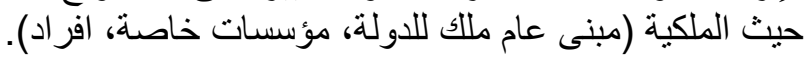

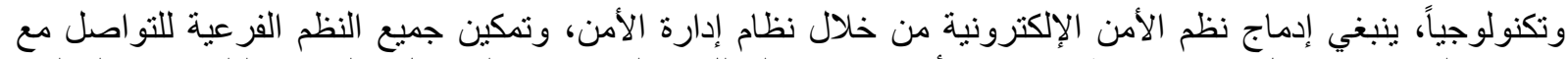

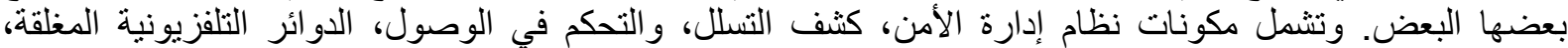

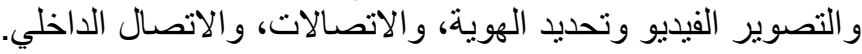

شكل (؟ ؟) يوضح در اسات ومعايير لتصميم المباني ضد الانفجار وأحداث العنف على مستوى الكتلة و المسقط و العلاقات الوظيفية

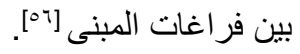

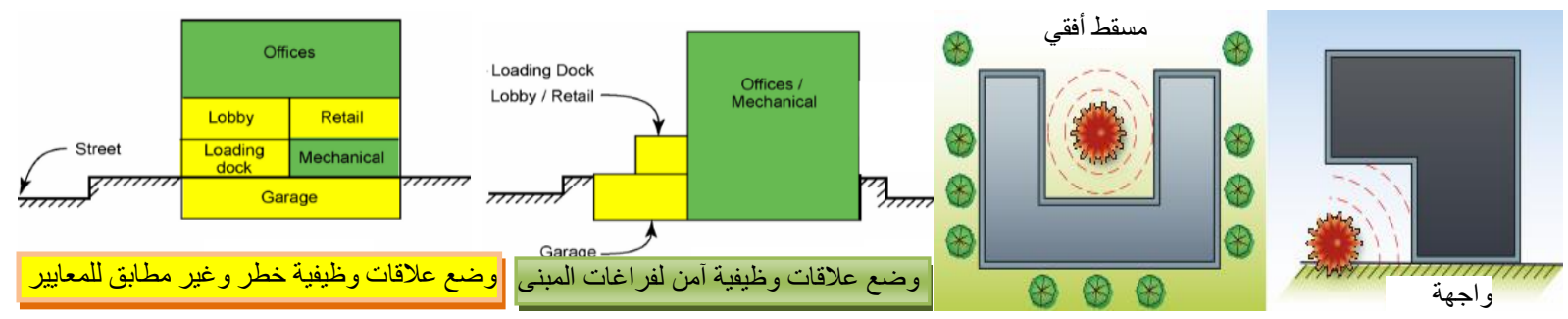

شكل (Y0) يوضح قياس مدى تضرر هيكل المبنى الإنثائي تبعاً لقوة العنف و الانفجار المُعرض له، ومعايير توجيه الفتحات

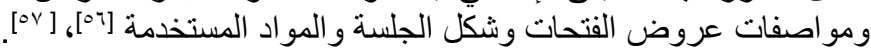
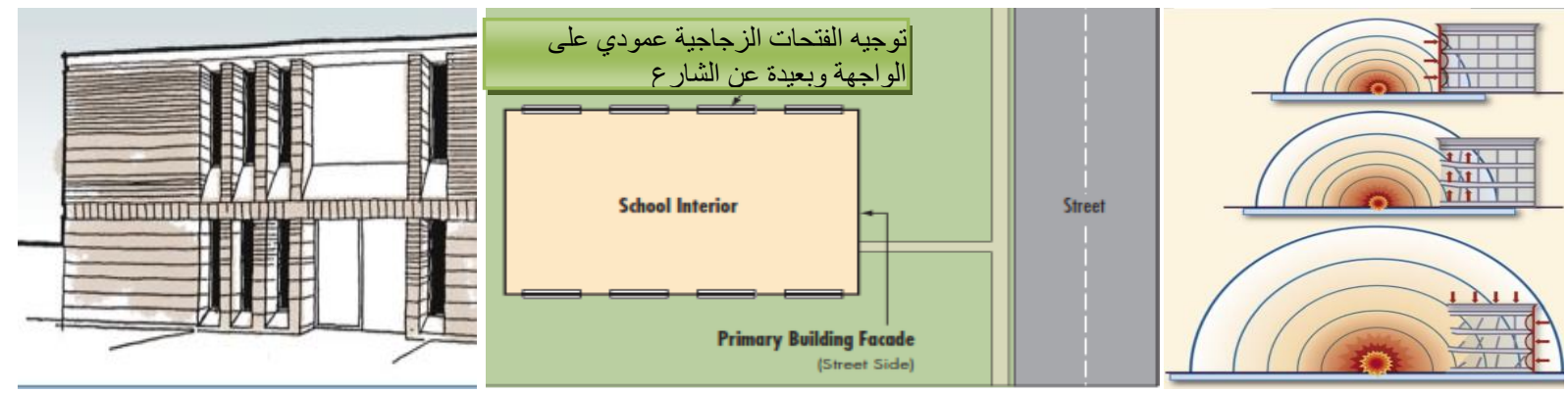

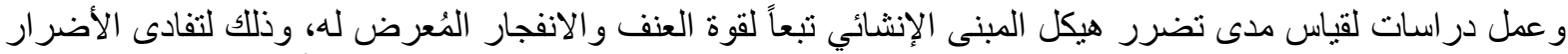

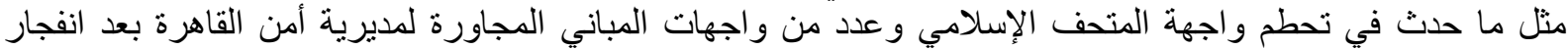

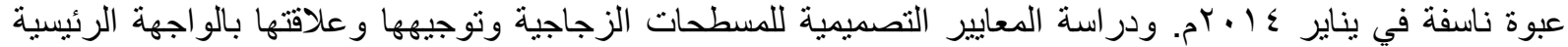

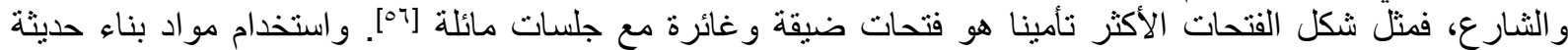
تُقاوم الانفجار كالمو اد الذكية ومو اد النانو.

و عمل در اسات موقع لعلاقة المبنى بالمباني المجاورة لتأمينها وتدرج مُقتترحات التأمين بدء من الاشجار و الأسوار لعرقلة

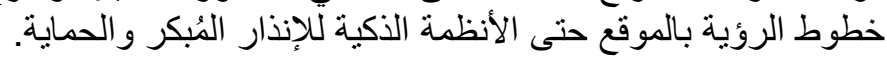

${ }^{[54]}$ Barbara A. Nadel, "Building Security 7-1/8 Handbook For Architectural Planning And Design

”,FAIA,2009 Kemper Award Winner,McGraw-Hill companies, New York,2004 ,P 1.3, 1.15, 1.29

[55]_-_-"IITK-GSDMA Guidelines on measures to mitigate effects of terrorist attacks on buildings ",Indian

Institute of Technology Kanpur,Gujarat State Disaster Mitigation Authority ,July

2007,http://www.iitk.ac.in/nicee/IITK-GSDMA/TM01.pdf

${ }^{[56]}$ U.S. AIR FORCE, “ Installation Force Protection

Guide",http://www.wbdg.org/ccb/AF/AFDG/ARCHIVES/afinstal.pdf,P.33 


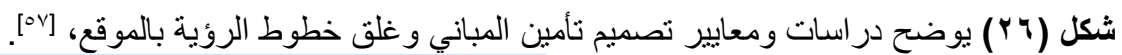

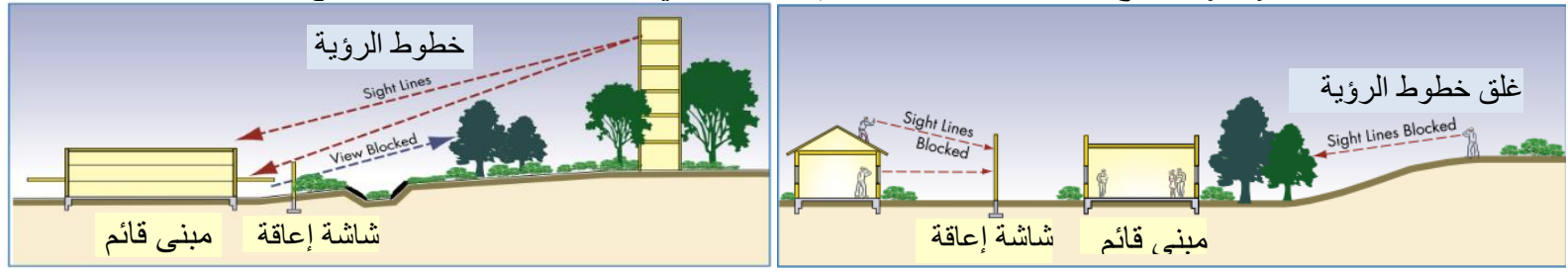

و إتباع المعايير التصميمية الأمنية حتى في الخدمات الكهربية والإلكتروميكانيكية للمبنى، التي ثُراعى أدق التفاصيل الأمنية

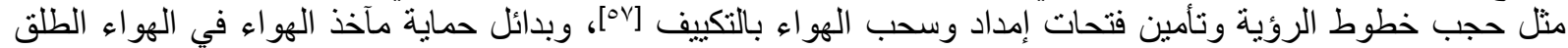

شكل (YV) يوضح بدائل تأمين فتحات سحب و إمداد الهو اء بالتكييف ومعايير اماكن وضع الخدمات الالكتروميكانيكية[م]، [09].

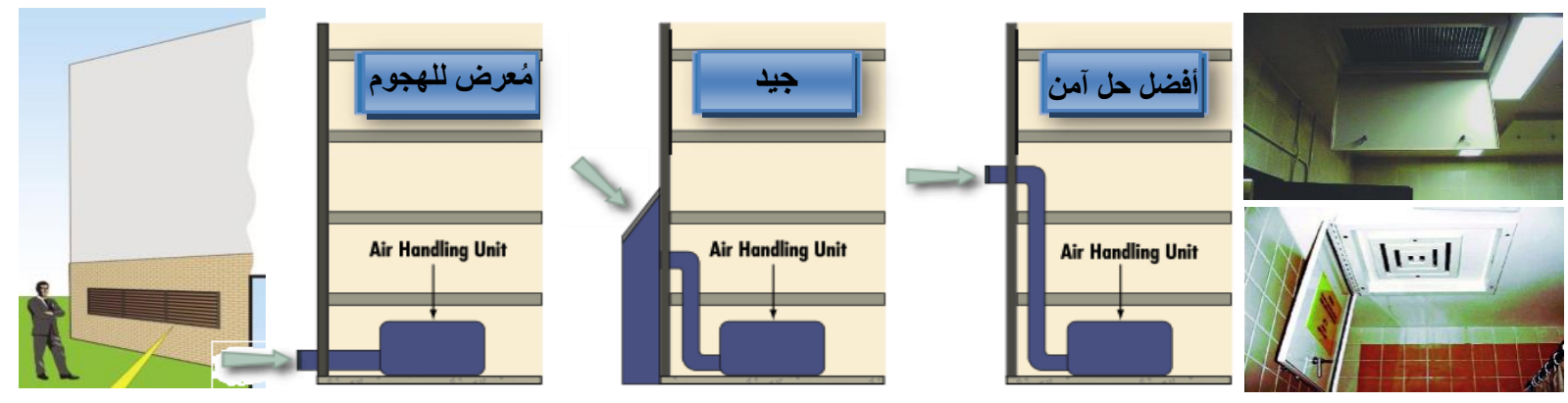

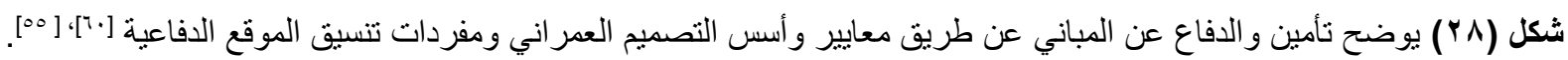
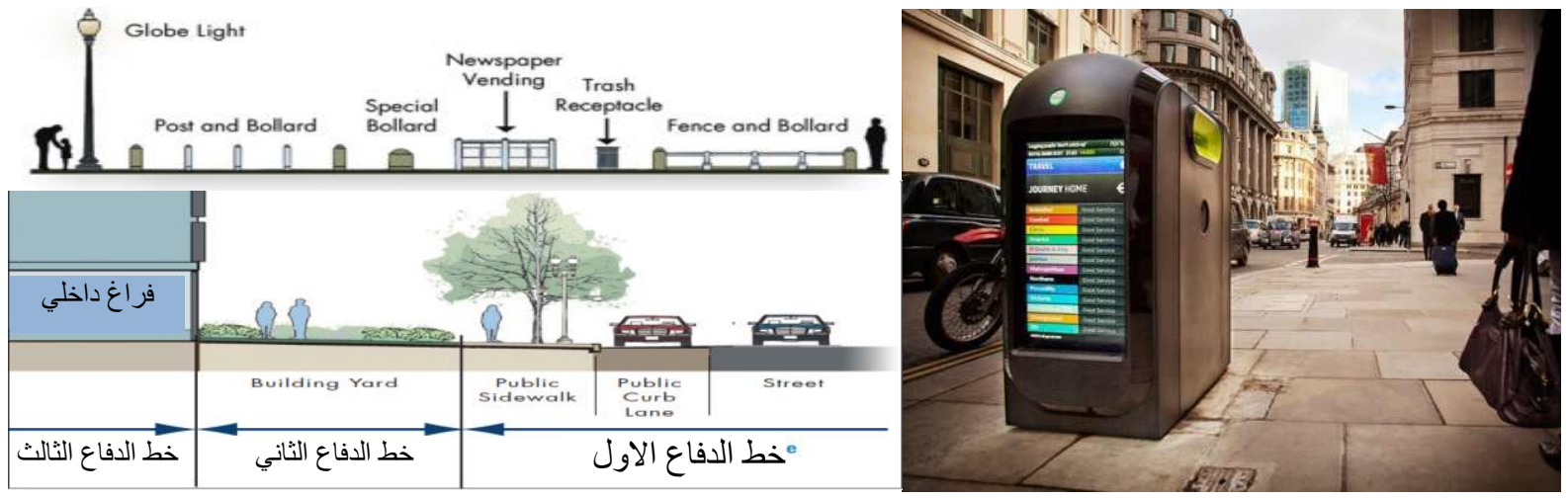

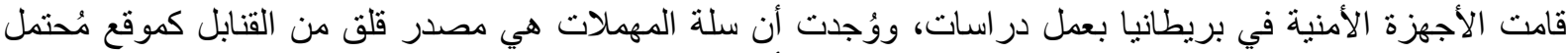

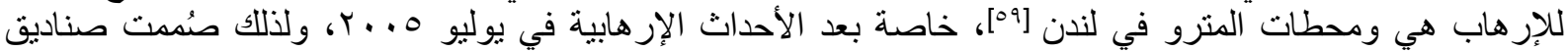

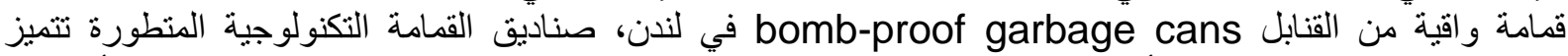

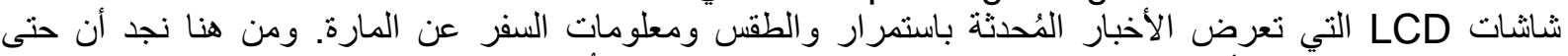

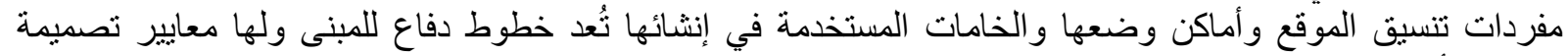
لمو اجهة أحداث العنف و الحروب.

${ }^{[57]}$ CDC/NIOSH, Publication No. 2002-139, “ Guidance For Protecting Building Environments From Airborne Chemical, Biological, Or Radiological Attacks”, May 2002

[58]_-_-“ Risk Management Series -Design Guidance for Shelters and Safe Rooms -Providing Protection to PeoPle and Buildings against terrorist attacks "FEMA 453 / May 2006" Federal Emergency Management Agency ,US department of homeland security, http://www.fema.gov/media-

library/assets/documents/3140?id=1657, P3 - 13, (Accessed 22-4 -2014)

${ }^{[59]}$ http://inhabitat.com/nyc/bomb-proof-renew-recycle-bins-will-soon-bring-news-and-weather-to-new-yorkers, (Accessed 29-5 -2014) 


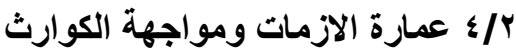

ويتمثل في ثلاث محاور رئيسية، اولاً: في متابعة تطور الأبحاث و الدراسات في مجال سبق التجهيز و التصنيع لتعويض ما

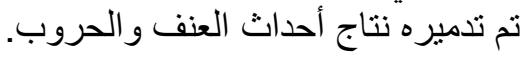

وثنانياً: في تطور المباني المتنقلة التي ثُستخدم في حالات الطوارئ لتقوم بدور المأوى والمستشفيات وخدمات اخرى يحتاجها المجتمع المتضرر من هذه الأحداث المُدمرة.

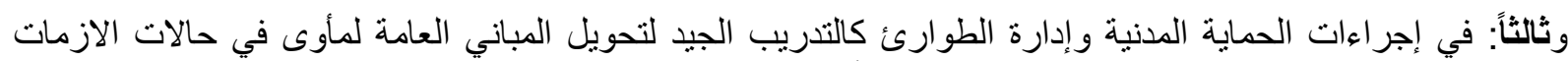

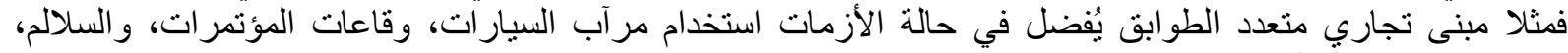

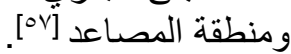

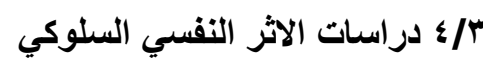

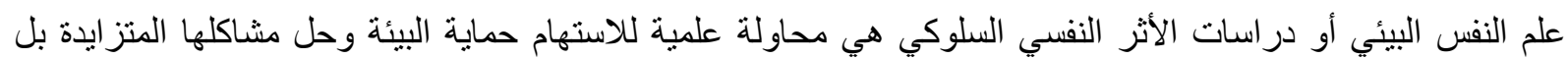

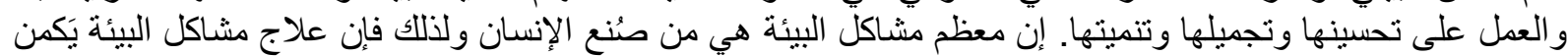

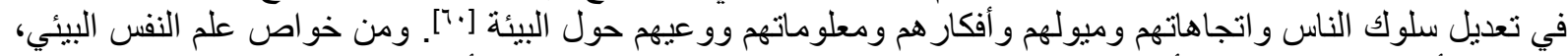

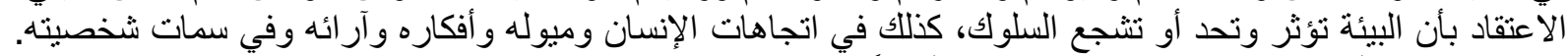

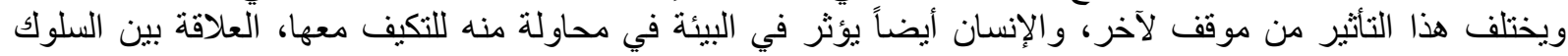
و والبيئة متبادلة ومتفاعلة.

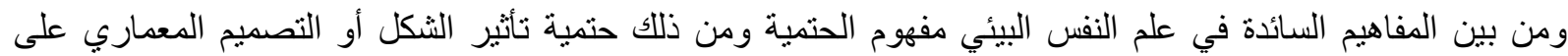

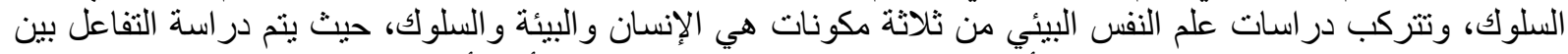

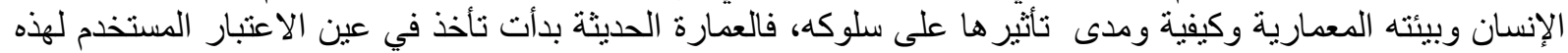

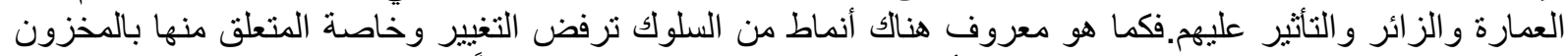

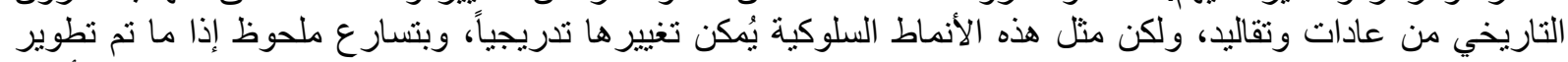

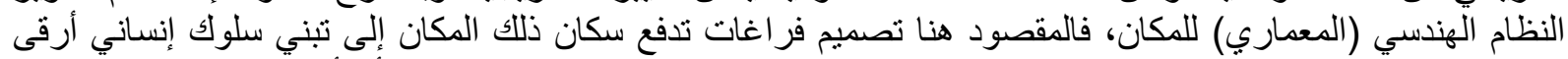

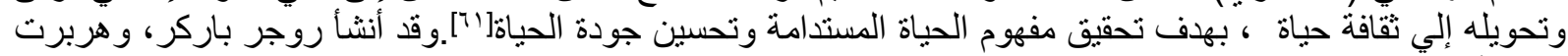

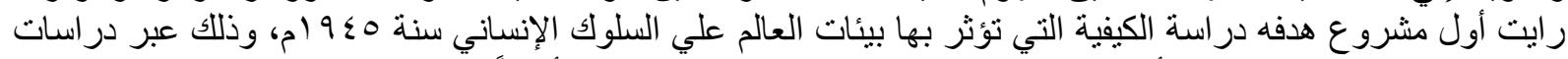

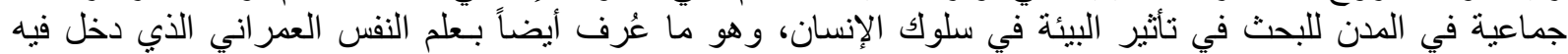

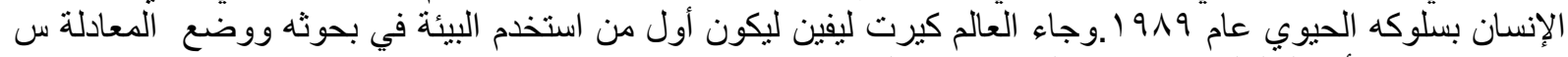

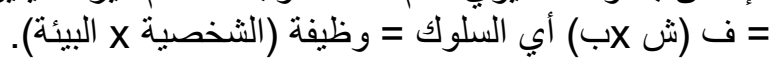

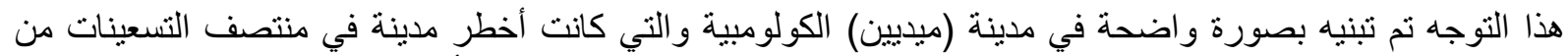

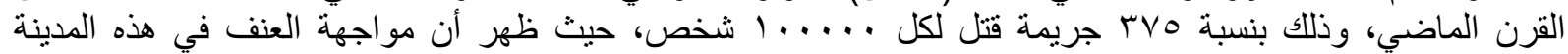

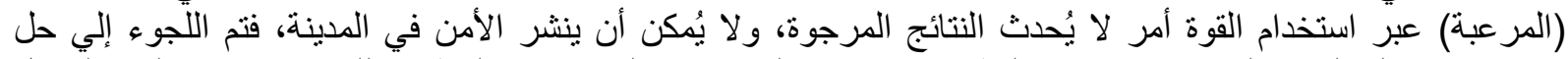

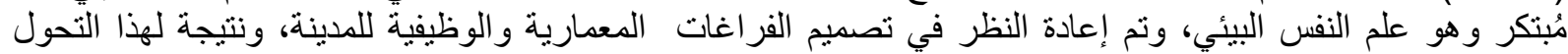

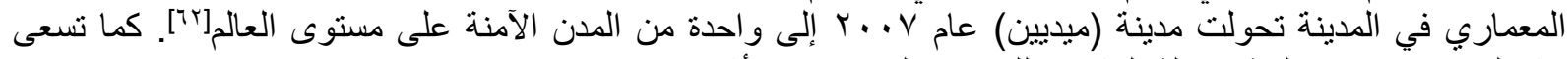
هذه الدرأسات في مُعالجة مشكلة الكثافات للحد من العشو عام ائيات و أثنار ها.

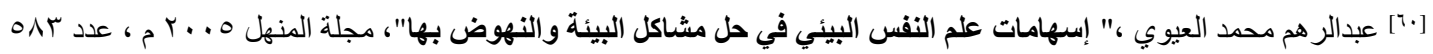
http://www.greenline.com.kw/ArticleDetails.aspx?tp=358, (Accessed 29-5 -2014)

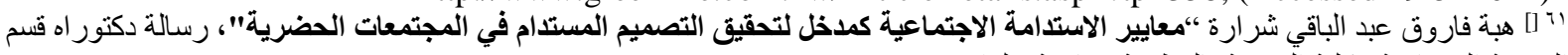

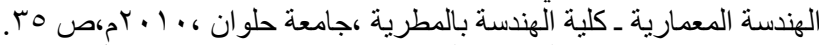

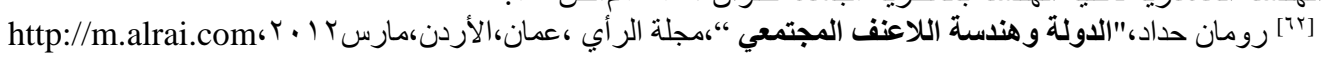




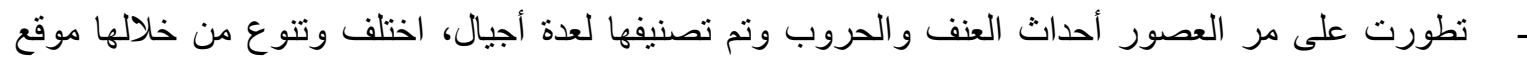

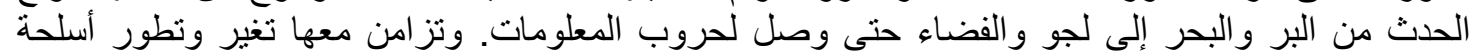

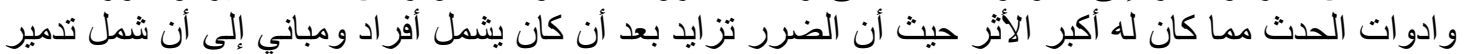

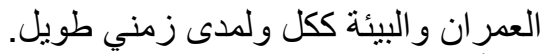

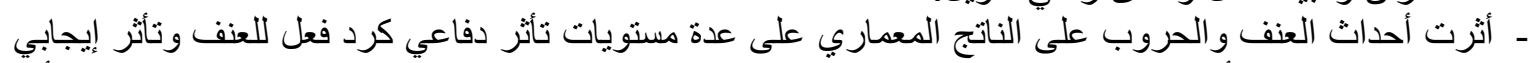

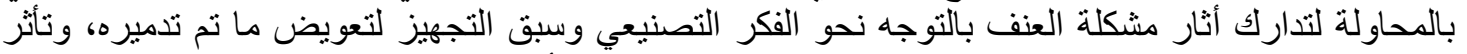

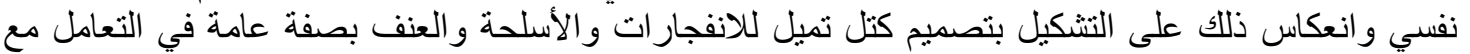

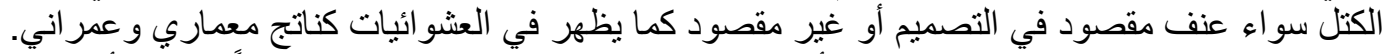

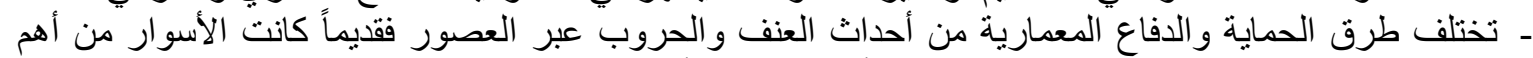

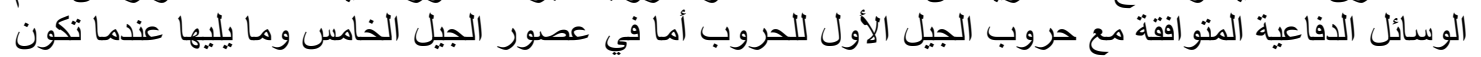

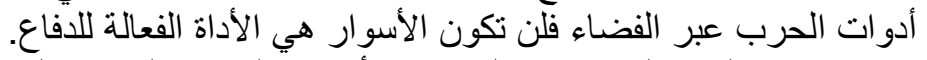

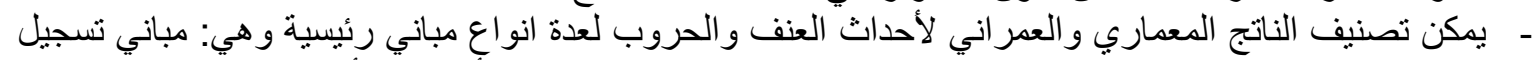

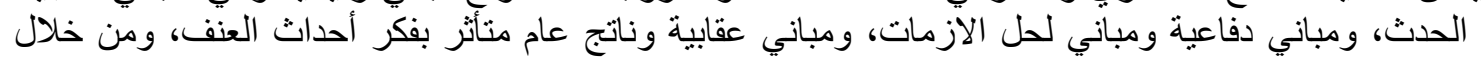

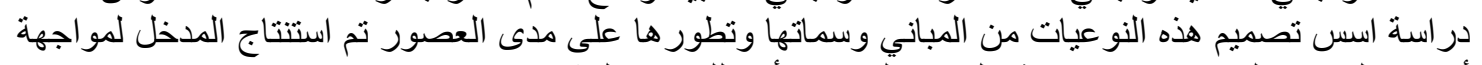

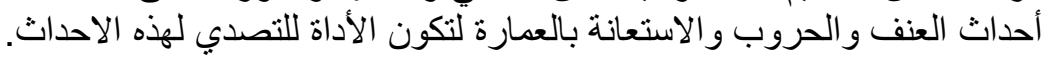

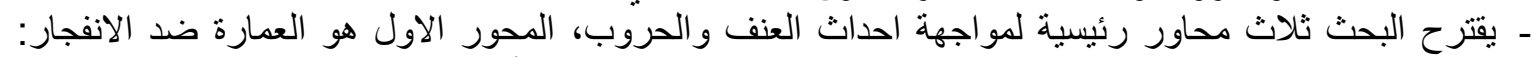

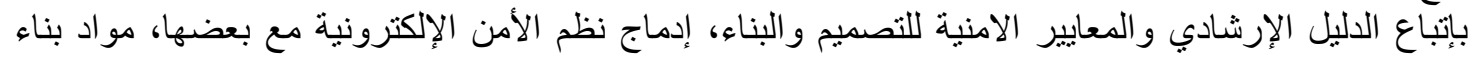

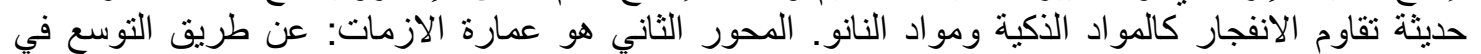

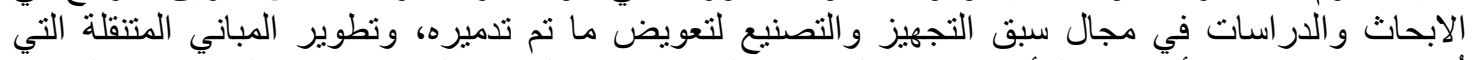

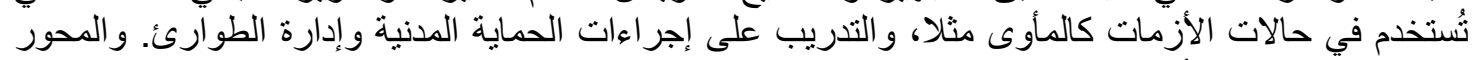

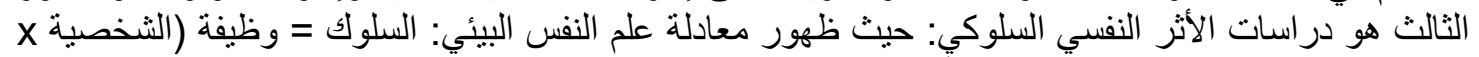

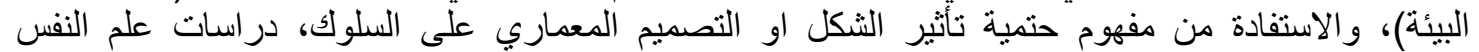

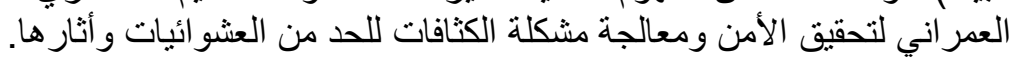

شكل (9 ץ) يوضح دراسة الناتج المعماري لأحداث العنف و الحروب و الاستفادة من الخبر ات و التكنولوجياسمدخل للحل، [الباحث]

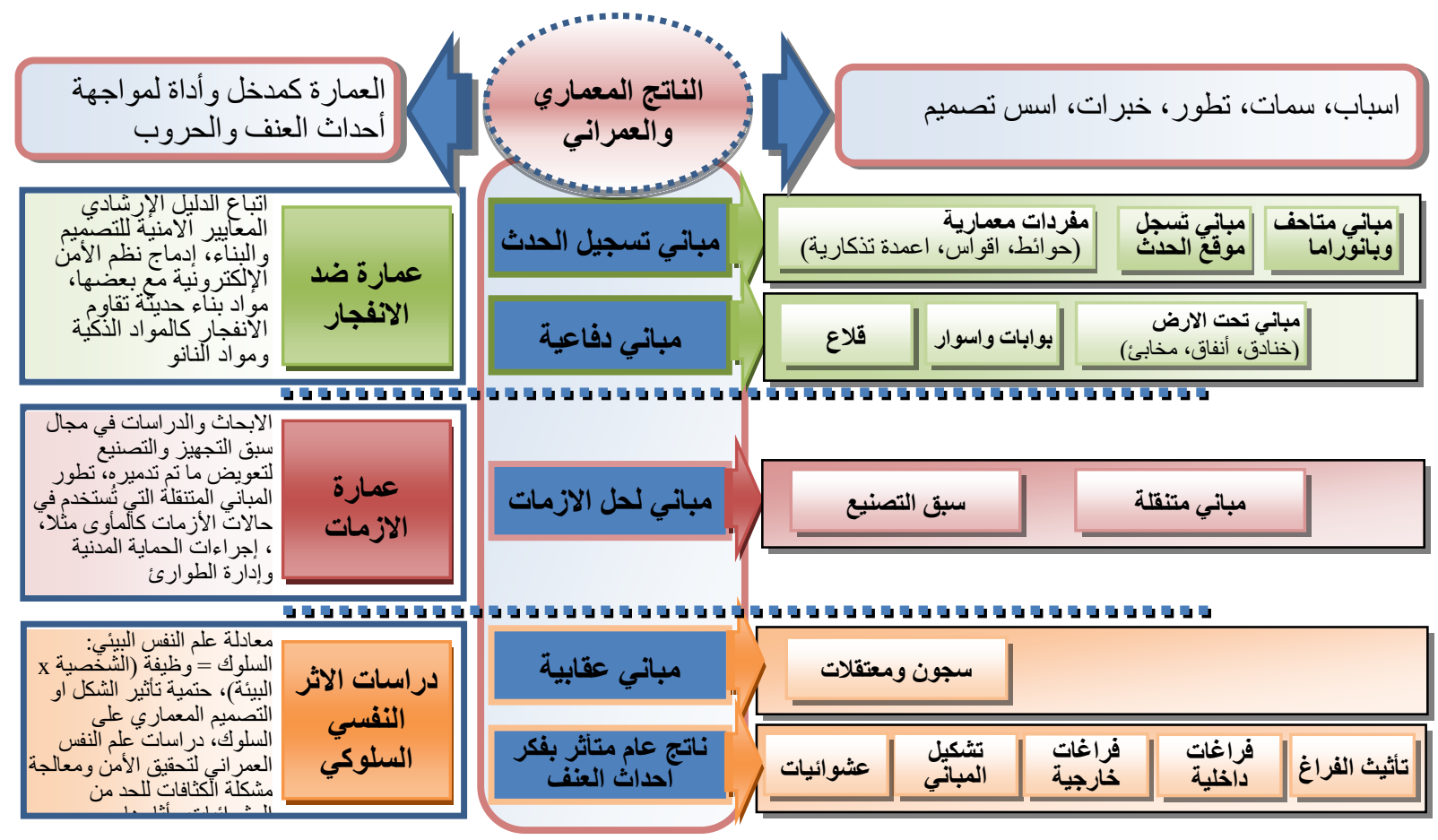


ــ تشير الورقة البحثية إلى ضرورة دمج الخبرات و الدروس المستفادة من أحداث العنف و الحروب و الناتج المعماري

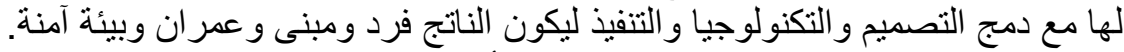

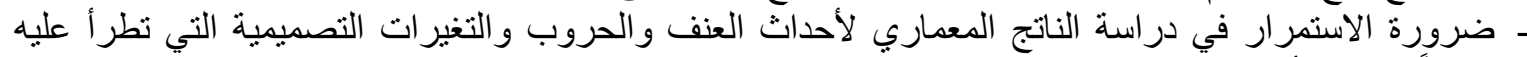

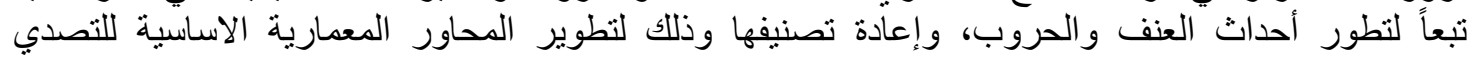
ومواجهة هذه الاحداث.

\section{References:}

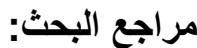

ـ ـ د. أحمد الصاوي،" من موقع لمقاومة الغزو إلى معتقل للمعارضين ققلعة الاشرف قايتباي تخفي أسرار فنار الإسكندرية"، جريدة

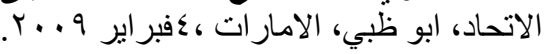

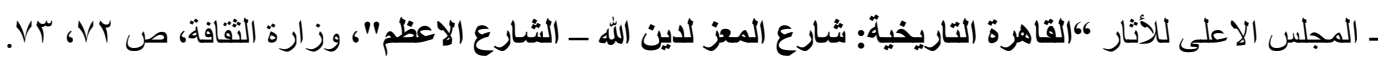
http://permedjat.blogspot.com/2013/09/El-moaezStreetTheGreatestStreet.html

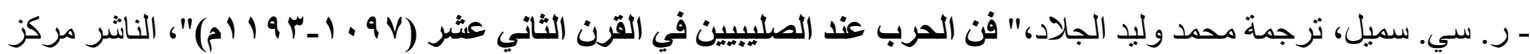

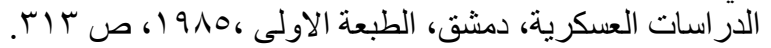

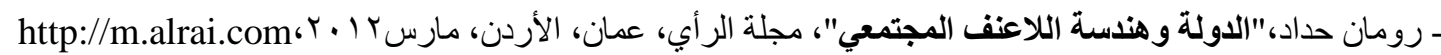

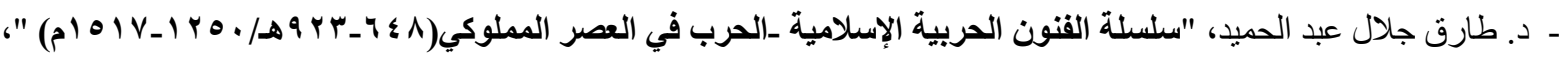

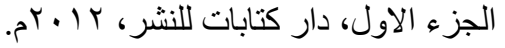

ـ عبدالر هم محمد العيوي،" إسهامات علم النفس البيئي في حل مشاكل البيئة والنهوض بها"، مجلة المنهل ه . . ب م، عدد بماه http://www.greenline.com.kw/ArticleDetails.aspx?tp=358, (Accessed 29-5 -2014)

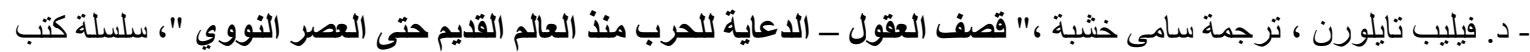

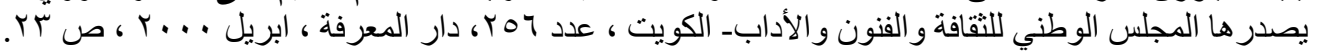

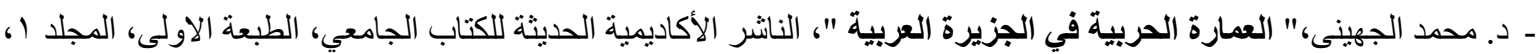

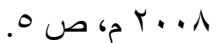

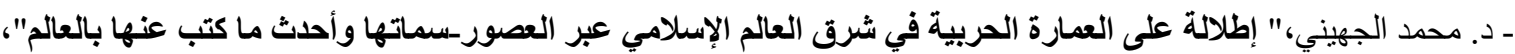

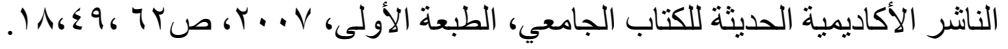

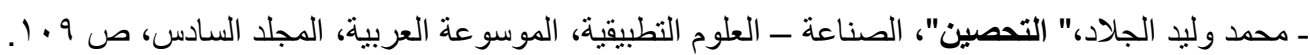

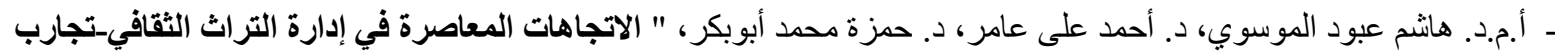

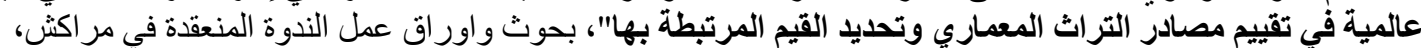

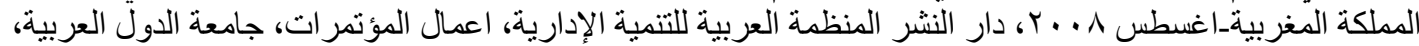

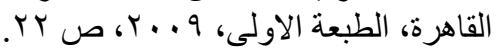

http://digital.ahram.org.eg/Policy.aspx?Serial=1521247، هالة عصام الدين،" أجيال الحروب" ، الأهرام اليومي الإل

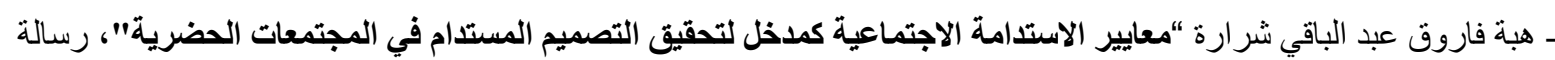

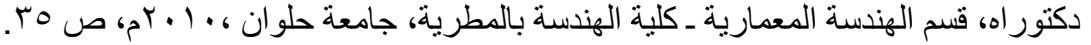

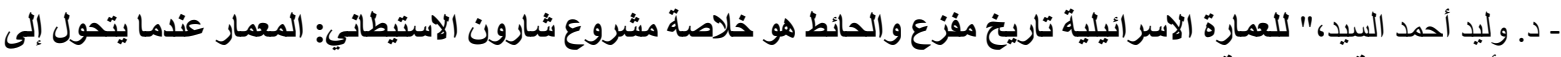

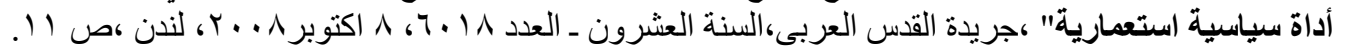

- Banister Fletcher، F.R.I.B.A.، "A History Of Architecture On The Comparative Method"، Bradbury، Agnew، \& CO. L1X` Printers، London And Tonbridge, 2000.

Barbara A. Nadel, "Building Security 7-1/8 Handbook For Architectural Planning And Design

”,FAIA,2009 Kemper Award Winner,McGraw-Hill companies, New York,2004 ,P 1.3, 1.15, 1. 29 
- Carlo Aiello، "eVolo Skyscrapers 2-150 new projects redefine building high" ،eVolo Publications ،ISBN: 978-1938740053,2014، http://www.evolo.us/

CDC/NIOSH, Publication No. 2002-139, "Guidance for Protecting Building Environments from Airborne Chemical, Biological, or Radiological Attacks", May 2002

-Daniel Libeskind، “Jewish Museum Berlin”، G + B Arts International، Publisher: Verlag der Kunst. 1999-06, ISBN10: 9057012529.

- Ian V. Hogg، “The History of Fortification”، Orbis Publishing; 1st edition، London، ISBN-10: 0856130281، November 1981.

- Iqbal Imran, “Underground nuclear bomb proof home worth \$18 million”, Saranac Lake, NY: USA | Jun 01, 2012, http://www.allvoices.com/contributed-news/12292064-underground-nuclearbomb-proof-home-worth-18-million-for-sale-at-only-172-million, (Accessed 29-5 -2014)

-Nae' ma Samir, Waheed Samy, “october War Panorama”, Free days Egypt Magazine, Touist monthly free magazine, Issue 115 - October 2013, http://www.freedaysegypt.com/magazine/freedaysegypt_115_lr.pdf ,P61-75

- Paul Vitello، "Steuart Pittman Dies at 93; Led Fallout Shelter Program"، The New York edition، NY Times، February 21, 2013، Page B17، http://www.nytimes.com/2013/02/19/us/steuartpittman-head-of-fallout-shelter-program-dies-at-93.html?ref=obituaries\&_r=0

- Richard Fleetwood، "SHELTER: How Fallout Shelters Work"، http://www.survivalring.org/survival/shelter-how-fallout-shelters-work/

- Robert Bevan، “The Destruction of Memory -Architecture at War”، ISBN: 1861893191، Publisher: Reaction Books، UK, 2007.

-Thomas Heatherwick، "Making”، The Monacelli Press، New York، edition 8, 2012، ISBN: 9781580933346

- U.S. AIR FORCE, "Installation Force Protection Guide",http://www.wbdg.org/ccb/AF/AFDG/ARCHIVES/afinstal.pdf,P.33

-Yuhong Zhu، "Surmount Style + Copy II"، Volume 1، Material facade shape window 'Sheung Wan hotel ‘Hong Kong، China، thomas heatherwick Studio ‘Edited by: Hong Kong Architecture Science Press، HKASP Amsterdam، ISBN: 978-988-15680-0-7 , 2013، P 136,139

----“IITK-GSDMA Guidelines on measures to mitigate effects of terrorist attacks on buildings", Indian Institute of Technology Kanpur, Gujarat State Disaster Mitigation Authority, July 2007,http://www.iitk.ac.in/nicee/IITK-GSDMA/TM01.pdf

----“" Risk Management Series -Design Guidance for Shelters and Safe Rooms -Providing Protection to People and Buildings against terrorist attacks "FEMA 453 / May 2006" Federal Emergency Management Agency ,US department of homeland security, http://www.fema.gov/media-library/assets/documents/3140?id=1657, P3 - 13

- http://alhayat.com/Articles/، (Accessed 29-5 -2014)

- http://alialamri.wordpress.com/2013/04/06/ (Accessed 20-2-2014)

- http://architecture.about.com/od/greatbuildings/ig/Richard-Rogers-Partnership-/

http://daniel-libeskind.com/design , (Accessed 22-4 -2014)

- http://dechive.blogspot.com/2011/12/seoul-south-koreas-cloud-buildings-are.html

- http://english.sina.com/world/p/2011/0714/380993.html,(Accessed 20-4-2014).

http://first-ten.blogspot.com/2013/12/10_1324.html,(Accessed 20-4-2014)

- http://godofmuseums.blogspot.com/2012/09/blog-post_4394.htm,(Accessed 20-4-2014).

http://inhabitat.com/(Accessed 29-5 -2014)

- http://knowledge-ks.blogspot.com/2012/07/blog-post_6859.html\#ixzz31RCQeSwb 
- http://wakarimasen.fr/kanazawa/, (Accessed 29-5 -2014)

- http://www.alittihad.ae/details.php?id=4534\&y=2009\&article=full

- http://www.arab-ency.com/index.php، (Accessed 20-4-2014)

- http://www.buro-os.com/mahanakhon/، (Accessed 20-4-2014)

- http://www.designboom.com/architecture/sou-fujimoto-white-tree-architectural-folly-of-the-21stcentury-montpellier-03-07-2014/

- http://www.designswan.com/archives/interesting-cartoon-furniture-from-straight-line-design.html - http://www.dubbed-adventourer.com/trips/trekking-svaneti، (Accessed 11-5-2014)

- http://www.evolo.us/competition/hyper-filter-skyscraper/

- http://www.greenerimpact.com/wp-content/uploads/2012/10/ren.jpg

- http://www.gwu.edu/ memory/issues/museums/9.18HistoricalMuseum.html، (Accessed 20-22014)

- http://www.leandroerlich.com.ar/works.php?id=27\#

- http://www.loti.com/fifties_history/surviving_nuclear_attack.htm، (Accessed 11-5-2014)

- http://www.kierantimberlake.com/pages/view/88/embassy-of-the-united-states-of-america/parent:3

- http://www.richard-seaman.com/Travel/Japan/Hiroshima/AtomicDome/، (Accessed 20-4-2014)

- http://www.ripleys.com/attractions/

- http://www.telegraph.co.uk/news/worldnews/southamerica/brazil/9356129/Brazil-prisonersreading-books-to-shorten-their-sentences.html، (Accessed 19-1-2014)

- http://www.thaqafnafsak.com/2012/10/blog-post_5628.html، (Accessed 11-5-2014)

- http://www.trumanblog.com/tag/vietnam-memorial، (Accessed 25-4-2014).

- http://www.waraqat.net/13925/، (Accessed 11-5-2014)

- http://www.webpages.uidaho.edu/arch504ukgreenarch/2009Archs-CaseStudies/Swiss\%20ReFinal.pdf، P.6

- http://www.youm7.com/News.asp?NewsID=1580656\#.UzQ0H_mSwbd، (Accessed 11-5-2014) 


\title{
The Role of Violent Events and Wars in Thought and Architectural Output
}

\begin{abstract}
Recently, people in most parts of the earth are increasing the suffering from the violence and wars. Robert Bevan believed in his book "The Destruction of Memory - Architecture at War" is that "war is about killing cultures, identities and memories as much as it is about killing people and occupying territory"[1].

The question is why research combines violence and wars, while, the war word can be enough to express meaning. The answer is for several reasons, first because wars throughout the ages have evolved and taken many forms of violence. Even violence became one of its forms, not the usual concept of wars. Secondly, because the human are dealing with environment violently, sometimes, have the same impact of the war on the building and the environment. Research begins to display problem, it is the impact of violence and war in Thought and architectural output, evolution of the output depending on the evolution of forms of violence. Aims to analyze the types of wars and violence forms in order to study the output architectural and urban of these events, are as follows: event registration buildings, defensive buildings, resolve crises buildings, punitive buildings, and affected output in thought violence and wars, in terms of the basis of its design and its determinants, and benefit from the expertise of design for this product. Aim of proposing visualize combines this expertise and technological development to achieve safe architectural output. Research depends on the analytical and deductive method, analysis of the types of wars, deductive basis of buildings design adopted the inferential method, which the experience gained from output of buildings design from violence. Access to the desired results, that architecture should be a tool to cope with these events, and approach to resolve in accordance with the developments of the era. It consists of three basic axes: against explosion architecture, crises architecture, studies of the psychological affect of behavioral.
\end{abstract}

\section{Key Words:}

Violent events, wars, architectural output, registration event, security design criteria at buildings. 